Florida International University FIU Digital Commons

6-11-2018

\title{
Facing the Rising Tide: How Local Governments in the United States Collaborate to Adapt to Sea Level Rise
}

Vaiva Kalesnikaite

Florida International University, vkale002@fiu.edu

DOI: $10.25148 /$ etd.FIDC006865

Follow this and additional works at: https://digitalcommons.fiu.edu/etd

Part of the Environmental Policy Commons, Public Administration Commons, and the Public Policy Commons

\section{Recommended Citation}

Kalesnikaite, Vaiva, "Facing the Rising Tide: How Local Governments in the United States Collaborate to Adapt to Sea Level Rise" (2018). FIU Electronic Theses and Dissertations. 3770.

https://digitalcommons.fiu.edu/etd/3770 


\title{
FLORIDA INTERNATIONAL UNIVERSITY \\ Miami, Florida
}

FACING THE RISING TIDE: HOW LOCAL GOVERNMENTS IN THE UNITED STATES COLLABORATE TO ADAPT TO SEA LEVEL RISE

\author{
A dissertation submitted in partial fulfillment of the \\ requirements for the degree of \\ DOCTOR OF PHILOSOPHY \\ in \\ PUBLIC AFFAIRS \\ by \\ Vaiva Kalesnikaite
}

2018 
To: Dean John F. Stack, Jr.

Steven J. Green School of International and Public Affairs

This dissertation, written by Vaiva Kalesnikaite, and entitled Facing the Rising Tide: How Local Governments in the United States Collaborate to Adapt to Sea Level Rise, having been approved in respect to style and intellectual content, is referred to you for judgment.

We have read this dissertation and recommend that it be approved.

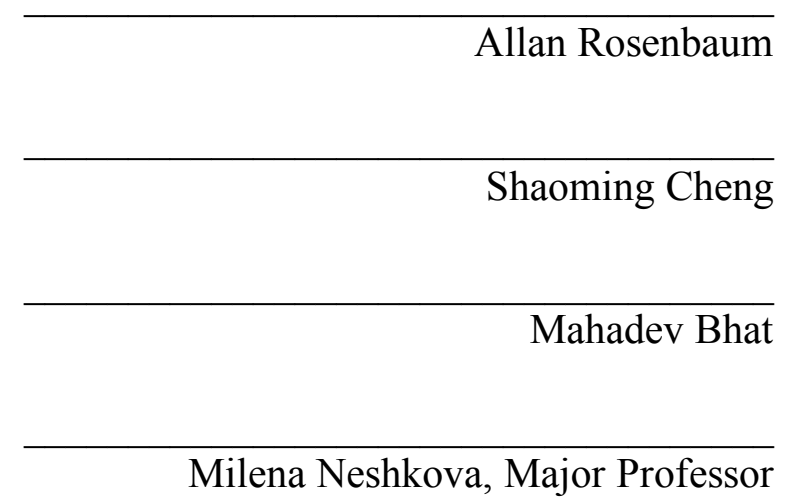

Date of Defense: June 11, 2018

The dissertation of Vaiva Kalesnikaite is approved.

Dean John F. Stack, Jr. School of International and Public Affairs

Andrés G. Gil

Vice President for Research and Economic Development and Dean of the University Graduate School

Florida International University, 2018 


\section{DEDICATION}

I dedicate this dissertation to my family. To my parents, Danguole and Vytautas, who have continuously inspired my curiosity for knowledge and discovery since my childhood. Thank you for teaching me the value of perseverance and always believing in me, in things big and small. You made this journey possible through your unwavering love and support. To my sisters, Agne and Kristina, thank you for your love, sense of humor, and always being there for me. 


\section{ACKNOWLEDGMENTS}

To my dissertation committee members, Dr. Allan Rosenbaum, Dr. Shaoming Cheng, and Dr. Mahadev Bhat, thank you for all your continuous advice, guidance, and support throughout this process. I owe a debt of gratitude to all of you. I would like to express the deepest appreciation to my dissertation advisor Dr. Milena Neshkova, for the generous mentorship and encouragement you have provided me over the years. I am forever grateful for the expertise, time and patience you dedicated to guide me throughout the $\mathrm{PhD}$ journey and shape my academic identity.

I wish to thank the faculty and staff at the Department of Public Policy and Administration for all their generous help during my time at FIU. Thank you for fostering an environment of learning and all the support and resources you provided. To my fellow colleagues in the $\mathrm{PhD}$ program, thank you for the friendship and encouragement throughout the years.

I also wish to acknowledge the financial support from the FIU University Graduate School through the Dissertation Evidence Acquisition Fellowship and the Dissertation Year Fellowship, which have greatly contributed to the completion of this work. 


\author{
ABSTRACT OF THE DISSERTATION \\ FACING THE RISING TIDE: HOW LOCAL GOVERNMENTS IN THE \\ UNITED STATES COLLABORATE TO ADAPT TO SEA LEVEL RISE \\ by \\ Vaiva Kalesnikaite \\ Florida International University, 2018 \\ Miami, Florida \\ Professor Milena Neshkova, Major Professor
}

While communities in the United States are already experiencing the effects of climate change, scientists project that sea level rise, increased precipitation, and recordbreaking extreme weather events will devastate vulnerable regions in the following decades. The absence of federal strategies for climate change adaptation leaves state and city governments with broad discretion to undertake climate change adaptation measures. Yet cities may be unable to adapt to climate change without external assistance, particularly in states where the state leadership has not recognized the need to provide political and financial support to local governments. Collaboration allows cities to pool resources and work across boundaries to ameliorate significant problems such as climate change.

Scholars of public administration have extensively researched collaboration. However, we still know little about what factors facilitate horizontal collaboration and why and how collaborative governance may lead to improved policy outputs and outcomes. Using the case of sea level rise preparedness in US cities, this dissertation contributes to better understanding of horizontal collaboration and its effects on public 
service provision. The analysis draws on quantitative data from surveys, administered to US municipal governments, and qualitative data from semi-structured interviews with city officials.

This research has several principal findings. First, organizational propensity to collaborate on sea level rise preparedness is driven by leadership that recognizes the value and need for collaboration, and internal organizational characteristics. Second, horizontal collaboration helps cities advance plans for sea level rise adaptation, particularly when partnering with institutions of higher learning and businesses. Third, the findings show that collaboration with other municipalities and businesses is a positive contributing factor toward better preparedness for sea level rise in US cities.

By shedding more light on horizontal collaboration as a tool to help cities adapt to changes in climate, the study contributes to two bodies of literature, including research on climate change policy and collaborative governance. The study also provides a number of recommendations to local policy makers and public administrators on how to facilitate horizontal collaboration to utilize local resources in public problem-solving. 


\section{TABLE OF CONTENTS}

CHAPTER

PAGE

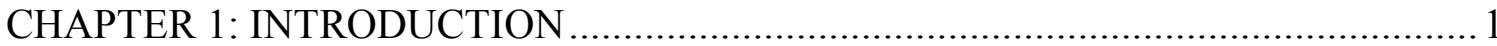

1.1. Statement of the Problem and Motivation ........................................................ 2

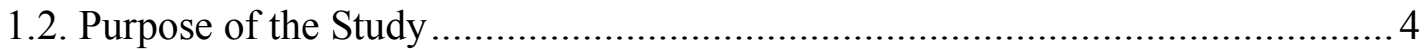

1.3. Significance of the Study .................................................................... 4

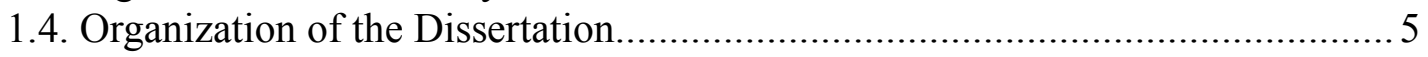

CHAPTER 2: CLIMATE CHANGE ADAPTATION IN THE UNITED STATES ......... 7

2.1. Causes of Sea Level Rise and Projected Threats at the Local Level................. 8

2.2. Sea Level Rise Adaptation Measures .............................................................. 11

2.3. Sea Level Rise Adaptation Action at the Federal Level ................................ 15

2.4. Federal Support to State and Local Governments to Address Sea Level Rise .. 17

2.5. State-Level Action to Address Sea Level Rise ......................................... 21

2.6. Local-Level Government Action to Address Sea Level Rise ......................... 22

CHAPTER 3. LITERATURE REVIEW ................................................................ 26

3.1. Climate Change Adaptation Literature Review ........................................ 26

3.1.1. Gaps in the Literature on Climate Change Adaptation ............................ 30

3.2. Collaborative Governance Literature Review .......................................... 32

3.2.1. Definition of Collaborative Governance .............................................. 33

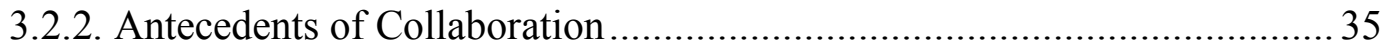

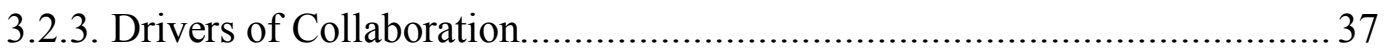

3.2.4. Outputs and Outcomes of Collaboration......................................... 42

3.2.5. Extant Research on Outputs and Outcomes of Collaboration ................... 43

3.2.6. Gaps in the Literature on Collaborative Governance ............................. 46

\section{CHAPTER 4: RESEARCH QUESTIONS, HYPOTHESES, AND CONCEPTUAL}

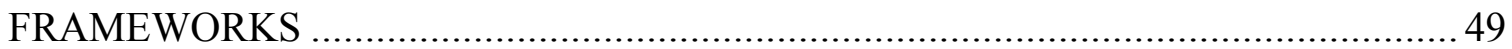

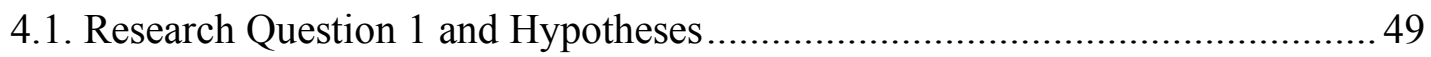

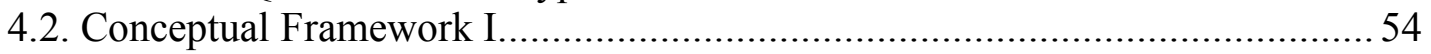

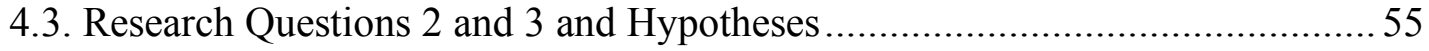

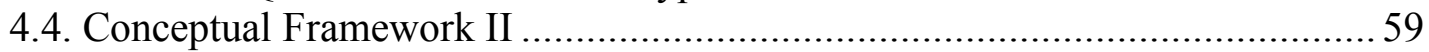

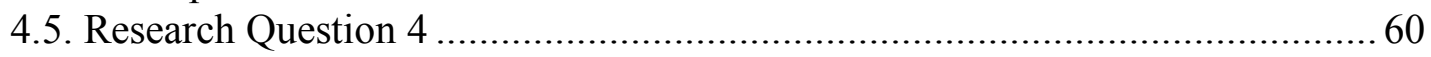

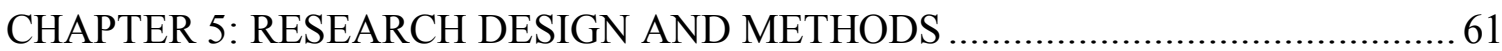

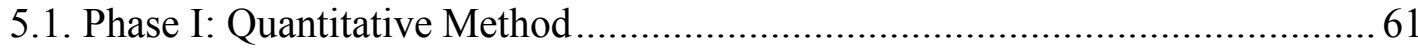

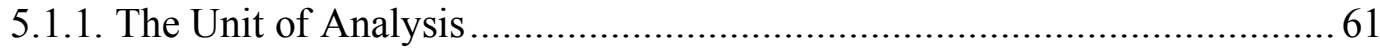

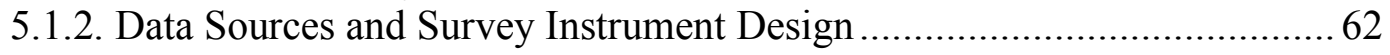

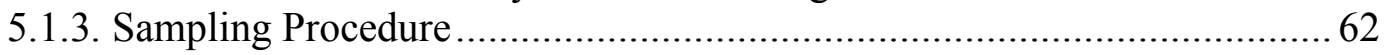

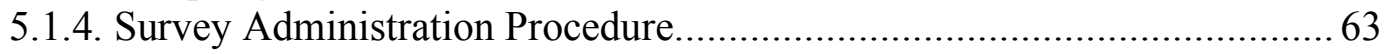

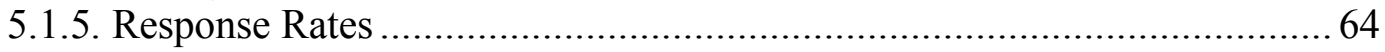




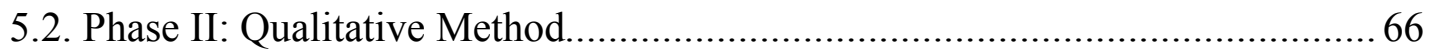

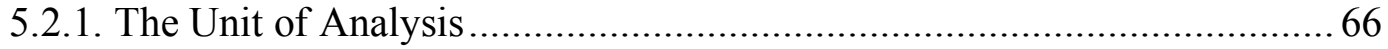

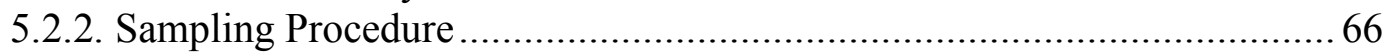

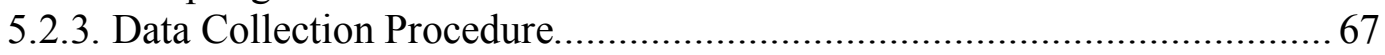

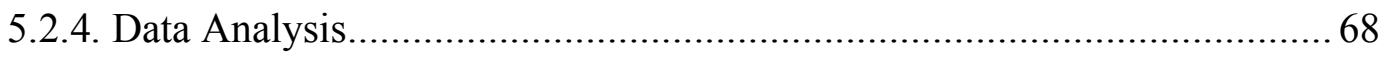

CHAPTER 6: VARIABLE OPERATIONALIZATION, ESTIMATION ROUTINES, AND QUANTITATIVE RESEARCH RESULTS .....................................................69

6.1. Factors Influencing Horizontal Collaborative Activity ......................................69

6.1.1. Dependent Variable - Collaborative Activity .............................................69

6.1.2. Main Independent Variables - Drivers of Collaborative Activity............... 73

6.1.3. Control Variables............................................................................... 76

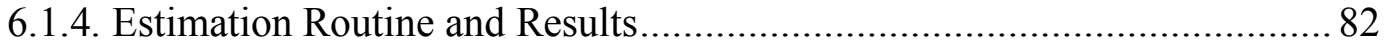

6.2. Factors Influencing Sea Level Rise Adaptation Outputs and Outcomes........... 85

6.2.1. Dependent Variable - Sea Level Rise Adaptation Outputs .........................86

6.2.2. Dependent Variable - Sea Level Rise Adaptation Outcomes ..................... 87

6.2.3. Main Independent Variables - Horizontal Collaborative Activity and

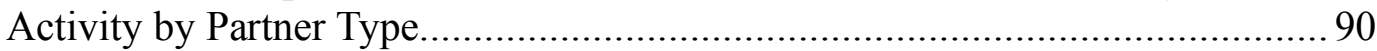

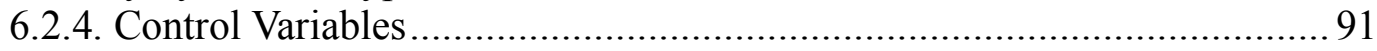

6.2.5. Estimation Routine and Results (Research Question 2) ............................ 94

6.2.6. Estimation Routine and Results (Research Question 3) ............................ 97

CHAPTER 7: COMPLEMENTARY QUALITATIVE RESEARCH FINDINGS......... 102

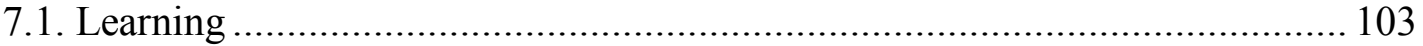

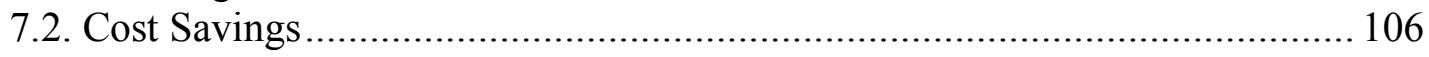

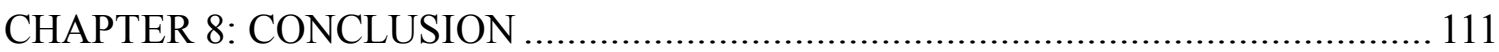

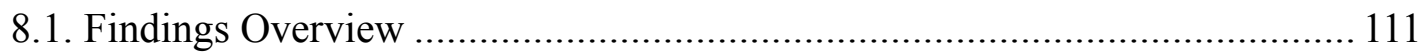

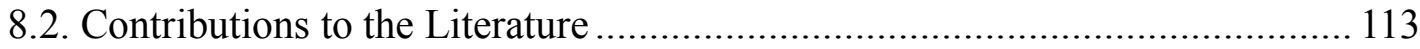

8.3. Strengths, Limitations and Opportunities for Future Research........................ 114

8.4. Implications for Policy and Practice............................................................ 117

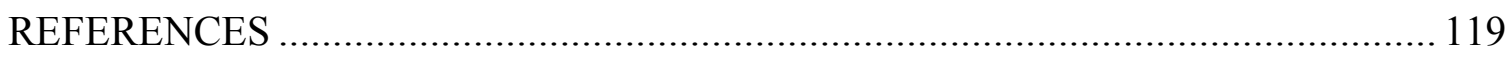

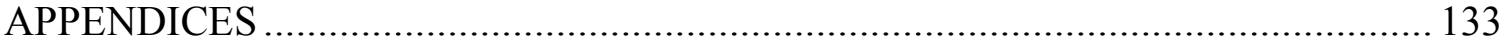

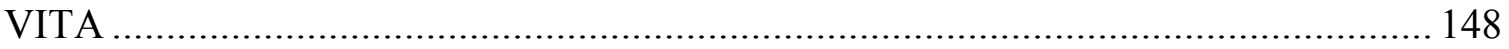




\section{LIST OF TABLES}

TABLE

PAGE

Table 1. Characteristics of the Sample and Response Rates by US Census Division...... 65

Table 2. Variable Operationalization and Data Sources for the First Research Question 80

Table 3. Descriptive Statistics for the Variables for the First Research Question..... 81

Table 4. OLS Regression Results with Coefficients and Robust Standard Errors, Clustered by State (Dependent Variable - Collaborative Activity). 83

Table 5. The Distribution of CRS Scores Across the Cities in the Study

Table 6. Descriptive Statistics for the Variables for the Second and Third Research Questions

Table 7. Variable Operationalization and Data Sources for the Second and Third Research Questions

Table 8. Ordinal Logistic Regression Results with Coefficients and Robust Standard Errors, Clustered by State (Dependent Variable - Outputs)

Table 9. OLS Regression Results with Coefficients and Robust Standard Errors, Clustered by State (Dependent Variable - Outcomes)

Table 10. The Characteristics of the Interview Respondents 


\section{LIST OF FIGURES}

FIGURE

PAGE

Figure 1. The Conceptual Framework for the First Research Question: Factors

Influencing City-level Horizontal Collaborative Activity..... .55

Figure 2. Conceptual Framework for the Second and Third Research Questions:

Factors Influencing Sea Level Rise Adaptation Outputs and Outcomes in City

Governments.

Figure 3. The Distribution of the Variable Collaborative Activity Across the Responding Cities

Figure 4. The Distribution of Collaborative Activities Across the Sample Cities by

Type of Activity

Figure 5. The Distribution of Collaborative Activities by Type of Partner .................... 73

Figure 6. The Distribution of Sea Level Rise Adaptation Outputs Across Cities 87 


\section{LIST OF ABBREVIATIONS AND ACRONYMS}

\begin{tabular}{ll} 
AICP & American Institute of Certified Planners \\
ASCE & American Society of Civil Engineers \\
CCPR & Council on Climate Preparedness and Resilience \\
CEQ & Council on Environmental Quality \\
CRS & Community Rating System \\
DMA & Disaster Mitigation Act \\
EPA & Environmental Protection Agency \\
EO & Executive Order \\
FEMA & Federal Emergency Management Administration \\
GDP & Gross Domestic Product \\
GhG & Greenhouse Gas Emissions \\
ICCATF & Interagency Climate Change Adaptation Task Force \\
ICLEI & ICLEI - Local Governments for Sustainability \\
NASA & National Aeronautics and Space Administration \\
NFIP & National Flood Insurance Program \\
NOAA & National Oceanic and Atmospheric Administration \\
NYSCAC & New York State Climate Action Council \\
OLS & Ordinary Least Squares \\
SFRCCC & Southeast Florida Regional Climate Change Compact \\
SHMP & Statewide Hazard Mitigation Plan \\
USACE & US Army Corps of Engineers \\
\hline
\end{tabular}


USGCRP US Global Change Research Program

VIF

Variance Inflation Factor 


\section{CHAPTER 1: INTRODUCTION}

Growing scientific concern over climate change worldwide has resulted in a large body of literature on climate change adaptation. Prior research has extensively examined climate change adaptation in developing countries (e.g., Adger, Huq, Brown, Conway, \& Hulme, 2003; Barnett, 2001; Denton, 2002; Eriksen \& O’Brien, 2011), national governments' strategies (e.g., Brooks, Adger, \& Kelly, 2005; Haddad, 2005), and the concepts of resilience, vulnerability (e.g., Adger et al., 2003; Grothmann \& Patt, 2005; Janssen \& Ostrom, 2006; Kuhlicke, Kabisch, Krellenberg, \& Steinfuehrer, 2012), and adaptive capacity (e.g., Brooks et al., 2005; Haddad, 2005; Smit \& Pilifosova, 2001). Less attention has been directed to the city-level response to climate change, especially in countries with federal systems of government, such as the United States-which currently lacks a national strategy for climate change adaptation. In the few existing representative research studies on this topic, scholars have mostly focused on evaluating the relationship between the quality of local climate change adaptation plans and various factors that contribute to plan quality. As a result, knowledge on the management strategies that cities can utilize to improve their adaptation plans has remained limited.

While local governments have ample discretion to undertake adaptation measures, fragmentation of authority and inefficacies arising from small size and capacity may prevent their ability to successfully adapt to the challenges of climate change. Collaboration has been examined as a possible mechanism to overcome local governments' deficiencies in size and capacity. The term collaborative governance refers to situations in which multiple governments and other actors pursue solutions to their 
common problems. The need for collaboration arises, in part, because complex problems, such as terrorism or climate change, do not have easily implementable solutions and require extensive resources. Collaborative governance helps organizations work across sectoral boundaries to pool resources and attain mutually beneficial goals.

Scholars of public administration have substantially developed the literature on collaborative governance (e.g., Agranoff, 2006; Feiock, 2007, 2008, 2013; Feiock \& Scholz, 2010; McGuire, 2006; Provan \& Milward, 2001). Yet, knowledge on which factors facilitate horizontal collaboration and how this collaboration may improve public policy outputs and outcomes is still limited. Using the case of sea level rise adaptation in the US, the present study aims to contribute to the better understanding of collaborative governance and its effects on public service provision.

\subsection{Statement of the Problem and Motivation}

Communities in the US have begun experiencing the adverse effects of climate change. Scholars have found that climate change and sea level rise have significantly contributed to an increase in flooding and permanent inundation over the past century (Strauss, Kopp, Sweet, \& Bittermann, 2016). Some communities have already been affected by the rising tides to the degree that warrants relocation to other areas. Scientists have also found that even if with severe cuts to greenhouse gas emissions (GhG) were implemented immediately, the climate will continue to warm due to self-reinforcing cycles - positive feedbacks that accelerate human-caused climate change (US Global Change Research Program, 2014). In effect, it is expected that the US population will experience more frequent and intense hurricanes, increasing droughts, flooding, and other adverse effects of climate change. 
By 2009, 31 villages in Alaska had already been identified as being at great risk from the adverse effects of climate change, specifically beach erosion and sea level rise. Residents have initiated talks with higher levels of government regarding relocation (Government Accountability Office, 2009). However, no comprehensive program has been developed to help residents relocate to safer areas, and while the Federal Emergency Management Administration (FEMA) administers a number of programs targeting disaster preparation and recovery, villages are often unable to qualify for assistance (Government Accountability Office, 2009).

Currently, the US lacks a comprehensive federal strategy for sea level rise preparedness in all three adaptation areas-protection, accommodation, and retreat (Gornitz, 2013; Nicholls \& Cazenave, 2010)—which has left state and local governments with broad discretion to undertake adaptation measures. Yet, according to a tracking tool for state and local adaptation plans developed by the Georgetown Climate Center, as of 2018, 35 state governments had not yet finalized climate change adaptation plans, and eight states were in progress of developing their plans (Georgetown Climate Center, n.d.). In effect, local governments are left with two options to adapt to sea level rise: (1) independent action or (2) collaboration. In option one, local governments act independently and implement their own measures. However, these initiatives are often costly and require extensive resources. Given that fragmentation of authority in the US has resulted in small jurisdictions that are facing inefficiencies due to small size and available resources (Feiock \& Scholz, 2010), local governments may not be able to adapt without external assistance. In option two, local governments may leverage local 
resources through collaboration with other stakeholders, including public and nongovernmental actors.

\subsection{Purpose of the Study}

There are four main purposes of the study: first, to provide a better understanding of factors that facilitate horizontal collaboration at the local level; second, to assess the relationship between horizontal collaboration and outputs and outcomes of public service delivery at the local level of government; third, to explore whether the relationship between collaborative governance and outputs and outcomes of public service delivery vary according to the type of collaborative partner; and fourth, to investigate how collaborative activity might improve public policy outputs and outcomes. As a basis for this research, I have utilized the extant literature on climate change action in the field of planning and the literature on collaborative governance in public administration. More specifically, the study focuses on horizontal collaborative governance as a tool of public management, which is defined as a type of collaboration, where "players are local and represent multiple interests within the community" (Agranoff \& McGuire, 2003, p. 21). This type of collaboration has been understudied in the field of public administration; in particular, few studies have examined horizontal collaborative governance involving actors outside of the public sector.

\subsection{Significance of the Study}

The present study is significant in terms of its theoretical and practical implications. It contributes to theory and the growing bodies of literature on horizontal collaborative governance and climate change preparedness at the local level of government. While the body of literature on collaborative governance is substantial, there 
is a paucity of knowledge on its relationship with objective outputs and outcomes of public service delivery (for exceptions, see Kelman, Hong, \& Turbitt, 2012; Scott, 2015, 2016). Many studies to date have used the "second best" approach to capture various outcomes of collaborations, typically measuring outcomes through perceptions of participants. Most studies on climate change adaptation have focused on the quality of climate change adaptation plans; expanding on this objective, and thereby contributing to the literature on climate change adaptation planning, the present study assessed the relationship between horizontal collaboration as a management tool and the outputs and outcomes of sea level rise preparedness.

In terms of practical implications, the present study reaffirms that horizontal collaboration is a tool to manage local public organizations and solve complex public problems when support from higher levels of government is insufficient. The findings also demonstrate that cities can achieve better preparedness through the learning and cost savings that collaboration helps achieve. Additionally, findings highlight the importance of local leadership as a driving force behind horizontal collaboration. In effect, local leaders can take advantage of various resources by brokering collaborative connections with other actors, including those outside of the public sector.

\subsection{Organization of the Dissertation}

This dissertation is organized as follows. Chapter 2 provides a background of the study, including climate change adaptation risks and government action to adapt at the federal, state, and local levels. Chapter 3 discusses two main bodies of literature that are used in the study: climate change action and collaborative governance, followed by a discussion of the existing gaps in the literature. Chapter 4 outlines research questions, 
hypotheses, and conceptual frameworks used in the dissertation. Research design and methods are then presented in Chapter 5. Chapter 6 details the operationalization of the variables, estimation routines, and quantitative research results. Chapter 7 contains the findings from a complementary qualitative research design. Finally, Chapter 8 concludes with a discussion of the main findings, contributions made by the study, opportunities for future research, and practical implications of the findings. 


\section{CHAPTER 2: CLIMATE CHANGE ADAPTATION IN THE UNITED STATES}

The aim of this chapter is to introduce the background of climate change adaptation with a focus on sea level rise in the US. The chapter focuses on the adverse effects of sea level rise in the US and government action that is targeted at improving local community resilience to sea level rise.

Scientific consensus on the existence of climate change was reached in the 1990s, when it was recognized that human activities have contributed to raising global temperatures worldwide, "including changes in ocean heat content, precipitation, atmospheric moisture, and Arctic sea ice” (US Global Change Research Program, 2009, p. 1). Doran and Zimmerman (2009) found that $82 \%$ of 10,257 scientists agreed that human activity is the main cause of climate change. Because changes in climate significantly affect how individuals in communities live and work, several solutions to climate change have been offered and implemented by different levels of government (Adger et al., 2003).

Climate change action falls into two broad categories: mitigation and adaptation. Climate change mitigation refers to initiatives aiming to curtail the GhG emissions, which are named by the US Environmental Protection Agency (EPA) as the primary cause of increasing average global temperatures (EPA, 2014). Climate change adaptation aims to prepare for the consequences of climate change by taking appropriate action and reducing the risks that can arise from climate change. These efforts typically occur at the local level. Given that each region, country, state, or city may be impacted in a different manner, successful climate change adaptation calls for site-specific knowledge and 
solutions. For instance, while coastal communities in the US are exposed to risks related to sea level rise, the Midwest region is threatened by droughts and extreme heat events. Examples of adaptation measures include updating building codes and requiring real estate development companies to construct buildings at higher elevations and erect sea walls to protect coastal areas from flooding and inundation.

Because the impact of climate change can be catastrophic and, to some extent, irreversible, a wide range of actors have been searching for ways to increase the resilience of individual communities. Some adaptation initiatives trigger preparedness for saltwater and freshwater flooding, erosion, and declining water supplies, among other impacts. While communities in the United States are already experiencing the effects of climate change, it is projected that impacts, including sea level rise, increased precipitation, and more frequent and stronger extreme weather events, will continue to pose significant threats to human health, agriculture, natural ecosystems, and the economy in the future.

\subsection{Causes of Sea Level Rise and Projected Threats at the Local Level}

According to the US National Oceanic and Atmospheric Administration (NOAA)

(n.d.), climate change has been continually provoking a rise in sea levels. Increasing global temperatures have accelerated thermal expansion, and melting ice sheets and glaciers have been contributing to global sea level rise. In 2014, the recorded global sea level was 2.6 inches higher than the 1993 average-when it was first recorded using high-precision altimeter satellites (NOAA, n.d.). On average, global sea levels have been rising by about $1 / 8$ inch per year. Yet, sea level rise has not been uniform across regions: in some regions, sea level rise has occurred much faster than in others. For instance, since 
1993, the western Pacific has experienced sea level rise three times faster than the global average (Nicholls \& Cazenave, 2010). Moreover, even with immediate, deep cuts to GhG emissions, the oceans will continue to warm due to oceanic thermal inertia: "Avoiding these changes requires, eventually, a reduction in emissions to substantially below present levels. For sea level rise, a substantial long-term commitment may be impossible to avoid" (Wigley, 2005, p. 1766). In other words, due to the oceans' slow response any changes in GhG emissions, also known as a time lag, the effects of sea level rise will be felt for centuries. As a result, an effective response to climate change must include both measures: mitigation and adaptation.

In 2010 , about $40 \%$ of the US population, roughly 123 million people lived in densely-populated coastal areas, with a projected increase of $8 \%$ by 2020 (NOAA, n.d.). According to a recent study, the states with the largest populations living less than a meter above sea level rise are Florida, Louisiana, California, New York, and New Jersey (Strauss, Ziemlinski, Weiss, \& Overpeck, 2012). A study by Climate Central (2017) showed that even with deep cuts to GhG emissions, states with coastal borders-on the East Coast, West Coast, and in the south of the US-will continue to be significantly impacted in the future. Louisiana and Florida have the largest populations that will be affected—one million residents, and over five million residents, respectively. Sea level rise has been associated with numerous adverse effects, including increased flooding and permanent inundation of certain areas, loss of plant and animal species, contamination of drinking water, beach erosion, and others. In effect, to prepare for sea level rise, and to pay for resulting damage, communities in the US are expected to face significant economic costs (Fu, Song, Sun, \& Peng, 2016). Using data from NOAA, a study by 
Zillow showed that if oceans rise by six feet by the end of the century, almost 1.9 billion homes will be underwater in the US, with an estimated total value of $\$ 882$ billion. According to the study, Florida homeowners would suffer the largest financial losses, approximately $\$ 413$ billion from almost one million homes (Rao, 2017). With a six-foot sea level rise, almost three million people would be living under the projected high tide line in Florida alone. Apart from commercial and residential buildings, sea level rise poses threats to infrastructure. With a six-foot increase in sea levels, nearly 15,000 miles of roads will be threatened in Florida, of which over 13,000 miles are local roads (Climate Central, n.d.). Sea level rise has also been projected to cause issues in water management by compromising local sewer management systems: increased precipitation and sea level rise raise groundwater levels, flooding septic tanks. In Miami-Dade County, about 93,000 homes were relying on septic tank systems in 2013.

In a recent study, Hsiang et al. (2017) estimated the projected damage of climate change using climate science, econometric analyses, and process models at the county level in the US. They found that the various costs associated with damages of climate change are not uniform across the country. They write: "Southern and Midwestern populations suffer the largest losses, while Northeastern and Western populations have smaller or even negative damages" (Hsiang et al., 2017, p. 1363). At the national level, it is expected that across a number of sectors included in the study (agriculture, crime, coastal storms, energy, human mortality, and labor), damage from climate change increases quadratically with increasing global mean temperature, diminishing the US gross domestic product (GDP) by about $1.2 \%$ for every average $1{ }^{\circ} \mathrm{C}$ increase of mean temperature (Hsiang et al., 2017). 
Some residents of US cities are already experiencing the effects of sea level rise. Strauss et al. (2016) found that since the 1950s, "human-caused global sea level rise effectively tipped the balance, pushing high water events over the threshold, for about two-thirds of the observed flood days" (p. 6). In other words, human-caused increase in sea level has accounted for over $67 \%$ increase in flooding since the $1950 \mathrm{~s}$. As a result, cities in Florida, such as Miami Beach and Fort Lauderdale, have experienced an increase in flooding due to perigean spring tides, projected to increase with future sea level rise.

\subsection{Sea Level Rise Adaptation Measures}

Three broad adaptation measures to address sea level rise include protection, accommodation, and retreat (Gornitz, 2013; Nicholls \& Cazenave, 2010). A response to sea level rise may also take a hybrid approach and use a combination of these measures (Nicholls, 2002). All three measures have certain advantages and disadvantages, given varying geographical, political, and social conditions (Griggs, 2017). As a result, the type of measure or a mixed-approach employed will depend on local conditions.

As an adaptation measure, protection pertains to precautionary actions, where "natural system effects are controlled by soft or hard engineering, reducing human impacts in the zone that would be impacted without protection" (Nicholls, 2002, p. 101). Examples of protection measures include building seawalls and levees to fortify the coast and prevent flooding, also known as hard engineering techniques. Protection measures are a common policy tool to increase public safety and prevent damages from flooding. According to a report by the American Society of Civil Engineers (ASCE, 2013), there were approximately 100,000 miles of levees in the US in 2013 - which could be found in all 50 states - with $43 \%$ of the national population living in a county with at least one 
levee. The ASCE also reported that most levees (approximately 85\%) are managed locally (ASCE, 2013). For instance, recently, the City of New Orleans, together with the US Army Corps of Engineers, built an infrastructure to protect the city's residents from sea level rise that cost over $\$ 14$ billion, including a system of levees and flood walls.

Soft engineering protection techniques include beach nourishment and dune stabilization. Miami-Dade County’s “Miami-Dade County Beach Erosion Control Master Plan," an example of soft engineering measures, aimed to restore eroded beaches across coastal municipalities in the county. While protection measures can be effective in reducing the effects of sea level rise and damage to property, they are typically costly, as in the case of New Orleans, and require continuing costs for regular maintenance. Also, researchers have argued that hard engineering measures create an adverse effect, referred to as the levee effect (Montz \& Tobin, 2008). The levee effect occurs when governments build sea walls and levees to protect existing coastal developments from natural hazards - generating a sense of safety in these vulnerable coastal areas - which results in expanding real estate development in these communities (Tobin, 1995). Levees provide flood protection only to a certain degree, depending on their design, and sometimes fail or breach, as was the case in New Orleans during Hurricane Katrina.

Accommodation, as an adaptation measure, aims to manage the effects of sea level rise, while making adjustments to cope with these effects (Agrawala, Crick, JetteNantel, \& Tepes, 2008). For instance, local governments may design more stringent building codes that mandate real estate developers to construct buildings at a higher elevation. The City of Miami Beach began implementing a plan to raise the city by 2 feet in 2015, beginning in the Sunset Harbor neighborhood, which has been flooding regularly 
with an increase in sea levels. While accommodation allows for further use and occupation of coastal areas, the costs associated with accommodation measures may be very high, particularly for densely developed and populated coastal areas of the country, such as South Florida.

The final adaptation measure-retreat-involves relocation of threatened communities and abandonment of certain areas. In this context, retreat occurs in two forms: managed and unmanaged. Managed retreat includes a proactive planning approach in which communities may be moved from threatened areas before heavy flooding or permanent inundation. While recurring economic costs (e.g., maintenance of levees and sea walls) are associated with protection and accommodation approaches, retreat measures do not involve continuing expenses. At the same time, managed relocation of coastal residents is controversial "because of social and psychological difficulties in displacing people from their homes" (Hino, Field, \& Mach, 2017, p. 364). Additionally, retreat includes an abandonment of the built environment and infrastructure. In 2016, the residents of an Alaskan village, Shishmaref, voted to abandon their homes on the Sarichef Island due to a gradual loss of land associated with the rise in sea levels. Although there will be no ongoing costs after the relocation, the move is estimated to cost the community from $\$ 100$ million to $\$ 200$ million US dollars (Government Accountability Office, 2009). Unlike managed retreat, unmanaged retreat is a reactive approach. It pertains to abandoning coastal areas in reaction to a natural hazard. Unmanaged retreat occurs when sea level rise makes it impossible to live in an area due to flooding or permanent inundation. These phenomena also bring about a number of adverse effects, including loss of drinking water and food supply, collapse of economies, 
spread of disease, and other effects. While rare in the US, unmanaged retreat has occurred in small island nations in the Pacific Ocean such as Tuvalu and Kiribati. Displaced residents from these islands have sought refuge in New Zealand and have been labeled as climate change refugees.

In some cases, the governments may not design and implement any of the three adaptation approaches, and instead do nothing to address sea level rise. Because climate science has been continuously evolving, there is a degree of uncertainty about the exact timing and the magnitude of the effects of sea level rise in a certain community. In turn, decision-making may be hindered by imperfect data, and the need to choose future projections of sea level rise, ranging from very liberal to very conservative ones. Given imperfect data, it has been difficult to project the future damages associated with sea level rise and the best course of public policy (McGuire, 2013). As a result, elected officials may employ a wait-and-see approach instead of investing in sea level rise solutions that would continue beyond their terms of office. They may instead focus their attention on problems with easier solutions to receive immediate credit and recognition from the public. At the same time, sea level rise preparedness action may be hindered by public risk perception. Scholars have found that "Americans view climate change as a threat distant in space and time - a risk that will affect far away places, other species, or future generations more than people here and now" (Leiserowitz, Maibach, RoserRenouf, Feinberg, \& Howe, 2013). Residents in threatened areas may not connect various already-occurring effects of sea level rise (e.g., increase in hurricane intensity) with the global problem of climate change (Moser, 2013). 


\subsection{Sea Level Rise Adaptation Action at the Federal Level}

Various efforts are in motion at the federal level to adapt to sea level rise in the US. However, currently, this country lacks a concerted and comprehensive strategy to address the issue (Moser, 2013). Most federal action to date has been incremental, and largely focused on assessing vulnerabilities to sea level rise and assessing available options (Moser \& Boykoff, 2013). This section provides an overview of the most important attempted and implemented efforts to address sea level rise at the federal level. The efforts have been broadly grouped into two types: inter-agency and individual agency action (Bierbaum et al., 2013).

One of the first federal, inter-agency efforts to address sea level rise is the US Global Change Research Program (USGCRP), which focused on advancing the science and research related to global climate change. It was mandated by Congress in the Global Change Research Act of 1990, and brings together 13 federal agencies (the Department of Agriculture, the Department of Commerce, the Department of Defense, the Department of Energy, the Department of Health and Human Services, the Department of the Interior, the Department of State, the Department of Transportation, the Environmental Protection Agency (EPA), the National Aeronautics and Space Administration (NASA), the National Science Foundation, the Smithsonian Institution, and the US Agency for International Development). The main task of the USGCRP has been to integrate research on climate change across federal agencies and work with various stakeholders to produce science-based data and tools that inform decision-making on climate change (White House, 2015). The USGCRP has routinely compiled and released reports on climate science and climate change impacts in the US. According to 
the National Academies of Sciences, Medicine, and Engineering report (2017), the USFCRP has significantly contributed to advancing climate science in the US and abroad, helping inform decision-making on how to better respond to changes in climate.

In 2009, President Obama created the Interagency Climate Change Adaptation Task Force (ICCATF), charged with advancing climate change adaptation at the federal level (Petes, Howard, Helmuth, \& Fly, 2014). The ICCATF was primarily led by the White House Council on Environmental Quality (CEQ), the Office of Science and Technology Policy, and NOAA, and included representatives from 20 federal agencies. The ICCATF released progress reports in 2010 and 2011, providing recommendations to federal leadership and agencies for climate change adaptation.

In 2013, President Obama issued an Executive Order (EO) 13653: Preparing the United States for the Impacts of Climate Change, urging federal agencies to assess the impacts of climate change and work with state, local, and tribal leaders. One of the key efforts under EO 13653 was the establishment of an interagency Council on Climate Preparedness and Resilience (CCPR), which was tasked with developing and overseeing interagency efforts related to climate preparedness and resilience, as well as working with lower levels of the government to improve preparedness for climate change (Executive Order No. 13653, 2013). The CCPR replaced the ICCATF, which was terminated by the EO. Additionally, EO 13653 also established the State, Local, and Tribal Leaders Task Force on Climate Preparedness and Resilience, composed of elected state, local, and tribal officials to open intergovernmental channels of information exchange and sharing of best practices. 
In 2017, President Trump issued Executive Order 13783, revoking EO 13653 (Executive Order No. 13783, 2017), which halted the initiatives under EO 13653. Additionally, EO 13783 terminated the production of several reports, targeted at climate change action, including the President's Climate Action Plan and CEQ's "Final Guidance for Federal Departments and Agencies on Consideration of Greenhouse Gas Emissions and the Effects of Climate Change in National Environmental Policy Act Reviews."

\subsection{Federal Support to State and Local Governments to Address Sea Level Rise}

Apart from inter-agency efforts, there have been attempts to facilitate the climate change adaptation actions of individual federal agencies and support local governments in their adaptation efforts. In 2009, President Obama issued EO 13514: Federal Leadership in Environmental Energy, and Economic Performance. While EO 13514 mainly focused on achieving sustainability goals of federal agencies by reducing energy and water use, Section 8 (i) also mandated that federal agencies prepare Agency Strategic Sustainability Performance Plans that would include an evaluation of "agency climatechange risks and vulnerabilities to manage the effects of climate change on agency's operations and mission in both short and long term" (Executive Order No. 13514, 2009, p. 255), along with annual updates in improvement and evaluation of agency projects. As required by the EO (13514) that President Obama issued in 2009, over 30 federal agencies and departments had developed their climate change adaptation plans, including assessments of vulnerabilities and adaptation performance measures, by the end of 2014 (Congressional Research Service, 2015).

Various federal agencies have contributed to a better understanding of future sea level rise through research and various decision-making tools, including the Army Corps 
of Engineers (USACE), NOAA, the US Geological Survey (USGS), and NASA. For instance, local governments and collaboratives (e.g., Southeast Florida Regional Climate Change Compact (SFRCCC)) have planned for sea level rise effects by using USACE and NOAA sea level rise projection tools. Additionally, NOAA has administered the National Sea Grant College Program since 1966-a network of 33 university-based programs targeting coastal conservation in the US. Through this program, NOAA works with universities and local communities to conduct research, extend knowledge, and provide education about various topics in coastal management, including climate change and sea level rise. NOAA has also worked with local governments through the National Coastal Zone Management Program, which was authorized by the Coastal Zone Management Act in 1972. Under this program, NOAA has supported state and local governments with technical assistance and funding to address various coastal issues, including sea level rise.

In terms of direct practical efforts to help state and local governments adapt to sea level rise, USACE has maintained a policy regarding sea level rise since 1986, regularly updating the guidelines for civil works programs with improvements in climate science. In 2009, USACE updated the guidelines for existing and future projects to be evaluated for vulnerability to sea level rise. USACE also assists local governments in funding and completing various projects that help improve coastal resilience. For instance, USACE is engaged in routine beach renourishment projects-soft engineering techniques-to protect coastal areas from storm surges and floods.

Since 1990, FEMA has offered a voluntary incentive program, the Community Rating System (CRS), which helps communities secure discounted flood insurance 
premiums under the National Flood Insurance Program (NFIP). To qualify for the discounted rates, communities must implement actions that are designed to reduce flood risk and damage. The CRS aims to reduce flood damage to insurable property, strengthen and support insurance aspects of the NFIP, and encourage a comprehensive approach to flood-plain management. Over 1,200 communities nationwide participate in the CRS. Participating communities earn credits on 19 public information and floodplain management activities.

CRS activities are divided into four categories: (1) Public Information (elevation certificates, map information service, outreach projects, hazard disclosure, flood protection information, flood protection assistance, and flood insurance promotion); (2) Mapping and Regulations (floodplain mapping, open space preservation, higher regulatory standards, flood data maintenance, and storm water management); (3) Flood Damage Reduction (floodplain management planning, acquisition and relocation, flood protection, and drainage system maintenance); and (4) Flood Preparedness (flood warning and response, levee safety, and dam safety). The credits earned for implementing these activities vary. For instance, elevation certificates earn 116 credits for the community, while higher regulatory standards earn up to 2042 credits. The number of total community credits is translated into a rating, referred to as the CRS Class. The discount on insurance premiums depends on the CRS Class for which the community classifies, ranging from 1 to 10 [1 being the highest discount (45\%), 9 being the lowest discount (5\%), along with 10 (no discount)]. Since 2013, the CRS Coordinator's Manual has included guidance for cities to receive credits for sea level rise adaptation activities as well. For instance, if a community decreases future flood risk by changing building codes 
that account for future sea level rise under Activity 430 - Higher Regulatory Standards, it receives credits for sea level rise accommodation measures. The 2017 updated CRS Coordinator's Manual further expanded on these activities.

Finally, major federal legislation — the Disaster Mitigation Act (DMA) of 2000has guided federal-state-local relationship in preparation for disasters, mandating state and local governments to prepare statewide hazard mitigation plans (SHMPs), which must be approved by FEMA every three years in order to qualify for federal pre- and post-disaster funds. The main goal of the DMA has been to reduce potential losses from natural hazards. To comply with the DMA, state, local and tribal governments must develop a plan that identifies potential natural hazards in the jurisdiction, including associated risks and vulnerabilities. Accordingly, the plans must address actions required to mitigate these natural hazards. As of 2017, all 50 states had SHMPs, approved by FEMA (FEMA, 2017). Additionally, 22,124 local governments had FEMA-approved or pending-adoption plans, with over $82 \%$ of national population living in local governments with hazard mitigation plans.

While the DMA mentions earthquakes, tsunamis, tornadoes, hurricanes, flooding and wildfires as natural hazards, there is no reference to climate change or sea level rise (Disaster Mitigation Act, 2000). Additionally, until 2015, there was no mention of sea level rise in FEMA rules that guided the review of hazard mitigation plans, leaving discretion to state and local governments to address these challenges. The DMA has been utilized to include climate change concerns in state and local government hazard mitigation planning (Babcock, 2013) even before the climate change element was mandated in SHMPs in FEMA's revision of State Mitigation Plan Review Guide (FEMA, 
2015). However, there have been cases in which these challenges were overlooked in state and local hazard mitigation plans due to an absence of a mandate prior to 2015 (Babcock, 2013). Although climate change must be considered in SHMPs, this mandate is not legally required in local government hazard mitigation plans (Stults, 2017). As a result, local governments can include climate change in hazard mitigation plans voluntarily - unless mandated by the state.

\subsection{State-Level Action to Address Sea Level Rise}

While various federal agencies have provided research, technical assistance, and financial support to state and local governments to plan for sea level rise, the US lacks a comprehensive federal strategy for climate change adaptation. As a result, state and local governments have ample discretion to undertake relevant climate change adaptation measures. While many coastal populations in the US are vulnerable to sea level rise, state governments have demonstrated varying degrees of political and technical support for local governments in adaptation efforts. According to the Georgetown Climate Center, 35 state governments have not finalized state-led climate change adaptation plans as of 2018, including North Carolina and Louisiana, both of which will be impacted by sea level rise in the future (Georgetown Climate Center, n.d.). On the other hand, the State of California developed a comprehensive "California Climate Change Adaptation Strategy" in 2009, with a set of 345 goals to be implemented in areas of public health, biodiversity and habitat, ocean and coastal resources, water management, forestry, and transportation and energy infrastructure (California Natural Resources Agency, 2009). In terms of sea level rise, the strategy promotes inter-organizational collaboration between state and local agencies and encourages local governments to consider strategies to mitigate flood risk 
and limit development in highly vulnerable areas. Additionally, California mandates that all local governments include a climate change element in their hazard mitigation plans prepared under the DMA (Stults, 2017).

The State of New York has also taken steps toward climate change adaptation. In 2009, Governor Paterson signed Executive Order No. 24 establishing the New York State Climate Action Council (NYSCAC), which was tasked with drafting a Climate Action Plan by September 2010. In 2010, the NYSCAC released the Climate Action Plan Interim Report, focusing on mitigation and adaptation to climate change in the State of New York. However, the final Climate Action Plan had not been adopted as of January 2018. In 2014, Governor Cuomo signed the Community Risk Assessment and Resiliency Act, which mandates consideration of climate risks, such as sea level rise, in various programs and permits in the State of New York. In 2017, the State of New York adopted official sea-level rise projections to improve planning for resiliency.

On the other hand, state leadership and assistance are lacking in other states that are vulnerable to sea level rise, such as North Carolina and Florida. In these cases, local governments have been planning and implementing climate change adaptation initiatives without substantial administrative and financial support from the state government.

\subsection{Local-Level Government Action to Address Sea Level Rise}

Local governments may plan for climate change adaptation and prepare for sea level rise utilizing federal and state-level financial and technical support. For instance, under the DMA of 2000, local governments can include a climate change adaptation element in their hazard mitigation plans. Additionally, decision-making tools and research, produced by federal agencies, are available to aid preparation. There is a large 
degree of variation in terms of state leadership on this issue. For instance, California and New York have established adaptation strategies, while the majority of other states have not started planning for climate change adaptation. Yet, climate change adaptation is largely viewed as a local issue, because solutions to climate change and sea level rise are very site-specific, and there is no single one-size-fits-all solution.

When support from higher levels of the government is insufficient, local governments may undertake climate change adaptation measures independently or resort to collective solutions. City preparedness for sea level rise has not been uniform. One issue that cities face is a lack of comprehensive standard approaches toward climate change adaptation planning (Measham et al., 2011; Woodruff \& Stults, 2016). As a result, there has been substantial variation in the quality of city climate change adaptation plans (Woodruff \& Stults, 2016). Nonetheless, a number of local governments in the US have designed - and are in the process of implementing - comprehensive climate change adaptation plans, including New York, Miami Beach, and Fort Lauderdale.

In terms of collaborative solutions, one notable example is the SFRCCC. The SFRCCC was founded in 2010 by four counties in Florida: Broward, Miami-Dade, Monroe, and Palm Beach. Within these counties, more than 30 municipalities have been actively involved in SFRCCC activities with the goal of planning and advocating for climate change adaptation regionally. The SFRCCC brings together policymakers and practitioners from all levels of government, citizens, nonprofit organizations, businesses, and academia (SFRCCC, 2016). During a visit to Florida in 2015, President Obama expressed his support for the SFRCCC: 
Five years ago, local leaders down here, Republicans and Democrats, formed the bipartisan Southeast Florida Climate Change Compact - an agreement to work together to fight climate change. And it has become a model not just for the country, but for the world (Office of the Press Secretary, 2015).

The SFRCCC has developed a collaborative Regional Climate Change Action Plan with a set of 110 action items, to be implemented by the member counties and cities. The SFRCCC meets annually in one of the participating counties, holding a series of panels and workshops related to the best practices in climate change adaptation that also serve as a tool to track progress toward climate change resiliency. The SRFCCC also surveys participating municipalities annually to track progress of action item implementation. Nonetheless, most SRFCCC activities relate to information sharingwhether it is the most recent climate science, or best practices that have been implemented by participating cities or counties.

Yet, SRFCCC provides only one example of the existing collaborative efforts to adapt to sea level rise. Other non-governmental actors have been involved in helping communities become more resilient to sea level rise, such as the private Rockefeller Foundation, which formed a city network: 100 Resilient Cities. Currently, 23 cities in the US participate in this network. In participating cities, the Rockefeller Foundation provides funds for a Chief Resilience Officer and provides access to financial and administrative resources to plan for various challenges that the cities face, including sea level rise.

Cities have also worked with nonprofit organizations on this issue. One example is the CLEO Institute in Florida, which provides training on climate science and solutions 
to climate change. Some cities in South Florida, with the help of the CLEO Institute, have provided training to city government employees to help integrate climate change preparedness into day-to-day operations and city departments. 


\section{CHAPTER 3. LITERATURE REVIEW}

This chapter outlines the extant literature on climate change action, primarily focusing on the extant knowledge and research in the field of planning. It also reviews the literature on public management, focusing on collaborative governance as a management strategy. The chapter concludes with a discussion on existing gaps in both bodies of literature.

\subsection{Climate Change Adaptation Literature Review}

Climate change adaptation refers to "efforts to reduce the vulnerability of society to climate change impacts" (US Global Change Research Program, 2014, p. 671). In the 2000s, climate change adaptation became recognized as the second important measure to address climate change, along with mitigation efforts (Birkmann \& von Teichmann, 2010). Since the early 2000s, scholars have written extensively about preparedness for climate change. The extant literature on climate change adaptation addresses a number of aspects, which can broadly be distinguished into four bodies of research: the current trends of climate change adaptation (Berrang-Ford, Ford, \& Paterson, 2011; Broto \& Bulkeley, 2013; Hamin, Gurran, \& Emlinger, 2014); barriers that jurisdictions face in designing and implementing solutions to the effects of climate change (Bedsworth \& Hanak, 2010; Bierbaum et al., 2013; Burch, 2010; Eisenack et al., 2014; Hamin et al., 2014; Measham et al., 2011; Moser \& Ekstrom, 2010; Mozumder, Flugman, \& Randhir, 2011; Tribbia \& Moser, 2008); characteristics and quality of adaptation plans, including factors that influence the quality (Bassett \& Shandas, 2010; Berke et al., 2015; Lyles, Berke, \& Heiman-Overstreet, 2017; Schrock, Bassett, \& Green, 2015; Shi, Chu, \& Debats, 2015; Tang, Brody, Quinn, Chang, \& Wei, 2010; Woodruff \& Stults, 2016; 
Wheeler, 2008); and various decision-making strategies that can be utilized for adaptation (Berke \& Lyles, 2013; Quay, 2010).

The first body of literature has investigated the trends of climate change adaptation. These typically exploratory studies have examined whether and how governments are addressing climate change (Hamin et al., 2014). Overall, researchers have described climate change adaptation as being in a relatively early stage, with current adaptation action largely focusing on documenting risks and vulnerabilities to climate change rather than specific implementable action plans intended to increase community resilience (Lyles et al., 2017; Preston, Westaway, \& Yuen, 2011; Woodruff \& Stults, 2016). Scholars have found that there is no single uniform approach to planning for climate change (Bassett \& Shandas, 2010; Hamin et al., 2014; Lyles et al., 2017). Some local governments have designed standalone climate change adaptation plans, while others have integrated a climate change adaptation element into their existing plans (e.g., comprehensive development plans, master plans, or sustainability plans) (Bassett \& Shandas, 2010). As a result, local governments vary in terms of their progress in adapting to climate change: some governments have not taken action; others have developed comprehensive strategies that are being implemented.

The second body of literature on climate change adaptation has examined the barriers that may prevent or complicate planning for climate change adaptation. Studies on barriers largely employ qualitative methods, such as interviews with key stakeholders, including experts and municipal employees. Scholars have found that adaptation may be hindered by inadequate leadership from higher levels of government or local government leaders (Burch, 2010; Hamin et al., 2014; Measham et al., 2011; Mozumder et al., 2011); 
lack of various resources, including funding, qualified staff, and time (Bierbaum et al., 2013; Hamin et al., 2014; Measham et al., 2011; Mozumder et al., 2011); and information constraints and uncertainty in decision-making (Bedsworth \& Hanak, 2010; Berke \& Lyles, 2013; Bierbaum et al., 2013; Hamin et al., 2014; Measham et al., 2011; Tribbia \& Moser, 2008; Mozumder et al., 2011). In the context of planning, barriers can be understood as obstacles that a government must ameliorate in order to improve climate change adaptation planning and implementation.

The third body of literature on climate change adaptation has focused on the characteristics and quality of local climate change adaptation plans, including various factors that influence plan quality (Bassett \& Shandas, 2010; Lyles et al., 2017; Schrock et al., 2015; Shi et al., 2015; Tang et al., 2010; Woodruff \& Stults, 2016; Wheeler, 2008). Studies on climate change adaptation plans have largely drawn from the literature on plan quality, which pertains to plan evaluation using content analysis methods and employing statistical analyses to determine the factors that influence quality (Berke \& French, 1994; Berke, Cooper, Aminto, Grabich, \& Horney, 2014; Berke et al., 2015; Brody, 2003a; Lyles \& Stevens, 2014; Tang \& Brody, 2009).

In a handful of large- $N$ studies to-date that have explored determinants of climate change adaptation plan quality in local governments, scholars have found that a number of local government characteristics are associated with higher quality in climate change adaptation plans, including higher expenditures per capita (Shi et al., 2015), higher commitment of local elected officials (Shi et al., 2015; Woodruff \& Stults, 2016), and previous experience of climate impacts (Shi et al., 2015). In their recent study, Woodruff and Stults (2016) demonstrated that climate change adaptation plan quality is higher in 
cities in which planning departments are charged with writing the plans. In higher levels of government, state mandates for climate change adaptation planning and state funding to local governments have been found to contribute to improved plan quality (Tang et al., 2010; Woodruff \& Stults, 2016).

Finally, the fourth body of literature on climate change adaptation, which is less developed compared to the previous three, has examined climate change through the lens of planning and management strategies (Berke \& Lyles, 2013; Quay, 2010). Researchers have argued that planning for climate change cannot be accomplished by utilizing historically traditional planning practices. While traditional planning includes an examination of past conditions, adapting to climate change requires different planning strategies due to high uncertainty about the future and the magnitude of adverse effects (Bedsworth \& Hanak, 2010; Lyles et al., 2017; Quay, 2010). Sea level rise, for instance, cannot be predicted by extrapolating past data, and requires a consideration of multiple possible future scenarios. As a result, Quay (2010) proposed anticipatory governance as a flexible planning tool that helps consider multiple future scenarios under a high level of uncertainty. Anticipatory governance is an alternative to the traditional predict-and-plan approach, as it "recognizes that some aspects of the future are not knowable and that any prediction or forecast represents only one of many possible futures" (Quay, 2010, p. 498).

Apart from anticipatory governance, scholars have also documented the involvement of multiple public and non-governmental actors in the process of planning (Berke \& Lyles, 2013; Berke et al., 2014; Brody, 2003b; Brody, Highfield, \& Carrasco, 2004; Drummond, 2010; Tang \& Brody, 2009). However, while citizen participation and collaborative governance have been applied in investigations of planning efforts, such as 
hazard mitigation, the application of these approaches in climate change adaptation planning has been limited. Berke and Lyles (2013) called for an integration of anticipatory and collaborative governance approaches to planning efforts that address adverse effects such as sea level rise. However, to my knowledge, no study to date has investigated the relationship between multiple actor involvement through collaborative governance approaches in the planning process and its effect on climate change adaptation efforts using representative samples.

\subsubsection{Gaps in the Literature on Climate Change Adaptation}

The existing body of literature on climate change adaptation sheds light on the current trends of climate change adaptation planning, barriers and opportunities of local governments, factors influencing the quality of plans, and planning strategies that can be utilized to adapt. Scholars have used various methods to improve the understanding of climate change adaptation, including qualitative techniques, such as interviews with key stakeholders, case studies, and content analysis. Several large- $N$ studies have investigated climate change adaptation, typically applying content analysis to measure climate change adaptation plan quality.

While there is a large body of research on climate change adaptation in the planning literature, some questions have not been fully answered. Research on local government efforts has mainly relied on plan quality as a dependent variable to investigate what drives planning efforts. While this line of research can help improve the practice of planning, it does not involve an assessment of the outcomes of these plans or their implementation (Berke \& Godschalk, 2009). Even plans of high quality may fall short of implementation due to various barriers, such as inadequate resources, including 
budget constraints and a lack of qualified staff. As a result, studies on plan quality have not addressed the effectiveness of these plans to increase community resilience. Because some communities are already experiencing the effects of climate change, such as sea level rise, scholars can potentially assess the effectiveness of local government efforts in addressing climate change adaptation-focusing on specific challenges and regions in the US. While the adverse effects of climate change will increase significantly in the following decades, evaluating current practices against already-occurring effects using mid-range outcomes could provide a deeper understanding of preparedness.

Additionally, studies that have focused on plan quality have assessed planning for climate change adaptation as a whole. While different regions in the US have experienced varying challenges associated with climate change, studying specific challenges may help improve our understanding of climate change adaptation preparedness in specific regions. For instance, most coastal communities in the US are already experiencing increased flooding due to sea level rise. Investigating the effect of local government efforts to mitigate flooding damage using large samples can provide a better understanding of factors contributing to better adaptation.

Little is known about planning and management strategies, such as anticipatory governance and collaborative governance as means to improve adaptation. It is unclear to what extent involvement of various stakeholders in the planning process may improve preparedness for climate change: can non-profit organizations, for instance, help enhance these efforts? Likewise, studies on climate change adaptation have lacked empirical evidence to assess the effectiveness of these strategies using large samples of local governments. 


\subsection{Collaborative Governance Literature Review}

Public organizations in the US have faced increasing problems and crises that transcend boundaries of public policy and jurisdictions (Kettl, 2006a). As a result, it has become burdensome for single organizations to design and implement administrative solutions alone (Kettl, 2002). Challenges such as natural disasters and acts of terrorism have revealed weaknesses in the federalist system that are rooted in vertical and horizontal fragmentation of authority (Kettl, 2006a). Complex public problems (e.g., climate change) typically do not have simple definitions and easily implementable solutions, and their consequences often cross local government, state, and even national boundaries (Emerson \& Nabatchi, 2015a). At the same time, these problems involve multiple stakeholders that are not limited to public sector, including citizens, businesses, and institutions of higher learning. In effect, public managers have increasingly engaged in collaborative arrangements and working with businesses, nonprofit organizations, and institutions of higher learning to address public problems and deliver public services. Collaborative skills have become essential for public administrators to keep pace with the growing multitude of actors involved in policymaking and implementation processes (McGuire \& Silvia, 2010).

Feiock (2013) has argued that collaboration can be utilized as a strategic tool at the local level of government. Some local governments have the necessary financial resources and staff to provide services to their constituents in an efficient manner. For cities with larger populations, direct trash collection or public safety services may be cost-effective. However, in cases when small jurisdictions are unable to deliver services efficiently, local governments may resort to alternative service delivery methods. In the 
latter condition, governments are exposed to a situation that Feiock (2013) labeled an institutional collective action dilemma, which can be resolved by utilizing tools of collaborative governance with other actors.

Collaborative governance in service delivery has recently gained academic attention (e.g., Agranoff, 2006; Feiock, 2007, 2008, 2013; Feiock \& Scholz, 2010; McGuire, 2006; Provan \& Milward, 2001). Researchers have examined collaboration in various public policy areas, including health (e.g., Huang \& Provan, 2007; Provan \& Milward, 1995), emergency management and services (e.g., Caruson \& MacManus, 2011; McGuire \& Silvia, 2010; Moynihan, 2008; Thurmaier, 2006), education (e.g., Meier \& O'Toole, 2003), environmental policy (e.g., Bentrup, 2001; Van Bueren, Klijn, \& Koppenjan, 2003; Imperial, 2005; Koontz \& Thomas, 2006; Scott, 2015, 2016), and economic development (e.g., Agranoff \& McGuire, 2003; Hawkins, 2010).

\subsubsection{Definition of Collaborative Governance}

There is no universal definition of collaborative governance in the context of public management. Definitions in the literature have typically been geared toward either vertical or horizontal collaboration. For instance, some scholars broadly describe collaboration as a process of crafting inter-organizational solutions to problems that cannot be tackled alone by single jurisdictions (Agranoff \& McGuire, 2003; Kettl, 2006b; McGuire, 2006; O'Leary, Gerard, \& Blomgren Bingham, 2006). Yet, collaboration is not restricted to inter-organizational action. Mitchell, O'Leary, and Gerard (2015) suggested that collaborative governance can also involve the public. The Ansell and Gash (2008) definition of collaboration is horizontally focused: "A governing arrangement where one or more public agencies directly engage non-state stakeholders in a collective decision- 
making process that is formal, consensus-oriented, and deliberative and that aims to make or implement public policy or manage public programs or assets" (p. 544). This definition indicates that collaboration is a formalized process that is typically led by public organizations. On the contrary, other scholars have argued that interactions between partners need not be exclusively formal; informal elements may be included (Emerson, Nabatchi, \& Balogh, 2012; Thomson \& Perry, 2006).

Expanding on the work of Ansell and Gash (2008), Emerson and Nabatchi (2015a) defined collaborative governance as "the processes and structures of public policy decision making and management that engage people across the boundaries of public agencies, levels of government, and/or the public, private, and civic sphered to carry out a public purpose that could not otherwise be accomplished" (p. 18). The latter definition includes horizontal and vertical collaboration and makes an important distinction from the Ansell and Gash (2008) definition: Emerson and Nabatchi (2015a) emphasized that collaborative governance does not have to be initiated by public agencies.

To investigate horizontal collaboration involving multiple stakeholders that are not limited to the public sector (Bryson, Crosby, \& Stone, 2006), the present study utilized the following, broad definition of collaboration: a process that aims to ameliorate complex public problems - which a single organization may not successfully solve alone-by involving public and non-governmental stakeholders (Agranoff \& McGuire, 2003; Kettl, 2006b; McGuire, 2006; O'Leary et al., 2006). This definition encompasses both city-to-city collaboration and collaboration between cities and multiple non- 
governmental stakeholders, including nonprofit organizations, institutions of higher learning, private businesses, and community groups.

Collaboration can further be classified as vertical and horizontal. Vertical collaboration typically refers to the relations between lower and higher levels of government (Agranoff \& McGuire, 2003). Horizontal collaboration, on the other hand, relates to collective problem solving that involves mostly local players who have shared interests (Agranoff \& McGuire, 2003) or organizations at the same level of government (e.g., municipal governments).

\subsubsection{Antecedents of Collaboration}

Scholars have extensively studied the factors that hinder or facilitate formation of collaborative governance (e.g., Ansell \& Gash, 2008; Bryson et al., 2006; Emerson et al., 2012; Emerson \& Nabatchi, 2015a; Feiock, 2007, 2008, 2013; Kwon \& Feiock, 2010; Scott \& Thomas, 2017; Thomson \& Perry, 2006). Theoretical and conceptual frameworks, designed to explain collaborative governance, have drawn from multiple streams of literature, including intergovernmental cooperation, conflict resolution, collective action, democracy theory, and policy implementation (Emerson et al., 2012).

Scholars have also developed multiple frameworks to study collaborative governance (Ansell \& Gash, 2008; Bryson et al., 2006; Chen, 2010; Emerson \& Nabatchi, 2015a; Emerson et al., 2012; Feiock, 2008; Thomson \& Perry, 2006). Some frameworks have assumed the input-process-outcome form, resembling systems theory thinking (Chen, 2010; Emerson \& Nabatchi, 2015a; Emerson et al., 2012; Thomson \& Perry, 2006). Most frameworks have emphasized the factors that facilitate or hinder initiation of collaborative governance and the process that explains the occurrence of 
collaborative arrangements and the products of collaboration: outputs and outcomes. There is overlap between the frameworks. For instance, scholars have argued that for collaboration to occur, one or more leaders must bring the interested parties to the table (Ansell \& Gash, 2008; Bryson et al., 2006; Emerson et al., 2012; Emerson \& Nabatchi, 2015a). Another common feature of the frameworks is that a history of conflict and litigation between potential partners hinder the ability to collaborate (Ansell \& Gash, 2008; Emerson et al., 2012; Emerson \& Nabatchi, 2015a; Thomson \& Perry, 2006).

Emerson and Nabatchi (2015a) offered the integrative framework for collaboration governance, which distinguishes between the system context [i.e., the complex of various antecedents that influence a collaborative governance regime] and the drivers - specific triggers that help instigate collaborative efforts. They argued that a favorable system context is not a sufficient condition for initiation of a collaborative effort; one or more drivers must be present for collaboration to occur. The system context consists of six elements: (1) public service and resource conditions; (2) policy and legal frameworks; (3) socioeconomic and cultural characteristics; (4) network characteristics; (5) political dynamics and power relations; and (6) history of conflict. The drivers in their framework include uncertainty, interdependence, consequential incentives, and initiating leadership. At the center of the collaborative governance framework is the collaborative governance regime, which is comprised of collaboration dynamics and collaborative actions that follow. Collaboration dynamics, in turn, includes three interrelated processes: shared motivation, principled engagement, and joint capacity. These processes lead to collaborative actions, or outputs, that ultimately translate into outcomes of collaboration. Finally, the outcomes feed back into the system and alter its context. Collaborative 
governance is a circular rather than linear process: system context and outcomes influence each other in an iterative way (Emerson \& Nabatchi, 2015a).

The Emerson and Nabatchi (2015a) framework provides a comprehensive list of interrelated concepts to explain collaborative governance and lends itself to the study collaboration from multiple units of analysis, including individual, organizational, and a collaborative governance regime itself. The framework is broad and may be utilized to study various types of collaboration, including vertical and horizontal, and the perspectives of different actors, including public and non-governmental stakeholders. Because it is very broad, the framework does not account for the multiplicity of organizational factors that may influence the formation of collaborative governance arrangements at the organizational level, such as organizational size, structure, and the level of bureaucratic professionalism.

This dissertation utilized the organization as the unit of analysis. To better reflect dynamics at the organizational level, I drew from the extant literature on climate change action in public administration and planning. Specifically, I borrowed the drivers from the Emerson and Nabatchi (2015a) framework to derive expectations about the triggers of collaboration. For organizational-level antecedents of collaboration and the broader context within which collaboration occurs, I utilized the extant research on organizational propensity to collaborate and climate change adaptation.

\subsubsection{Drivers of Collaboration}

This section discusses Emerson and Nabatchi's (2015a) drivers of collaborationuncertainty, interdependence, consequential incentives, and leadership - in more detail, using other relevant literature in public administration. 
Uncertainty. Scholars of collaborative governance have argued that public organizations seek collaborative solutions when problems have a large degree of uncertainty, in terms of problem definition and possible solutions (Bryson et al., 2006; Emerson et al., 2012; Emerson \& Nabatchi, 2015a). Public organizations face increasingly complex public problems - which, in certain instances, can be classified "wicked," borrowing terminology from Rittel and Webber (1973) — that are both hard to define and ameliorate. The policies needed to alleviate a problem may be difficult to determine, but public organizations also face challenges in clarifying and defining the problem itself (Emerson \& Nabatchi, 2015a). Complex public problems, such as terrorism and climate change, span across government boundaries-both vertically and horizontally—making it difficult for single organizations to design and implement administrative solutions alone (Kettl, 2002). Uncertainty drives organizations to collaborate in an attempt to increase stability (Bryson et al., 2006). Such a proposition is consistent with resource dependence theory, which explains how organizations strive to secure resources and decrease turbulence in their environments to survive.

To decrease uncertainty about the problem definition, public organizations may engage with partners that can provide scientific and technical expertise, such as institutions of higher learning. In the case of sea level rise preparedness, cities collaborate with universities to determine possible scenarios of future sea level rise and assess the risks of saltwater intrusion into drinking water systems, effects on endangered species, and other impacts. Collaboration can help unearth possible technical solutions that can be transferred from one location to another, albeit adjusting for local, specific contexts. 
Interdependence. The notion of interdependence in public administration originates from resource dependency theory, which concerns strategies that organizations use to adapt to their environments when resources are scarce (Pfeffer \& Salancik, 2003). The theory posits that organizational behavior is a function of external factors, such as the organizational environment, that provide both opportunities and constraints. According to Pfeffer and Salancik (2003), "As organizations try to alter their environments, they become subject to new and different constraints as their patterns of interdependence change, which the organizations try to further negotiate" (p. xii).

By definition, collaboration occurs when organizations are unable to effectively achieve results on their own (Agranoff \& McGuire, 2003; Kettl, 2006b; McGuire, 2006; O'Leary et al., 2006). Interdependence arises when organizations are unable to adequately accomplish their goals (Emerson \& Nabatchi, 2015a). This is evident in cases where the initiatives of single organizations fail to solve a problem (Bryson et al., 2006), pushing them to seek potential partners. In these cases, stakeholders may seek collaboration out of necessity (Emerson \& Nabatchi, 2015a). Even when there is a history of conflict between parties, the recognition of interdependence may result in successful collaboration (Imperial, 2005).

Interdependence is not necessarily commonplace in all service areas and organizations. For jurisdictions with large populations, direct supply of trash collection services or public safety may be cost-effective. However, when inefficiencies arise in small jurisdictions, a lack of available resources may impede efficient service delivery (Feiock, 2013). Interdependence is immediately evident in cases where organizations lack qualified staff and money to design and implement public programs. These conditions 
provide fertile ground in which organizations can seek partners and join forces in applying for grants, developing programs, or advocating on behalf of their constituents to higher levels of government. On the other hand, organizations may be unwilling to collaborate if they believe their goals could be achieved while working on their own, rather than dedicating time and resources to collaborate with others (Ansell \& Gash, 2008). Given that achieving results through collaboration is often time-consuming (Emerson \& Nabatchi, 2015a; Mitchell et al., 2015), organizations are expected to use collaboration as a strategy only when they recognize their inability to solve a problem on their own.

Consequential Incentives. The third driver, consequential incentives, consists of both positive and negative incentives. Positive incentives to collaborate may arise from a promise of external funding opportunity, or extreme events that require collective action (Emerson \& Nabatchi, 2015a). At the same time, organizations may be willing to collaborate if they believe that it will yield tangible policy outcomes (Ansell \& Gash, 2008), an opportunity to influence decisions (Emerson \& Nabatchi, 2015a), or possible benefits to the careers of organization (Feiock, 2008). Because collaboration requires dedication of time and effort, it diverts public employees from their day-to-day responsibilities. As a result, leaders must perceive collaboration as a worthy pursuit; otherwise, problem-solving will be contained within the organization. Moreover, organizations do not collaborate for purely altruistic reasons (Emerson \& Nabatchi, 2015a) but, instead, they will work together with hopes of acquiring "mutually reinforcing benefits" (Krueathep, Riccucci, \& Suwanmala, 2010, p. 161). Negative 
incentives will be evident recognized when organizations believe they may suffer losses if they fail to engage with other actors to solve public problems.

Leadership. Finally, for collaboration to occur, someone must assume the role of leader to bring the parties to the table (Emerson \& Nabatchi, 2015a) by drawing attention to the public problem (Bryson et al., 2006). Ansell and Gash (2008) wrote that leaders are "crucial for setting and maintaining clear ground rules, building trust, facilitating dialogue, and exploring mutual gains" (p. 554). At the same time, for employees in organizations to engage in collaboration, leaders must approve collaborative efforts. Because collaboration is a time-consuming effort, organizational leaders must decide how much public employee time will be allocated to collaboration.

The responsibility of solving public problems - including the responsibility of providing resources for solutions - is often spread across various individuals and organizations and no "single individual, group or organization can make significant headway in fulfilling these needs without cooperating with other individuals, groups or organizations that have a stake in producing better outcomes" (Crosby \& Bryson, 2005, p. 184). As a result, one of the core responsibilities for leaders in an increasingly networked and complex world is to recognize organizational needs and broker partnerships with various public and non-governmental stakeholders and select appropriate partners (Silvia, 2017). Emerson and Nabatchi (2015a) described the leadership needed for collaboration as "initiating"-through recognition of three other drivers of collaboration (uncertainty, interdependence, and consequential incentives), an initiating leader "stimulates interest in and instigates preliminary discussions about creating a collaborative endeavor" (p. 47). 


\subsubsection{Outputs and Outcomes of Collaboration}

In the model devised by Emerson and Nabatchi (2015b), the analyses of outputs and outcomes of collaborative governance constitute the first and second levels of collaborative performance assessment. These levels can be evaluated using three units of analysis: participant organization, collaborative governance regime, and target goals.

Collaborative outputs can be defined as collaborative actions, or efforts that follow from the process of collaboration (Emerson \& Nabatchi, 2015a). The outputs are highly dependent on the context and the goals of collaboration, and may involve educating the public, enacting new laws and regulations, and acquiring external resources (Emerson et al., 2012). Koontz and Thomas (2006) defined collaborative outputs as "plans, projects, and other tangible items generated by collaborative efforts" (p. 457) and provide a set of existing measures to study environmental outputs that collaborative arrangements help produce, such as agreements, changes to public policy, and implemented programs. Emerson and Nabatchi (2015a) noted that collaborative actions can be executed collectively or individually. For instance, a participating organization may implement its own plans and policies, drawing from the benefits attained from collaboration, which may include an increase in funding and access to better information.

Collaborations are typically initiated to help organizations realize their missions (Emerson \& Nabatchi, 2015b). Therefore, all parties involved expect to attain mutually beneficial goals through the process of collaboration. While some scholars have argued that outcomes should operate as a feedback loop that informs the system context and alters it (Emerson et al., 2012), others have suggested that the goal of collaborative 
governance is to create public value (Bardach, 1998; Bryson et al., 2006; Thomson, Perry, \& Miller, 2008).

Gray (2000) cautioned that the evaluation of outcomes will depend on the theoretical lens through which we examine collaborations and offered five perspectives to evaluate collaborative success: resolution of the problem, creation of social capital, creation of shared meaning between the participants, changes in network structure, and changes in power distribution. The latter four types of outcomes are extensively covered in the literature (e.g., Bardach, 1998; Lubell, 2005; Leach \& Sabatier, 2005; Thomson et al., 2008; Ulibarri, 2015), while research on problem-solving outputs and outcomes is still underdeveloped.

\subsubsection{Extant Research on Outputs and Outcomes of Collaboration}

The large, extant body of research on collaboration has shed light on outputs and outcomes of collaboration. In terms of outcomes, the literature has primarily focused on social outcomes of collaborative participants and perceptual organizational outcomes as products of collaboration. However, collaboration as a tool to improve objective organizational outcomes has been less understood.

One line of research on collaborative governance has investigated social outcomes of collaboration using the perspectives of participants (Leach, Weible, Vince, Siddiki, \& Calanni, 2013; Lubell, 2005; Thomson et al., 2008; Ulibarri, 2015; Varda \& Retrum, 2015). For instance, Lubell (2005) noted that collaboration "causes the most favorable changes about fairness, trust, and conflict resolution" (p. 220) among stakeholders that participate in the National Estuary Program of the EPA. Collaboration has also been found to improve trust building (Lubell, 2005; Thomson et al., 2008; Varda \& Retrum, 
2015). Another potential desirable outcome of collaboration is an ongoing mutual learning process, which facilitates the development of shared understanding of what partners "can collectively achieve together" (Ansell \& Gash, 2008, p. 560). Collaborations involving a diverse array of actors - not limited to the public sector-have provided fertile ground for learning by allowing participants to acquire new knowledge and professional opinions about public policies. Leach et al. (2013) provided empirical evidence that learning occurs through collaboration. Most participants in their study reported acquisition of new knowledge and change of at least one professional opinion through their participation in collaboration.

Emerson and Nabatchi (2015b) indicated that organizations do not typically collaborate for altruistic reasons: they expect to attain a desirable goal and better achieve their mission. A number of studies have assessed the extent to which collaboration improves organizational outcomes (e.g., Chen, 2010; Gazley, 2010; Kelman et al., 2012; Scott, 2015, 2015; Mitchell et al., 2015; Thomson et al., 2008; Ulibarri, 2015).

Gazley (2010) provided evidence that more active collaborative partners report higher accomplishments of collaborations in public-nonprofit partnerships: "Partnerships in which more joint activity is carried out appear to reap greater benefits" (p. 665). More recently, Ulibarri's (2015) study on collaboration in the hydropower licensing process concluded that collaboration is linked to several positive outcomes as perceived by the participants, but the effect is less pronounced in predicted environmental and economic outcomes. Mitchell et al. (2015) demonstrated that for US local public managers, US federal public managers, and US-based non-governmental organization leaders, "the perceived positive link between collaboration and performance is the main catalyst for 
engaging in collaboration as a management strategy" (p. 684). Further, they found that local government managers report several positive returns resulting from collaboration: "economic benefits, such as efficiencies achieved through pooling resources, lower costs, and economies of scale, and mentioned improved quality of work product or decisionmaking, sustainability, timeliness, and better public service” (p. 695).

While these findings are encouraging to scholars and practitioners, perceptionbased measures of outcomes have also been scrutinized due to possible bias and overestimation of success of collaboration (Leach \& Sabatier, 2005). Because linking collaborative governance to actual organizational outcomes is difficult, organizational outcomes have been measured using the "second best" approach through stakeholder opinions (Ulibarri, 2015). Few studies have explored the link between collaboration and objective outputs of outcomes of public policies (for exceptions, see Kelman et al., 2012; Scott, 2015, 2016). Kelman et al. (2012) investigated the effect of collaborative managerial practices on objective service delivery outcomes in the United Kingdom and found that collaboration can modestly improve outcomes. However, they acknowledged that, "A collaboration might lower performance compared with individual agencies pursuing their goals separately, suggesting that in some circumstances, setting up a collaboration in the first place is a bad idea" (pp. 624-625). Scott $(2015,2016)$ provided compelling evidence that collaborative groups can improve desirable environmental outcomes in the context of watershed management.

The extant literature has scarcely addressed how different partners may affect organizational outputs and outcomes as a result of horizontal collaborative activity. Most research to date has investigated public-public collaboration, mainly focusing on 
agreements between municipal governments. One notable exception is a study by Andrews and Entwistle (2010), in which the authors conducted an exploratory quantitative study on cross-sectoral partnerships and their relation to three organizational goals: effectiveness, efficiency, and equity. They found that public-public partnerships are positively associated with all three goals, while public-private partnerships are negatively associated with effectiveness and equity, and public-nonprofit partnerships are not related to performance (Andrews \& Entwistle, 2010).

The present study focused on horizontal voluntary collaboration, which has been understudied in the public administration literature, and outputs and outcomes of public service delivery. More specifically, I investigated the relationship between city-led collaboration with other municipalities and non-governmental stakeholders, and policy outputs and outcomes of sea level rise preparedness in US cities.

\subsubsection{Gaps in the Literature on Collaborative Governance}

Scholars have written extensively about collaborative governance, including vertical (between lower and higher levels of the government), and horizontal (between governments at the same level and various non-governmental stakeholders). A large body of literature has investigated organizational propensity to collaborate with other stakeholders (Amirkhanyan, 2008; Ebrahim, 2004; Foster \& Meinhard, 2002; Hawkins, 2010; Jang, Feiock, \& Saitgalina, 2016; McGuire \& Silvia, 2010). However, many of these studies are limited to inter-organizational and vertical collaboration, typically involving higher levels of government.

A large share of collaboration in the public sector has been vertical-occurring within the context of intergovernmental relations between organizations at different 
levels of the government. However, public organizations have increasingly engaged in horizontal collaboration involving multiple non-governmental stakeholders. While the factors that facilitate vertical collaboration have been studied in the literature (McGuire \& Silvia, 2010; Amirkhanyan, 2008; Hawkins, 2010), less is known (for exceptions, see Gazley, 2010; Jang et al., 2016) about horizontal collaboration, which is often voluntary in nature. Agranoff and McGuire (2003) defined horizontal collaboration as a type of collaboration, where "players are local and represent multiple interests within the community" (p. 21). Unlike vertical collaboration, which is typically embedded in intergovernmental program implementation (Agranoff \& McGuire, 2003), horizontal collaboration may arise as a voluntary effort that will mutually benefit cities and other local stakeholders (e.g., nonprofits, businesses, and institutions of higher learning).

Scholars have also examined collaboration between local governments, but horizontal collaboration with non-state stakeholders has been given less attention in the public administration literature. The empirical findings of research on vertical collaboration may not necessarily apply to voluntarily-initiated collaboration, because actors are working together out of a mutual benefit, not due to a mandate or necessity to implement intergovernmental policy. At the same time, research on city-to-city voluntary collaboration has not provided a complete understanding of the factors that facilitate horizontal voluntary collaboration. Municipalities have increasingly worked with nonpublic stakeholders to obtain unique resources, such as scientific research from universities and volunteer work from nonprofit organizations.

Despite the expanding academic interest in collaborative governance (e.g., Agranoff, 2006; Feiock, 2007, 2008, 2013; Feiock \& Scholz, 2010; McGuire, 2006; 
Provan \& Milward, 2001), the evidence of its effects on organizational performance of public problem-solving has been modest (Emerson \& Nabatchi, 2015b; Kelman et al., 2012; Koontz \& Thomas, 2006; Ulibarri, 2015; Varda \& Retrum, 2015). McGuire (2006) noted that "many studies, perhaps wrongly in some cases, equate the presence of collaboration with success of a program without adequate empirical verification" (p. 39). It is also known that the outcomes may be very difficult to operationalize (Emerson \& Nabatchi, 2015a), and there is no universal method or approach to measure outcomes associated with collaboration (Gray, 2000). As a result, most studies to date have measured various outcomes of collaboration through surveys, asking participants to rate their satisfaction with various social and organizational outcomes (e.g., Chen, 2010; Gazley, 2010; Thomson et al., 2008; Ulibarri, 2015). While the use of perceptual measures has helped avoid the difficulty of linking collaboration to outcomes, participants involved in collaboration may have overestimated perceived success, because they are invested in the process of collaboration, which is typically costly in terms of time and resources (Leach \& Sabatier, 2005; Ulibarri, 2015). 


\section{CHAPTER 4: RESEARCH QUESTIONS, HYPOTHESES, AND CONCEPTUAL FRAMEWORKS}

This chapter introduces the four research questions of this dissertation, along with hypotheses that were formulated based on prior research and conceptual frameworks on collaboration.

Research Question 1: What are the factors that facilitate city-level collaboration for sea level rise adaptation?

Research Question 2: Is city-level collaborative activity associated with higher outputs of sea level rise adaptation? Does the effect vary depending on the type of collaborative partner?

Research Question 3: Is the city-level collaborative activity associated with higher outcomes of sea level rise adaptation? Does the effect vary depending on the type of collaborative partner?

Research Question 4: How does collaboration help cities improve their preparedness for sea level rise?

\subsection{Research Question 1 and Hypotheses}

The first research question guided the investigation of factors that facilitate citylevel horizontal collaboration for sea level rise adaptation. The literature review drew from Emerson and Nabatchi's (2015a) integrative framework of collaborative governance and other relevant work, including extant knowledge on organizational propensity to collaborate and enter into voluntary arrangements (Chen, 2010; Gazley, 2010; Jang et al., 2016; McGuire \& Silvia, 2010) and planning literature on climate change action (Shi et al., 2015; Tang et al., 2010). 
Based on Emerson and Nabatchi's (2015a) integrative framework of collaborative governance, the drivers of collaboration are specific triggers, without which "the call for collaboration would likely go unheeded and collaborative governance would not unfold" (p. 43-44). According to the framework, which draws from previous inter-disciplinary literature on collaborative governance, there are four drivers: uncertainty, interdependence, consequential incentives, and initiating leadership. Not all drivers must be present for collaboration to unfold; however, scholars have argued that at least one driver is necessary for organizations to consider collaboration. Uncertainty has been defined as a lack of information about the definition and solutions of a public problem (Bryson et al., 2006; Emerson et al., 2012; Emerson \& Nabatchi, 2015a). In the context of complex public problems, where uncertainty is common, organizations are expected to attempt to decrease uncertainty and increase organizational stability through collaboration with other organizations and non-governmental actors that may possess better information and expertise (Bryson et al., 2006; Emerson \& Nabatchi, 2015a). As a result, the following expectation about uncertainty and collaborative activity was formulated:

Hypothesis 1: A higher degree of uncertainty about a public problem's definition and solutions is associated with a higher horizontal collaborative activity of an organization.

The second driver, interdependence, pertains to the inability of an organization to achieve results and solve public problems on its own (Emerson \& Nabatchi, 2015a). When dealing with scarce resources, including financial and human, organizations have increased their problem-solving capacity by pooling various resources with other 
organizations and stakeholders. In particular, this has occurred in cases when small jurisdictions are unable to deliver services in an efficient manner, providing an incentive to create economies of scale with other jurisdictions (Feiock, 2013). As a result, the following expectation was formulated:

Hypothesis 2: A higher degree of interdependence in public service delivery will be associated with higher horizontal collaborative activity of an organization.

The third driver, consequential incentives, includes both positive and negative incentives. Because the present study focused on voluntary horizontal collaboration, I focused primarily on positive incentives. Positive consequential incentives pertain to positive returns from collaboration, ranging from securing more funding to solving a public problem through collective action (Ansell \& Gash, 2008; Emerson \& Nabatchi, 2015a; Feiock, 2008; Krueathep et al., 2010). Based on the literature review, the following expectation was formulated:

Hypothesis 3: A higher degree of expected positive consequential incentives attained through collaboration will be associated with higher horizontal activity of an organization.

Finally, scholars have extensively documented the importance of leaders that help facilitate collaboration (Ansell \& Gash, 2008; Bryson et al., 2006; Emerson \& Nabatchi, 2015a). Through recognition of all three previous drivers (uncertainty, interdependence, and consequential incentives), leaders draw attention to the public problem and bring interested parties to the table. As a result, organizational leaders must recognize collaboration as an avenue to solve public problems and facilitate collective action through brokerage of partnerships for collaborations to form. At the same time, if leaders 
prefer traditional, hierarchical approaches to problem solving, the organization will be less likely to partner with others in various collaborations. Based on this, the following expectation was formed:

Hypothesis 4: More positive organizational leader views toward collaboration will be associated with higher horizontal collaborative activity of an organization.

Apart from the drivers of collaboration, researchers have noted alternative plausible explanations for differences in organizational collaborative activity. Through the literature review in public administration and planning, I identified three alternative explanations that may affect the extent of collaborative activity: problem severity, political commitment, and a set of organizational characteristics.

Problem severity is an explanation that has garnered scholarly attention. Feiock (2008) argued that the likelihood of collaboration will be influenced by the size of issue at hand. Larger public problems may not only require larger fixed costs, but other resources, such as expertise, information, and an overall increase of capacity-which collaboration can help achieve (Steinacker, 2010). Similarly, wicked public problems that are difficult to solve may motivate public agencies to seek partners beyond their organizational boundaries (Emerson et al., 2012; Emerson \& Nabatchi, 2015a; Bryson et al., 2006). Prior research has also shown that problem severity is related to the extent of governmental collaboration; scholars have found empirical support for the hypothesis that "[t]he greater the problem severity for organizations, the greater the level of external collaboration" (McGuire \& Silvia, 2010, p. 281).

Given that public organizations tackle multiple public problems, some issues may be prioritized over others. While governmental action on a public problem may be 
undertaken on some issues to serve the constituency and re-election, public interest in certain public problems may help move agendas forward, particularly on policy issues split along party lines, such as climate change (Krause, 2010). For instance, in the context of climate change policies in US cities, scholars found that a city's likelihood of participating in the Cities for Climate Protection program increased in relation to the percentage of citizens that voted for the Democratic Party candidates (Zahran, Brody, Vedlitz, Grover, \& Miller, 2008). Similarly, research by Hultquist, Wood, and Romsdahl (2017) on climate change adaptation policies in the Great Plains suggested that percent change in Democratic vote and local mayor support for climate change adaptation is associated with the adoption of more climate change adaptation policies at the local level. Thus, in the context of climate change adaptation, empirical research should account for two types of political commitment from actors: city elected officials and residents.

Finally, the ability of an organization to collaborate is influenced by its internal characteristics, such as organizational capacity, professionalism, and structure. Because collaboration requires time and resources, it is expected that public organizations that possess higher governmental capacity and level of professionalism will be more likely to collaborate. For instance, McGuire and Silvia (2010) found that managerial capacity is positively related to collaborative activity in the context of emergency management. Organizational structure may also affect the extent of horizontal collaborative activity. Following previous research, I anticipated that organizational structure may also affect the extent of horizontal collaborative activity. If a department responsible for a policy area in which collaboration occurs is a stand-alone entity (i.e., not located within another department), the city will have higher collaborative activity in that area, given the lead 
manager can focus on a given responsibility, rather than on multiple, often conflicting responsibilities (McGuire \& Silvia, 2010).

\subsection{Conceptual Framework I}

The conceptual framework for the first research question is presented in Figure 1. As discussed previously, horizontal collaborative activity was expected to be influenced by four elements: drivers of collaboration, problem severity, political commitment, and organizational characteristics.

Based on the literature review and Emerson and Nabatchi's (2015a) integrative framework of collaborative governance, it was hypothesized (hypotheses one to four) that four drivers of collaboration-uncertainty, interdependence, consequential incentives, and leadership-positively related to horizontal collaborative activity. However, organizations are also embedded in a broader context that can influence horizontal collaborative activity. In terms of problem severity, it was expected that the more severe the public problem, the more actively public organizations would participate in horizontal collaboration. Also, a higher degree of political commitment to climate change as a public issue would likely to contribute to greater collaborative activity because support for climate change policies has largely been divided across party lines in the US. Finally, a set of organizational characteristics-organizational capacity, professionalism and structure - were expected to affect horizontal collaborative activity. 
Figure 1. The Conceptual Framework for the First Research Question: Factors Influencing City-level Horizontal Collaborative Activity

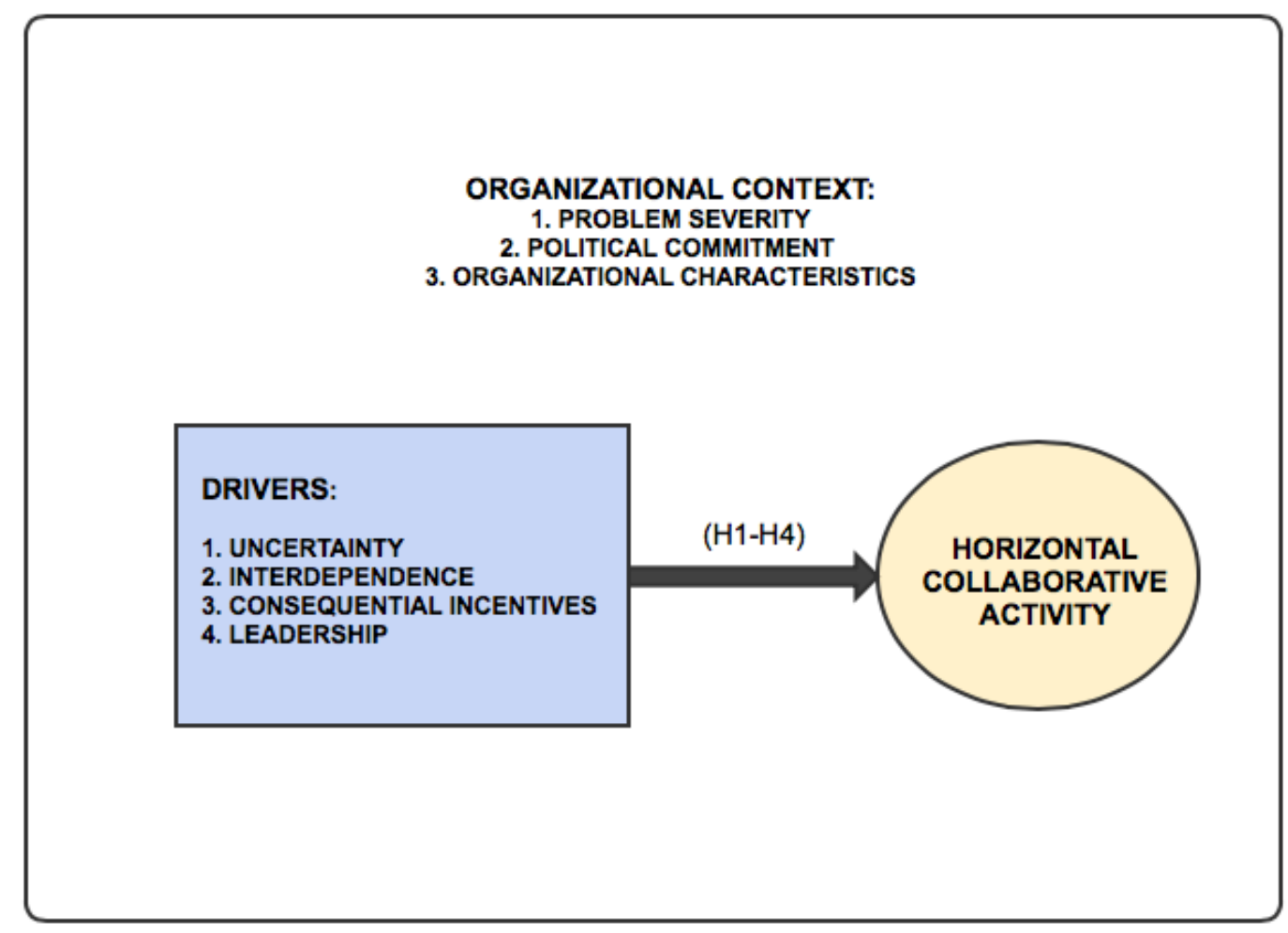

\subsection{Research Questions 2 and 3 and Hypotheses}

The second and third research questions guided the investigation of the relationship between collaborative activity and sea level rise adaptation outputs (Is citylevel collaborative activity associated with higher outputs of sea level rise adaptation? Does the effect vary depending on the type of collaborative partner?) and outcomes (Is the city-level collaborative activity associated with higher outcomes of sea level rise adaptation? Does the effect vary depending on the type of collaborative partner?). The literature review drew from the extant literature on collaborative governance and climate change policies at the local level. 
By definition, collaboration is a management tool that allows organizations to achieve results that they could not achieve on their own and to better serve their missions (Agranoff \& McGuire, 2003; Kettl, 2006b; McGuire, 2006; O’Leary et al., 2006). Scholars have found that collaboration helps improve a number of social outcomes (Leach et al., 2013; Lubell, 2005; Thomson et al., 2008; Ulibarri, 2015; Varda \& Retrum, 2015), and facilitates participant knowledge of public policies (Leach et al., 2013). Researchers have also indicated that collaboration increases organizational outputs and outcomes, using participant perception measures of success (Gazley, 2010; Mitchell et al., 2015; Ulibarri, 2015). While research on objective organizational outputs and outcomes is scarce, some scholars have argued that organizations collaborate to attain desirable organizational goals and that organizations will abandon collaborations that do not yield desirable results (Emerson \& Nabatchi, 2015b). As such, collaboration has aimed to create public value for organizations and their clients (Selden, Sowa, \& Sandfort, 2006).

Moreover, collaborating comes at a cost (Emerson \& Nabatchi, 2015b; Mitchell et al., 2015), and by participating in collaborative activities, public employees are disengaged from their day-to-day routine tasks. City leaders would abandon certain collaborations if they did not show significant promise to help the organization achieve its goals. As a result, there are two expectations about the relationship between collaborative activity and outputs and outcomes of public service delivery:

Hypothesis 5: Higher city collaborative activity will be positively associated with higher sea level rise adaptation outputs. 
Hypothesis 6: Higher city collaborative activity will be positively associated with higher sea level rise adaptation outcomes.

Alternatively, collaboration may not cure complex public problems (Bryson et al., 2006; Koontz \& Thomas, 2006). A diversity of collaborative partners contributes to an increase in the costs of collaborative action - the conflicting interests and opinions can prevent organizations from successfully learning and deliberating (Ansell \& Torfing, 2015). Collaboration can also impose significant time burden on partners because decision-making becomes more time-consuming in this context (Mitchell et al., 2015). Some scholars have argued that achieving favorable outputs and outcomes through collaboration is extremely difficult and, in some cases, collaboration may not produce desired results (Kelman et al., 2012).

The literature is less developed on the relationship between the type of collaborative partner and outputs and outcomes of public service delivery. Different types of collaborative partners may bring distinct resources to the table: governmental partners have some political and administrative capacity to solve complex problems, nonprofit organizations provide education and the perspective of disadvantaged community groups (Andrews \& Entwistle, 2010), and institutions of higher learning offer scientific evidence and research on complex problems to decrease uncertainty and improve decision-making. In this sense, the organizations' capacity to ameliorate complex public problems increases due to distinct advantages that collaborative partners bring (Andrews \& Entwistle, 2010).

In their study on city collaborative activity for economic development, Agranoff and McGuire (2003) found that in terms of horizontal collaboration: "Cities seek out a 
collaborative player for a specific purpose and for a certain type or types of resources; each player may play a strategic role for the city" (p. 120). The study suggested that, in order to achieve their goals, public organizations are strategic and purposeful when picking their partners-selecting partners with resources that could help them achieve organizational goals and missions. Others have argued that public organizations may seek partners not solely for resource purposes, but as means to increase the legitimacy of their organizations and garner broader support for policy decisions (Scott \& Thomas, 2017). Research on the relationship between collaboration by type of partner and outputs and outcomes of service delivery is under-developed. As such, I did not formulate separate expectations about each partner.

Finally, to account for plausible alternative explanations, as in the case of the first research question, the extant literature helped me identify a set of factors that can also affect outputs and outcomes of public service delivery. Most importantly, research has shown that the collaborative process shapes various outputs and outcomes of collaboration (Emerson \& Nabatchi, 2015b; Thomson et al., 2008; Ulibarri, 2015). For instance, Ulibarri (2015) found that participant experiences with the process of collaboration are related to a number of social and predicted environmental outcomes. As a result, city experiences with the collaborative process were anticipated to be related to their public service delivery; that is, more positive experiences were expected to positively contribute to outputs and outcomes. Finally, as in the case of the first research question, additional control variables included problem severity, political commitment, and a set of organizational characteristics that are accounted for in the statistical models. 


\subsection{Conceptual Framework II}

The conceptual framework for the second and third research questions is presented in Figure 2 below. Based on the literature review, a positive relationship was expected to exist between horizontal collaborative activity and outputs and outcomes of city-level service delivery. The collaborative process also affects outputs and outcomes; that is, more positive experiences with the process were expected to lead to improved outputs and outcomes, and vice versa. The organizations under study are also embedded in a broader context that needs to be taken into account. In line with previous research, it was expected that problem severity would positively contribute to outputs and outcomes, because more salient problems may be prioritized over other needs of city residents. Similarly, in order to obtain improved outputs and outcomes, city government and residents must consider the public problem as salient and demonstrate a level of commitment to solve it. Finally, the ability of the city government to attain better results was expected to associate with a set of organizational characteristics of the city, such as organizational capacity and professionalism. 
Figure 2. Conceptual Framework for the Second and Third Research Questions: Factors Influencing Sea Level Rise Adaptation Outputs and Outcomes in City Governments

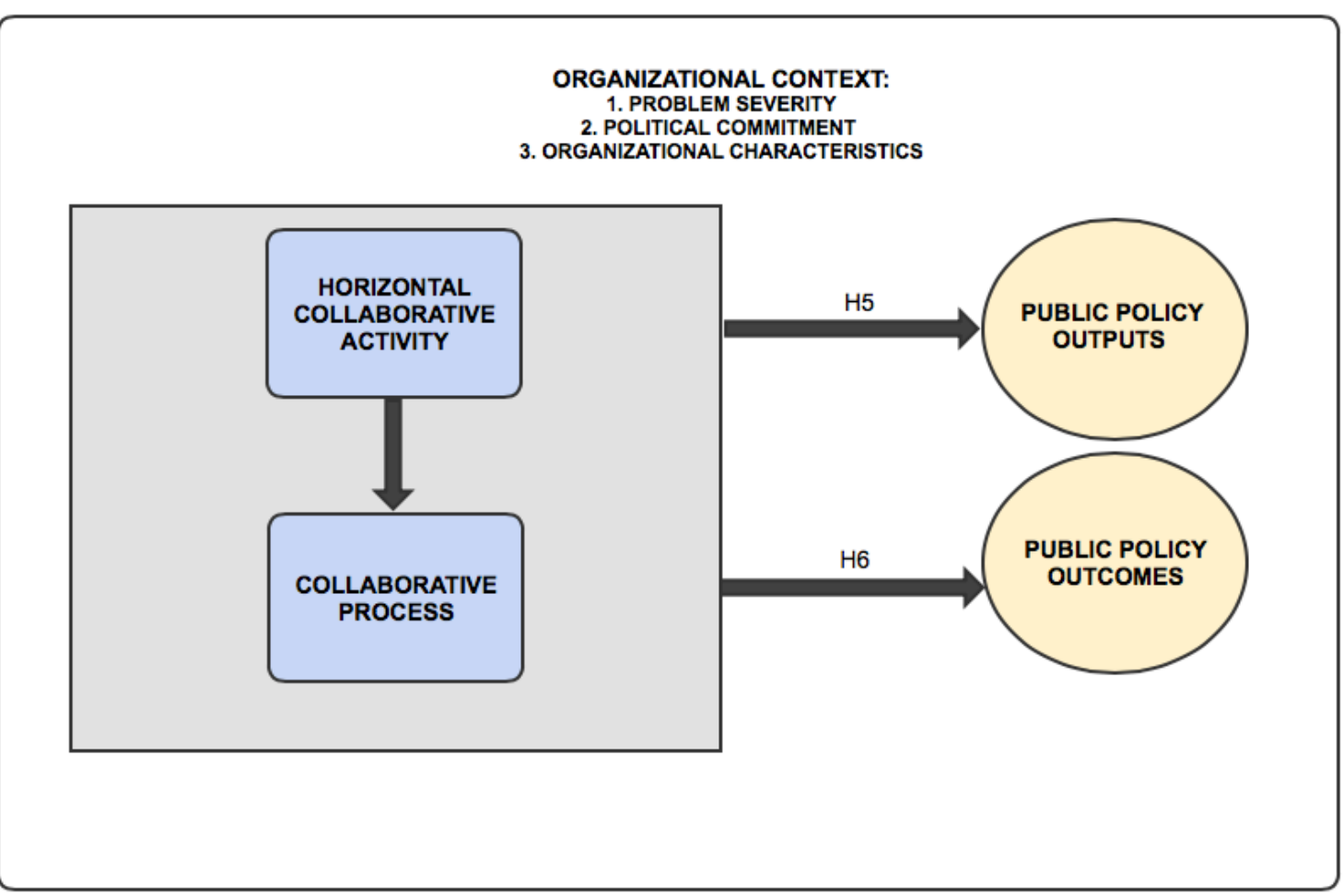

\subsection{Research Question 4}

The fourth research question was exploratory in nature, investigating how collaborative governance may have helped cities improve outputs and outcomes of sea level rise adaptation. As a result, no theoretical expectations were formulated regarding the relationship between collaborative governance and specific mechanisms to improve public service delivery. 


\section{CHAPTER 5: RESEARCH DESIGN AND METHODS}

This chapter introduces the methodology I used to answer the four research questions of this study. The main method of data collection for research questions one to three is quantitative (Phase I), while the fourth research question is answered using a qualitative method (Phase II).

\subsection{Phase I: Quantitative Method}

The first phase of the study employed a quantitative method to answer the first three research questions. The unit of analysis, survey instrument design, administration procedure and response rates are discussed below.

\subsubsection{The Unit of Analysis}

The units of analysis in the study are municipal governments in the US, including villages, towns, and city governments. As discussed in Chapter 1, in the US, there is no established strategy for sea level rise preparedness at the federal level of government and, in many cases, the same holds for state governments. Additionally, climate change adaptation has largely been regarded as a local issue-local governments across the US may be impacted in distinct ways and policy solutions must account for varying local conditions. Since the passage of the DMA in 2000, local governments have undertaken a more active role in mitigating various hazards in order to receive federal assistance. As a result, municipal governments present an important setting to study collaboration and preparedness for sea level rise. 


\subsubsection{Data Sources and Survey Instrument Design}

The main instrument of data collection for the study is a survey, informed by an extensive literature review and semi-structured interviews with municipal public administrators and policymakers conducted to answer the fourth research question. The survey instrument contains 22 questions, both open-ended and multiple choice. The questions mainly focus on the barriers and opportunities for sea level rise preparedness, ongoing collaborative activities, and information on collaborative activities and partners. The respondents were also asked a set of demographic questions and were provided the option to share any additional information with the researcher at the end of the survey. The survey questionnaire is presented in the Appendix.

Before the survey was administered to the sample of respondents, it was pilot tested with a small sample of potential respondents (4) and public administration experts (2). Feedback from respondents and experts was used to improve the survey questionnaire and the clarity of the questions.

\subsubsection{Sampling Procedure}

The sample for the survey was drawn from a study conducted by a non-profit organization, Climate Central, that compared US city elevation, population, and projected sea level rise (Climate Central, n.d.). To obtain a sample of cities of varying exposure to sea level rise risk, I selected cities with populations of 10,000 or more residents, where at least $1 \%$ of residents will be locked in below the projected high tide line of 2050 . In other words, given there are no significant cuts to GhG emissions in the immediate future, $1 \%$ or more of city residents across sample cities will be exposed to flooding and permanent inundation of city areas by 2050. This selection yielded a sample of 341 cities in 19 US 
states. The cities surveyed are located in the following states: Alabama, California, Connecticut, Delaware, Florida, Georgia, Louisiana, Maine, Maryland, Massachusetts, Mississippi, New Jersey, New York, Pennsylvania, Rhode Island, South Carolina, Texas, Virginia, and Washington. Smaller cities were included because they are generally understudied in similar research and are worthy of investigation (Hawkins, 2010). It was also expected that collaboration would be higher in small jurisdictions, because it helps pool resources and increase the efficiency of service delivery (Feiock, 2013).

Table 1 provides an overview of sample cities across US Census Regions and Divisions. Because the Midwest region of the US is not vulnerable to sea level rise, sample cities are located in the Northeast, the South, and the West. As noted in column 5, the largest share of the sample is located in the South Atlantic Division (42.2\%), which is also, on average, the most vulnerable to sea level rise, with $50.72 \%$ of population across sample cities vulnerable to sea level rise by 2050 . The second largest share of the sample was located in the Pacific Division, constituting $20.2 \%$ of the sample. Three US Census Divisions-East North Central, West North Central and Mountain —-were not included in the sample, because they are not vulnerable to sea level rise by 2050. Instead, these divisions face different climate change challenges, such as increased droughts and heat waves, among others.

\subsubsection{Survey Administration Procedure}

The survey was sent to all 341 selected city governments in the summer of 2017. It was sent via email invitation along with a web link to access the electronic survey in Qualtrics, an online survey software. The literature review and semi-structured interviews revealed that planning departments have significant involvement in sea level rise 
adaptation efforts, as they are responsible for preparing comprehensive development plans that outline long-term goals of community development, including land use, transportation, utilities, conservation, and other areas. Consequently, planning departments possess in-depth knowledge about city preparedness for sea level rise and ongoing collaborations that are intended to help the city prepare. As a result, the surveys were sent to the heads of departments that are involved in city planning functions. In cases where planning functions are contained within the other city departments (e.g., community development, building, zoning, public works), those department heads were contacted. When information on functions and contact was unavailable, I contacted city leaders (e.g., city managers, city mayors) to help identify a person familiar with sea level rise preparedness and ongoing collaborations in the city and respond to the survey. Two weeks after first contact, the non-responding departments were sent reminder messages via email.

\subsubsection{Response Rates}

Table 1 provides a comparison of the sample and responding cities across US Census Regions and Divisions, along with the percentage of sample and current respondent city population that will be locked in under the projected high tide line of 2050. A total of 135 city governments returned surveys out of 341 contacted, yielding a response rate of $39 \%$.

In terms of threat from sea level rise, the responding cities are relatively representative of the sample, with the exception of the South Atlantic and the West South Central US Census Divisions, where cities with larger threatened populations were more likely to respond to the survey. The highest response rates come from the South Atlantic 
Division (57.1\%). This division is the most vulnerable to sea level rise overall in terms of threatened population and constitutes the largest share of the sample. It is followed by the Pacific Division, which represents $19.3 \%$ of all returned surveys. Some divisions were less responsive, including the Middle Atlantic (20.9\%) and the West South Central (26.1\%) divisions.

Table 1. Characteristics of the Sample and Response Rates by US Census Division

\begin{tabular}{|c|c|c|c|c|c|c|}
\hline $\begin{array}{l}\text { Census } \\
\text { Region }\end{array}$ & $\begin{array}{l}\text { Census } \\
\text { Division }\end{array}$ & $\begin{array}{c}\text { Sample } \\
\text { City } \\
\text { Threat } \\
\text { to Sea } \\
\text { Level } \\
\text { Rise }\end{array}$ & $\begin{array}{c}\text { Respondent } \\
\text { City Threat } \\
\text { to } \\
\text { Sea Level } \\
\text { Rise }\end{array}$ & $\begin{array}{c}\text { Percent } \\
\text { of Total } \\
\text { Sample } \\
(341)\end{array}$ & $\begin{array}{l}\text { Survey } \\
\text { Response } \\
\text { Rate }\end{array}$ & $\begin{array}{c}\text { Percent } \\
\text { of } \\
\text { Returned } \\
\text { Surveys } \\
\text { (135) }\end{array}$ \\
\hline \multirow[t]{2}{*}{ Northeast } & $\begin{array}{l}\text { New } \\
\text { England }\end{array}$ & $14.57 \%$ & $20.25 \%$ & $14.5 \%$ & $26.8 \%$ & $8.1 \%$ \\
\hline & $\begin{array}{l}\text { Middle } \\
\text { Atlantic }\end{array}$ & $27.29 \%$ & $28.22 \%$ & $12.9 \%$ & $20.9 \%$ & $6.7 \%$ \\
\hline \multirow[t]{2}{*}{ Midwest } & $\begin{array}{l}\text { East North } \\
\text { Central }\end{array}$ & - & - & - & - & - \\
\hline & $\begin{array}{l}\text { West North } \\
\text { Central }\end{array}$ & - & - & - & - & - \\
\hline \multirow[t]{3}{*}{ South } & $\begin{array}{l}\text { East South } \\
\text { Central }\end{array}$ & $11.65 \%$ & $6.85 \%$ & $3.3 \%$ & $27.3 \%$ & $2.2 \%$ \\
\hline & $\begin{array}{l}\text { South } \\
\text { Atlantic }\end{array}$ & $50.72 \%$ & $61.12 \%$ & $42.2 \%$ & $57.1 \%$ & $59.3 \%$ \\
\hline & $\begin{array}{l}\text { West South } \\
\text { Central }\end{array}$ & $34.16 \%$ & $58.45 \%$ & $7 \%$ & $26.1 \%$ & $4.4 \%$ \\
\hline \multirow[t]{2}{*}{ West } & Mountain & - & - & - & - & - \\
\hline & Pacific & $16.33 \%$ & $16.24 \%$ & $20.2 \%$ & $38.8 \%$ & $19.3 \%$ \\
\hline
\end{tabular}




\subsection{Phase II: Qualitative Method}

The second phase of data collection aimed at answering the fourth research question. Due to the exploratory nature of the question, a qualitative research method was employed. I conducted qualitative semi-structured in-depth interviews with local policymakers and public administrators in Florida to answer the fourth research question: How does collaboration help cities improve their preparedness for sea level rise? Below, I describe the unit of analysis, sampling, and data collection and analysis procedures.

\subsubsection{The Unit of Analysis}

The units of analysis in this phase of the research are policymakers and public administrators in a US local government vulnerable to sea level rise. To gain a better understanding of sea level rise preparedness and collaborative governance at the local level, both elected officials and public administrators were included, given the importance of local leaders as brokers of collaborative relationships.

\subsubsection{Sampling Procedure}

The sampling technique for the semi-structured qualitative interviews was a mix of judgement sampling, which entailed selecting a productive sample that could help attain in-depth understanding of the phenomenon (Marshall, 1996), and snowball sampling, as the respondents were asked to refer the researcher to other contacts to interview (Biernacki \& Waldorf, 1981). In the first stage of sampling, email invitations, along with informational letters, were sent to respondents in leadership positions in local governments in Florida. The informational letters served as verbal consent forms, in accordance with the Florida International University Institutional Review Board approval of the study. The participants were assured confidentiality. The majority of respondents 
were public administrators in various city departments, including city managers and directors of public works, sustainability, and planning departments (7 respondents), two respondents were public administrators at the county level, and four others were policymakers at the municipal level, including three city mayors and one commissioner. The total number of respondents is 13 . I followed-up with two respondents, yielding 15 semi-structured interviews total.

\subsubsection{Data Collection Procedure}

Semi-structured interviews were chosen as the method of qualitative data collection because they provide an in-depth understanding of respondent experiences (Whittemore, Chase, \& Mandle, 2001). This method of data collection also allows for more flexibility to alter the order and content of questions (Berg, 2009). In order to establish better rapport with respondents, the interviews were conducted face-to-face (Berg, 2009; Charmaz, 2006; Leech, 2002). All respondents agreed to have the interviews audio recorded. The interviews lasted from 30 minutes to almost two hours.

The respondents were presented with broad questions about climate change adaptation in their local governments. For instance, respondents were asked about the challenges the local government is facing with regard to climate change, how mitigation and adaptation are being addressed, collaboration activity with local partners, and other questions. Probing questions were used to facilitate further explanation of respondent experiences and clarify some responses. The main goal was to understand the respondents' view and allow for new themes to emerge during the interviews. The complete set of questions that were used in the interviews is presented in the Appendix. 


\subsubsection{Data Analysis}

Audio recordings of the interviews were transcribed verbatim to assure better data accuracy and analyzed using NVivo 11 software. All identifiers that would allow identification of respondents were removed from the data during the transcription process.

The first cycle of data coding was performed using provisional coding methods. In this method of coding, the researcher is guided by a predetermined set of codes that emerge from the study's conceptual framework (Saldana, 2009). For instance, broad codes that covered the benefits and drawbacks of collaboration were created in advance, based on the study's goals. Because the interviews were semi-structured, the codes that emerged were influenced by the questions that each respondent was asked. After the initial coding stage, the first cycle codes were revised and modified, and some were deleted (Saldana, 2009). At the stage of the second cycle coding, some codes were refined in order to develop more general themes of data. Certain codes were merged or completely removed. For instance, codes on interdependence and negative externalities were merged due to content similarity. 


\section{CHAPTER 6: VARIABLE OPERATIONALIZATION, ESTIMATION ROUTINES, AND QUANTITATIVE RESEARCH RESULTS}

\subsection{Factors Influencing Horizontal Collaborative Activity}

The first research question focused on investigating what factors influence horizontal collaborative activity of public organizations (What are the factors that facilitate city-level collaboration for sea level rise adaptation?). The review of extant literature on collaborative governance and literature on planning for climate change action helped identify the dependent, independent, and control variables of interest to the study. Variables used in the analysis to answer the first research question are presented below, along with their operationalization and descriptive statistics.

\subsubsection{Dependent Variable - Collaborative Activity}

The dependent variable utilized to answer the first research question is voluntary horizontal collaborative activity, and the unit of analysis is municipal governments in the US that are vulnerable to sea level rise. Following Gazley (2010), collaborative activity was measured as a composite index of different activities that municipal governments undertook in the last three years with collaboration partners. The data for collaborative activity came from the survey. The respondents were presented with 11 possible collaborative activities (sharing information on best practices, sharing workers, sharing volunteers, joint program development, joint advocacy to higher levels of government, joint recruitment of staff, joint recruitment of volunteers, joint service delivery, joint fundraising, joint purchasing, and joint application for grants) and five types of partner for horizontal collaboration (other municipal governments, institutions of higher learning, nonprofit organizations, private businesses, and community groups). For 
example, a city may collaborate with a neighboring municipality in purchasing tidal valves to negotiate a lower cost (joint purchasing), or work with a nonprofit organization to apply for funding to adapt to sea level rise (joint application for grants). Five horizontal partner-types were identified through semi-structured interviews (described in more detail in Chapter 5); respondents mentioned these partners most frequently in terms of collaborative activity to address sea level rise preparedness.

The respondents were asked to select voluntary activities undertaken by their cities with the five types of partner for sea level rise preparedness in the last three years. The index of collaborative activity was calculated by adding the number of collaborative activities with different partners, with values ranging from 0 (no collaborative activity with any of the partners) to 55 (all 11 collaborative activities with all five partners). While operationalizing collaboration as a set of activities with partners is a rather crude measure - as it does not account for the intensity of the activities (McGuire \& Silvia, 2010) - it has been widely utilized in previous studies on collaboration (Agranoff \& McGuire, 2003; Foster \& Meinhard, 2002; Gazley, 2010; McGuire \& Silvia, 2010; Meier \& O’Toole, 2003).

Figure 3 represents the distribution of the variable Collaborative Activity across the responding cities. Cities reported varying involvement in collaboration. A total of 28 responding cities reported no involvement in any horizontal collaboration, while 36 cities indicated involvement in 10 or more collaborative activities with partners. The highest value of Collaborative Activity reported in the sample is 29 . 
Figure 3. The Distribution of the Variable Collaborative Activity Across the Responding Cities

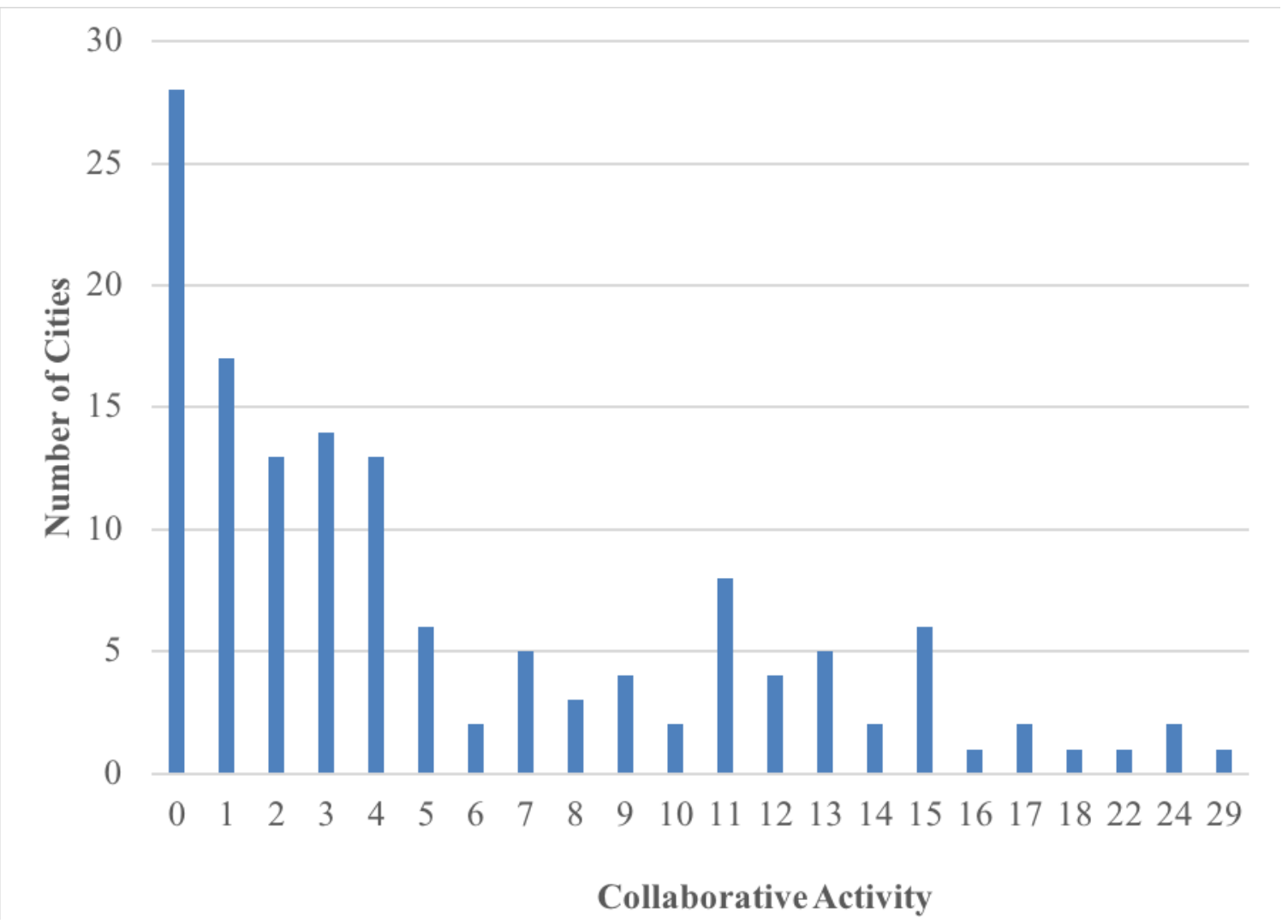

Figure 4 presents the overall distribution of collaborative activities that municipal governments engaged in with collaborative partners. The most common collaborative activity is sharing information on best practices (233 total activities), followed by joint advocacy to higher levels of government (136), and joint program development (108). The least popular collaborative activities to address sea level rise are joint purchasing and joint recruitment of staff (19 total activities each). 
Figure 4. The Distribution of Collaborative Activities Across the Sample Cities by Type of Activity

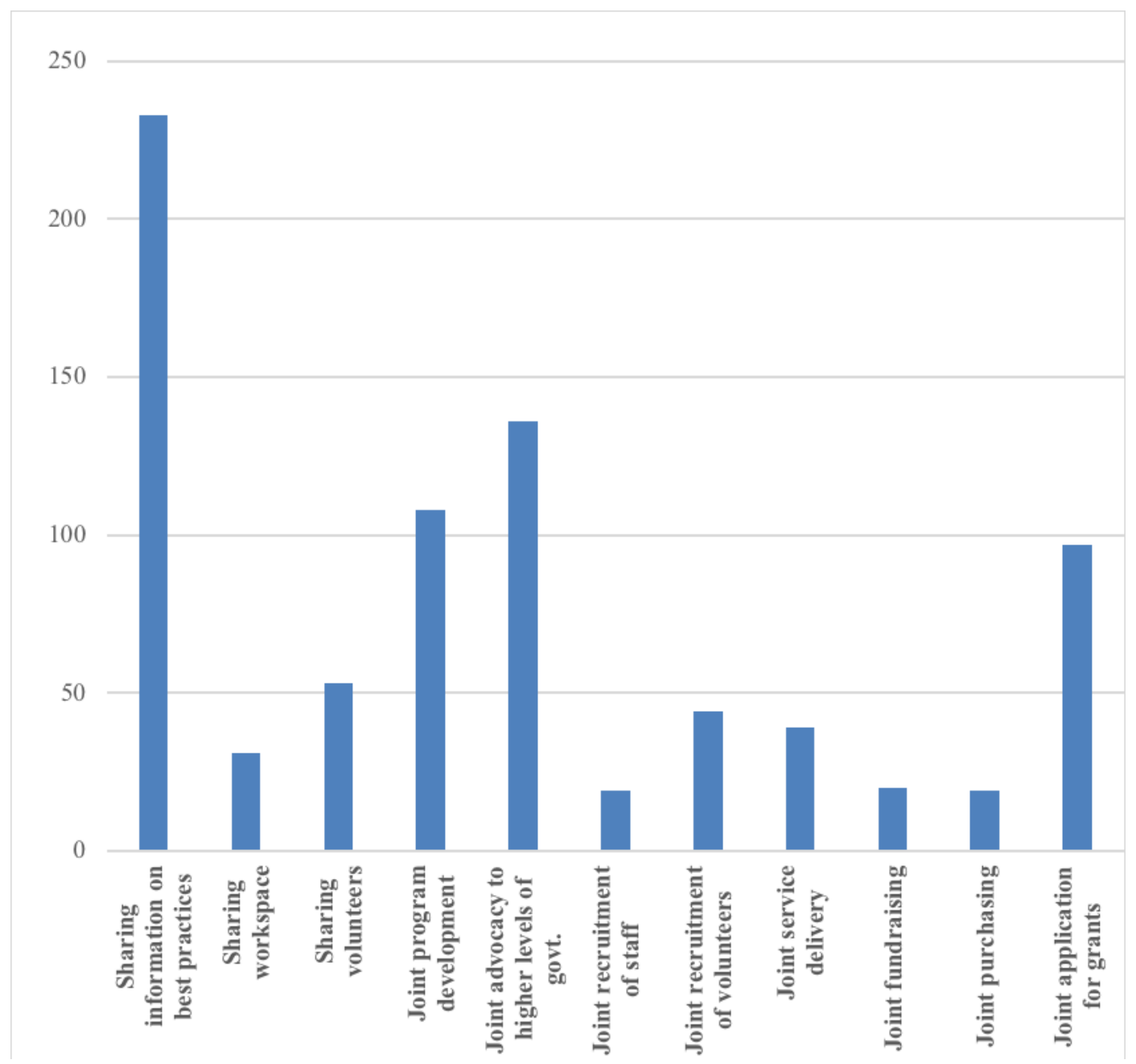

Figure 5 presents the distribution of collaborative activities with the five partnertypes included in the survey. Most activities are performed through city-to-city collaboration (305 activities), and in partnership with nonprofit organizations (189 activities). Municipal governments reported only 49 collaborative activities with businesses across the sample. 
Because the distribution of the variable Collaborative Activity was skewed, I used the natural logarithm. To address the zero values, I added a constant of 1 to each observation of the variable before the transformation. The complete operationalization of all variables that are used to answer the first research question is presented in Table 2. Table 3 presents variable descriptive statistics along with means, standard deviations, and minimum and maximum values.

Figure 5. The Distribution of Collaborative Activities by Type of Partner

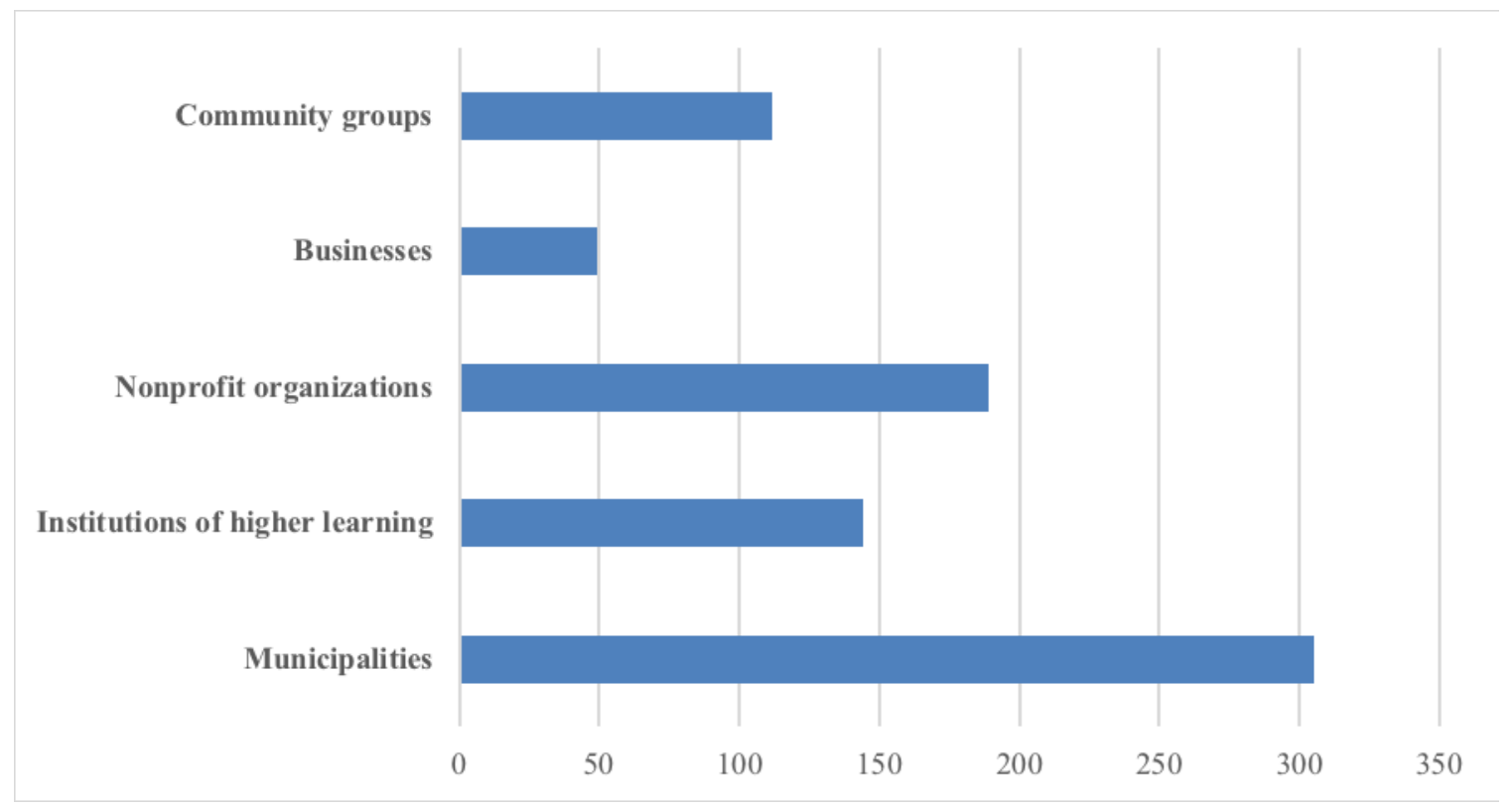

\subsubsection{Main Independent Variables - Drivers of Collaborative Activity}

To answer the first research question, the analysis used four main independent variables that constitute drivers of collaboration: uncertainty, interdependence, consequential incentives, and leadership. The data for all main independent variables came from the survey, and all variables were measured through multiple survey questions, described below. 
Uncertainty was defined in the scope of this study as a lack of information about the public problem and its solutions. The variable comprised three questions in the survey. Using a 5-point Likert-type scale, these questioned asked respondents to what extent they strongly disagree (1) to strongly agree (5) with the following statements regarding uncertainty in their organization: (1) Risks associated with sea level rise are well understood; (2) Solutions to address sea level rise are identified; and (3) Solutions to sea level rise are tailored to the city's needs. The responses to these three survey questions were summed and averaged to form the Uncertainty variable (Cronbach's Alpha $=0.86$ ). Due to the wording of the questions, higher values of the Uncertainty variable indicated lower uncertainty in terms of problem definition and solutions to sea level rise preparedness. Across the sample, the lowest value of the variable is 1 , the highest is 5 .

Interdependence, which has been broadly defined as the inability of an organization to achieve results on its own, was measured through three survey questions. Using a 5-point Likert scale, respondents were asked to what extent they strongly disagree (1) to strongly agree (5) with the following statements regarding interdependence: (1) The city has financial resources to prepare for sea level rise; (2) The city has qualified staff to prepare for sea level rise; and (3) The city is able to prepare without external assistance. The responses were summed and averaged to form the Interdependence variable (Cronbach's Alpha=0.71). Due to the wording of the questions, higher values of the Interdependence variable indicated lower levels of interdependence. Across the sample, the lowest value of the variable is 1 , the highest is 4.5 . 
The third independent variable, consequential incentives, was defined as an expectation that collaboration will yield tangible and positive returns to the organization. Using a 5-point Likert-type scale, the variable Incentives was measured through the survey; respondents were asked to rate the extent they strongly disagree (1) to strongly agree (5) with the following statements regarding expectations of results from collaboration: (1) The city will influence policies of higher-level governments; (2) The city will attain more funding; (3) The city will raise the awareness about the problem; (4) The city will be more prepared for sea level rise. The ratings of these questions were summed and averaged to form the Incentives variable (Cronbach's Alpha $=0.85$ ), where higher values represented a higher degree of expectations regarding positive consequential incentives from collaboration. Across the sample, the lowest value is 1, and the highest is 5 .

Finally, collaborative activity was expected to be higher in organizations where leaders support collaborative endeavors. The variable Leadership was measured through the survey as well; using a 5-point Likert-type scale, respondents were asked to rate the extent they strongly disagree (1) to strongly agree (5) with the following statements regarding the city leadership's approach to collaboration for sea level rise preparedness: (1) City leaders actively seek out partners; (2) City leaders actively pursue collaboration; (3) City leaders highly value collaboration; (4) City leaders encourage collaboration within the city. The ratings of these questions were summed and averaged to form the Leadership variable (Cronbach's Alpha=0.94), where higher values represented stronger city leadership support for collaboration for sea level rise preparedness. Across the sample, the lowest value is 1 , and the highest is 5 . 


\subsubsection{Control Variables}

Prior literature has identified three sets of control variables to account for plausible alternative explanations of collaborative activity: problem severity, political commitment, and characteristics of the organization (e.g., governmental capacity, professionalism, and structure).

Following similar studies on collaboration, the models here included control variables to account for problem severity. Borrowing from studies on climate change action in the field of planning, I included two variables to account for the degree of city's projected exposure-level to sea level rise. The first variable, Threat Level, is operationalized as the percentage of a city's population that will be living below the projected high-tide line by 2020 . I expected that cities with larger threatened populations would be more active in their collaborative efforts to address sea level rise. The data originated from a nonprofit organization-Climate Central-that focuses on climate science research and public information. To account for additional problem severity, I included a second variable Population Growth, operationalized as the percentage increase in city's population from 2010 to 2016. The data originated from the US Census Bureau. Unlike the Threat Level variable, the Population Growth variable may be either positively or negatively associated with collaboration. One possible scenario was that population growth increases exposure to sea level rise threats, and Population Growth may be positively related to collaboration, because municipalities will work with other actors to increase community resilience. On the other hand, Population Growth may be negatively related to collaboration due to real estate development pressures. In coastal cities, real estate development companies may be especially wary of sea level rise 
adaptation policies because they typically carry development restrictions in potentially vulnerable areas.

The second set of controls represent commitment to climate change as a public issue. It was expected that collaboration on sea level rise preparedness would be higher in municipalities that have demonstrated previous political commitment to climate change mitigation policies. To account for political commitment for climate change issues, I included a dummy variable, ICLEI Membership, that accounts for a city's membership in the ICLEI - Local Governments for Sustainability (ICLEI) (measured as 0 for cities that are not members, and as 1 for cities that are members). ICLEI is an international association of local governments that works toward climate change mitigation and adaptation initiatives. Given that membership fees for ICLEI members are substantial and ICLEI provides various resources for sustainability and adaptation planning (Krause, Feiock, \& Hawkins, 2014), a city's membership is a reliable measure of its leaders' commitment to addressing climate change issues.

Climate change is a highly politically charged issue. This has been evidenced in cases where states with conservative leadership have contested climate change science and banned local governments from planning for sea level rise. It was expected that governments with more liberal constituencies would be more favorable toward climate change policies compared to conservative ones (Krause, Yi, \& Feiock, 2016). To account for political orientation of the municipal residents, I included the variable Political Affiliation, measured as the percent of voters in a county who voted for President Obama in the 2012 election. 
The third set of control variables pertains to organizational characteristics: governmental capacity, structure, and professionalism. Following Krause et al. (2014), I included variables to account for governmental capacity. The first variable is Budget per Capita, representing city resources per capita in 2016. The data originated from municipal budget documents that were accessed through official city websites. Because collaboration typically requires financial resources, the expectation was that cities with higher resources per capita would be more involved in collaborative activities. Next, I included a variable to account for city population; it was expected that cities with larger populations would more actively collaborate on sea level rise preparedness initiativesbecause the costs of inaction are higher in comparison to smaller cities. The data originated from the US Census Bureau. Because the distribution of the Population variable was skewed, I transformed the variable by using its natural logarithm. Finally, previous studies on climate change adaptation in the planning field have also accounted for state-level planning for climate change (Shi et al., 2015; Woodruff \& Stults, 2016). If a municipality is located in a state with a climate change adaptation plan, there will be less need to collaborate with others on sea level rise issues, because local governments may take advantage of state leadership and funding to increase their capacity to adapt. The variable State Plan, thus, was coded as 0 if the municipality is located in a state without a climate change adaptation plan, and as 1 otherwise.

Scholars have also found that organizational structure matters for collaboration (McGuire \& Silvia, 2010); managers of agencies or departments that are tasked with multiple functions may have less opportunity to establish collaborative working relationships due to time constraints. In the context of planning responsibilities, they may 
either be established as stand-alone planning departments within the city government, or as a division of community development or other departments. Based on prior research, it was expected that collaborative activity would be higher in cities in which planning responsibilities are overseen by a distinct department—as opposed to a division within another department, such as community development. To account for this, I included a dummy variable Stand-alone Department, where 1 represents an independent stand-alone planning department within the municipal government, and 0 a planning division within another department. The data originated from official city government websites.

Finally, to account for administrative professionalism, I included two variables. First, the council-manager form of government (Manager Form) was expected to be positively associated with the dependent variable, because scholars argue that this form of government is more isolated from special interests and that city managers are actively involved in professional networks and information sharing (Hawkins, Krause, Feiock, \& Curley, 2016). As a result, cities of this form of government were expected to be more actively involved in collaborations - city managers can take advantage of their professional networks to broker problem-solving collaborations, especially with other municipalities. Manager Form is coded as 1 if the city has a council-manager form of government, and 0 otherwise. The data originated from official city government websites. Second, I included a variable to account for the lead planning manager's level of professionalism. The American Institute of Certified Planners (AICP) is a professional institute under the American Planning Association. Planning professionals may attain the AICP certification, given they have relevant education and professional experience, and pass the AICP certification exam. After receiving AICP certification, planning 
professionals must maintain it via continuing education. The $A I C P$ Certification variable is a dummy variable, measured as 1 if the lead planning manager in the city has attained the certification, and 0 otherwise.

Table 2. Variable Operationalization and Data Sources for the First Research Question

\begin{tabular}{|c|c|c|}
\hline Type of Variable & Variable Name & Operationalization and Data Sources \\
\hline Dependent variable & $\begin{array}{l}\text { Collaborative } \\
\text { Activity }\end{array}$ & $\begin{array}{l}\text { Additive measure of collaborative activities } \\
\text { with five partners for sea level rise } \\
\text { preparedness in the past three years, } \\
\text { transformed using a natural logarithm. } \\
\text { Source: Survey. }\end{array}$ \\
\hline \multirow[t]{4}{*}{$\begin{array}{l}\text { Main Explanatory } \\
\text { Variables (Drivers } \\
\text { of Collaboration) }\end{array}$} & Uncertainty & $\begin{array}{l}\text { An average score for three 5-point Likert- } \\
\text { type scale questions about uncertainty } \\
\text { surrounding climate change risks, } \\
\text { identification of risks, and identification of } \\
\text { solutions. Source: Survey. }\end{array}$ \\
\hline & Interdependence & $\begin{array}{l}\text { An average score for three } 5 \text {-point Likert- } \\
\text { type scale questions about the availability of } \\
\text { financial resources to prepare for sea level } \\
\text { rise, qualified staff, and dependence on } \\
\text { external assistance. Source: Survey. }\end{array}$ \\
\hline & Incentives & $\begin{array}{l}\text { An average score for four } 5 \text {-point Likert-type } \\
\text { scale questions about city expectations of } \\
\text { collaborative outputs and outcomes for sea } \\
\text { level rise preparedness-policies of upper- } \\
\text { level governments, attaining funding, raising } \\
\text { awareness, and better preparation. Source: } \\
\text { Survey. }\end{array}$ \\
\hline & Leadership & $\begin{array}{l}\text { An average score for three 5-point Likert- } \\
\text { type scale questions about a city's leadership } \\
\text { approach to collaboration-seeking out } \\
\text { partners, active pursuit of collaboration, } \\
\text { valuation of collaboration, and promotion of } \\
\text { collaboration. Source: Survey. }\end{array}$ \\
\hline \multirow[t]{2}{*}{ Control variables } & Threat Level & $\begin{array}{l}\text { The percent of a city's population that will be } \\
\text { living under the projected high tide line by } \\
\text { 2020. Source: Climate Central. }\end{array}$ \\
\hline & Population Growth & $\begin{array}{l}\text { A percentage increase in city's population } \\
\text { from } 2010 \text { to } 2016 \text {. Source: US Census } \\
\text { Bureau. }\end{array}$ \\
\hline
\end{tabular}


ICLEI

Membership

Political

Affiliation

Budget per Capita

Population

State Plan

Stand-alone

Department

Manager Form

AICP Certification
$1=$ the city is a member of ICLEI, $0=$ otherwise. Source: ICLEI website.

Percent voters in the county that voted for President Obama in the 2012 Presidential Election. Source: Politico.

City expenditures per capita in 2016. Source: City government budget documents.

A natural logarithm of city population in 2016. Source: US Census Bureau.

$1=$ the city is in a state with a climate change adaptation plan, $0=$ otherwise. Source: Georgetown Climate Center.

$1=$ the city has a stand-alone planning department, $0=$ otherwise. Source: City government websites.

$1=$ the city has the council-manager form of government, $0=$ otherwise. Source: City government websites.

$1=$ the city lead planning manager has attained the AICP Certification, $0=$ otherwise. Source: American Planning Association.

Table 3. Descriptive Statistics for the Variables for the First Research Question

\begin{tabular}{lllll}
\hline Variable & Mean & Std. Dev. & Min. & Max. \\
\hline Collaborative Activity $(\log )$ & 1.442 & 0.988 & 0 & 3.402 \\
Uncertainty & 3.06 & 1.028 & 1 & 5 \\
Interdependence & 2.563 & 0.725 & 1 & 4.5 \\
Consequential Incentives & 3.611 & 0.723 & 1 & 5 \\
Leadership & 3.47 & 1.05 & 1 & 5 \\
Threat Level & 13.865 & 19.184 & 0 & 87.1 \\
Population Growth & 7.164 & 5.576 & -2.7 & 31.5 \\
ICLEI Membership & 0.164 & 0.372 & 0 & 1 \\
Political Affiliation & 55.95 & 14.053 & 21.6 & 85.2 \\
Budget per Capita & 1998.912 & 1408.103 & 490.487 & 6548.934 \\
Population (log) & 10.69 & 1.151 & 9.221 & 14.265 \\
State Plan & 0.843 & 0.365 & 0 & 1 \\
Stand-alone Department & 0.421 & 0.496 & 0 & 1 \\
Manager Form & 0.75 & 0.434 & 0 & 1 \\
AICP Certification & 0.511 & 0.502 & 0 & 1 \\
\hline
\end{tabular}




\subsubsection{Estimation Routine and Results}

The dependent variable in the analysis is the natural logarithm of collaborative activity undertaken for sea level rise preparedness by US cities with five types of horizontal collaboration partners: other cities, institutions of higher learning, nonprofit organizations, businesses, and community groups. Therefore, I proceeded by fitting an ordinary least squares (OLS) regression to test the relationship between collaborative activity and the drivers of collaboration. In order to isolate state-level effects, I ran the model with robust standard errors, clustered by state. Table 4 presents the regression results. I used STATA 12 software to run the analysis.

I ran diagnostic tests to check if the model violates any OLS regression assumptions. First, I checked for multicollinearity between independent variables in the model to establish if any independent variables were correlated with each other and may violate the OLS regression assumption of no perfect collinearity. Specifically, I inspected the variance inflation factor (VIF) values of the independent variables. The highest VIF value is 2.13 (Leadership), which is significantly lower than the value of 10 that is typically used - as a rule of thumb - to further investigate the relationships between independent variables. The assumption of an absence of multicollinearity is not violated.

To test for heteroscedasticity, or constant variance of error terms, I ran the Breusch-Pagan test in STATA. The null hypothesis of the test is that the error terms are homoscedastic. The p-value of the test was 0.243 , indicating that the null hypothesis that the residuals are homoscedastic could not be rejected. 
Table 4. OLS Regression Results with Coefficients and Robust Standard Errors, Clustered by State (Dependent Variable - Collaborative Activity)

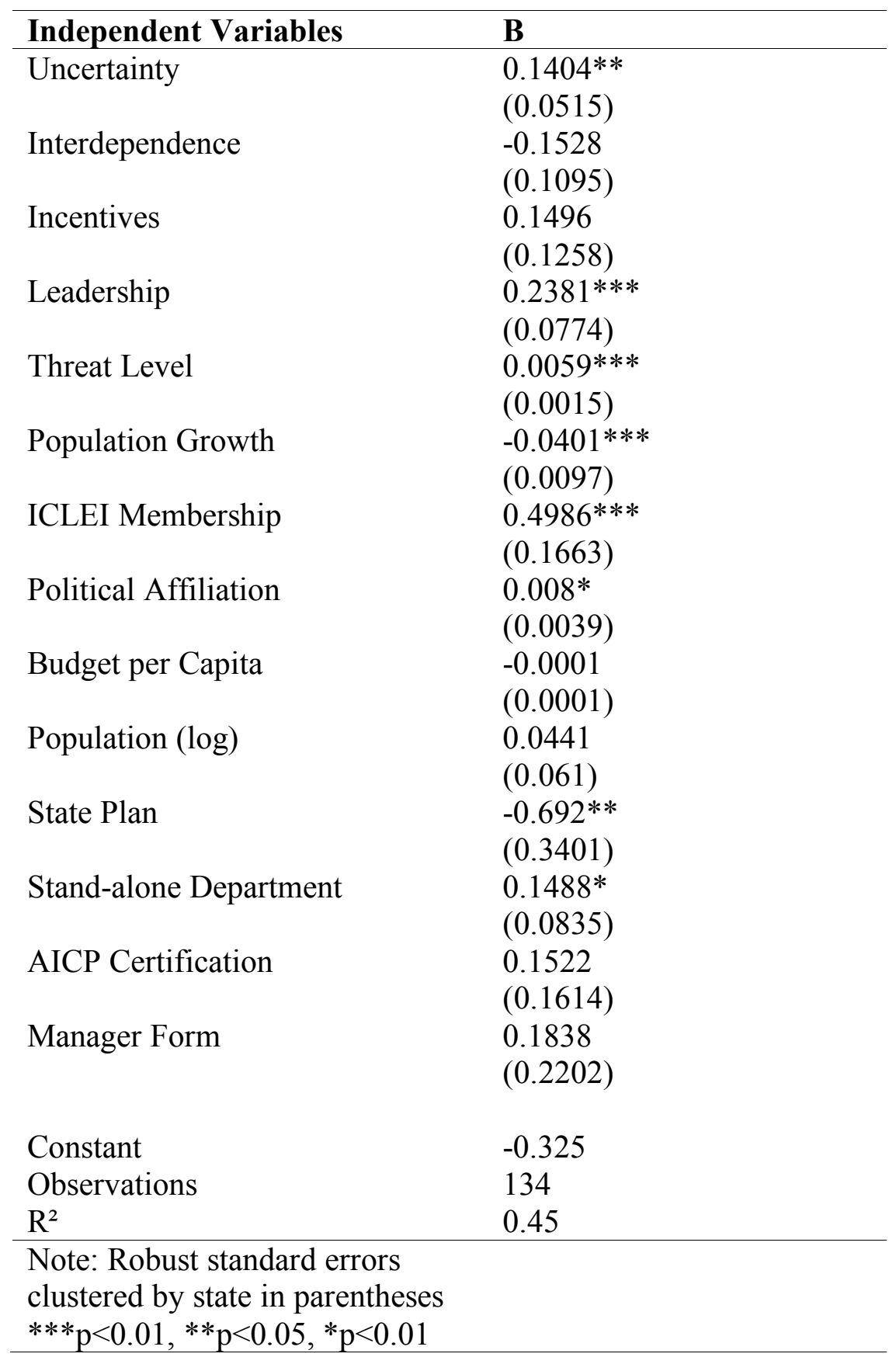

The $\mathrm{R}^{2}$ value revealed that the model explains $45 \%$ of variation of the Collaborative Activity variable. The results of the OLS regression demonstrate a 
differential relationship between collaborative activity and the four main explanatory variables - drivers of collaboration. Due to the wording of the questions, the positive coefficient sign of the Uncertainty variable indicates that the relationship between horizontal collaborative activity and uncertainty is negative - cities that are involved in more collaborative activity report lower uncertainty in terms of sea level rise preparedness and its solutions. This finding goes against the expectations that I developed, which were based on the literature review. One plausible explanation for this could be the cross-sectional nature of the data: city employees were asked about their horizontal collaborative activities in the past three years for sea level rise preparedness. It is possible that some collaborative efforts have been ongoing for a number of years, reducing uncertainty in risk assessment and decision-making for sea level rise preparedness efforts. Moving to the Leadership variable, it is statistically significant at the $1 \%$ level, and in the expected positive direction. For one unit increase in Leadership variable, we will expect to see an increase in about 24 percentage points in Collaborative Activity. The result indicates that city leadership plays an important role in facilitating horizontal collaborative activity.

As hypothesized, problem severity also affects collaborative activity: the variable Threat Level is statistically significant at the $1 \%$ level and in the expected positive direction. The finding reveals that cities with larger populations threatened by sea level rise risk are more engaged in horizontal collaborative activity to address these vulnerabilities. The other variable of problem severity, Population Growth, is negatively associated with the dependent variable. One possibility is that in cities experiencing an 
increase in population, the pressures of real estate development push sea level rise adaptation action further down the city's agenda.

The next two variables, ICLEI Membership and Political Affiliation, represent commitment to climate change policy by city officials and residents, respectively. Both variables are positively related to Collaborative Activity, indicating that commitment matters: cities that demonstrated higher political commitment to climate change mitigation and adaptation initiatives through involvement with ICLEI are more active in horizontal collaborative activity for sea level rise, along with those located in counties where residents tend to vote for the Democratic Party.

Among the variables that represent various organizational characteristics, only two variables are statistically significant in the model: State Plan and Stand-alone Department. As expected, cities that are located in states with climate change adaptation plans are less actively collaborating because they may be better supported with financial and technical resources by the state government. On the other hand, cities with no state plans are more actively collaborating to fill the policy vacuum that exists at the higher levels of the government. Further, cities in which planning departments are separated from other city functions, are more active in horizontal collaboration because these managers likely have fewer conflicting tasks and responsibilities and, thus, are able to dedicate more time to collaboration (McGuire \& Silvia, 2010).

\subsection{Factors Influencing Sea Level Rise Adaptation Outputs and Outcomes}

The second and third research questions focused on investigating the relationship between horizontal collaborative activity and outputs (the second research question) and outcomes (the third research question) of sea level rise adaptation in US cities. The 
literature review of collaborative governance and climate change action helped identify the dependent, independent, and control variables of interest to the study. Because the independent and control variables used to address the second and third research questions are operationalized identically, both research questions are presented in this subchapter. Below, I present variables used in the analysis to answer the second and third research question, including their operationalization and descriptive statistics.

\subsubsection{Dependent Variable - Sea Level Rise Adaptation Outputs}

The semi-structured interviews revealed that cities rarely have a major comprehensive strategy for climate change and sea level rise adaptation. More often, cities are pressed for funding and staff, and resort to small, incremental steps for climate change adaptation action. These actions are generally designed as elements of the comprehensive city development plan. As a result, policy outputs were measured on a scale from 1 to 6 in the survey. The respondents were asked what best describes their city's effort to adapt to sea level rise among six choices, which represent escalating stages of action: (1) Not on the city agenda; (2) Vulnerability assessment is under way; (3) Vulnerability has been assessed and documented; (4) Action steps are being designed;

(5) Action steps are being articulated and adopted; and, (6) Action steps are being implemented. In the sample, 35 cities indicated that sea level rise adaptation is not on the city's agenda, while thirteen cities reported that implementation of sea level rise adaptation measures has already been occurring. Most frequently, cities indicated stage 2 as their current stage, which corresponds to city's sea level rise vulnerability assessment (47 cities). Figure 6 depicts the distribution of the dependent variable Outputs across the responding cities. 
Figure 6. The Distribution of Sea Level Rise Adaptation Outputs Across Cities

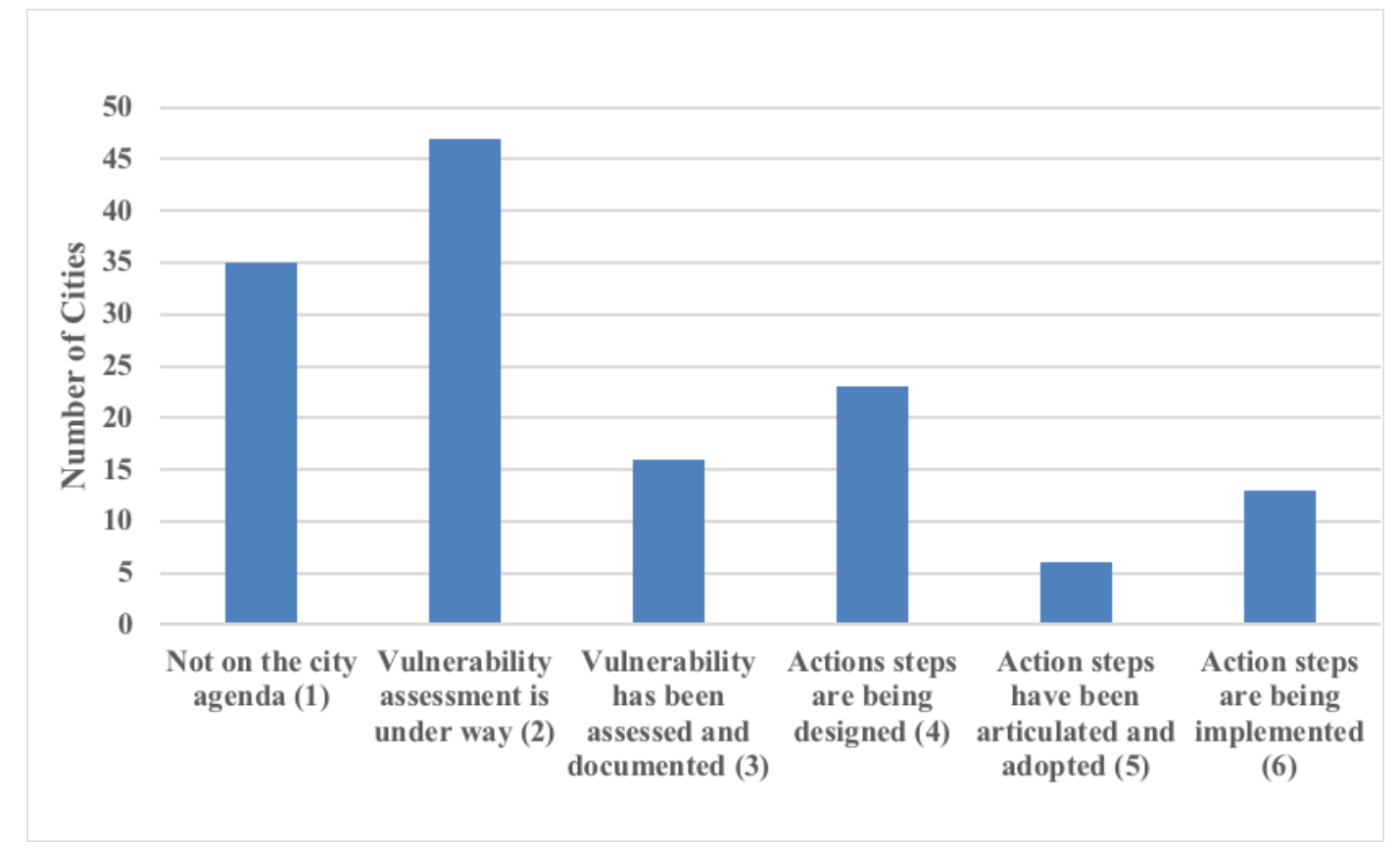

Table 6 contains the complete descriptive statistics of all variables used in the models to answer the second and third research questions, specifically their means, standard deviations, and minimum and maximum values.

\subsubsection{Dependent Variable - Sea Level Rise Adaptation Outcomes}

The NFIP was created in 1968 and has since been administered by FEMA. It provides flood insurance for homeowners, renters, and businesses. To participate in the NFIP, a community must meet or exceed NFIP minimum requirements, which are set by FEMA. Currently, over 20,000 communities in the US participate in the NFIP.

Since 1990, FEMA has offered a voluntary incentive program, the Community Rating System (CRS), which helps communities increase resiliency to flood risk and damage and secure discounted flood insurance premiums under the NFIP. Currently, over 1,200 communities in the US participate in this program. To qualify for the discounted 
rates, communities must implement actions that are designed to reduce flood risk and damage. As detailed in Chapter 2, communities can implement 19 activities that earn credits for flood insurance discounts. The activities fall into four categories: (1) Public Information (elevation certificates, map information service, outreach projects, hazard disclosure, flood protection information, flood protection assistance, and flood insurance promotion); (2) Mapping and Regulations (floodplain mapping, open space preservation, higher regulatory standards, flood data maintenance, and storm water management); (3) Flood Damage Reduction (floodplain management planning, acquisition and relocation, flood protection, and drainage system maintenance); and (4) Flood Preparedness (flood warning and response, levee safety, and dam safety).

The credits earned for implementing these activities vary depending on the specific activity and its effectiveness in reducing flood risk and damage. For example, acquisition and relocation of buildings in flood prone areas - as a flood preparedness activity_can earn a community a maximum of 1,900 credits, while drainage system maintenance activities can earn up to 570 . Finally, the number of total community credits earned translates into a rating, referred to as the CRS Class. The discount on insurance premiums depends on the CRS Class for which the community classifies, ranging from 1 to $10[1=$ the highest discount $(45 \%), 9=$ the lowest discount $(5 \%), 10=$ no discount $]$. The only publicly available data from this program are communities' CRS classes, so I filed a Freedom of Information Act Request with FEMA to attain data on community credits across the US.

Since 2013, the CRS Coordinator's Manual has outlined how communities can receive credits for sea level rise adaptation activities as well. The primary purpose of the 
CRS is to reduce flood risk and damage via human interventions; however, research has shown that human-caused sea level rise has been a major contributor to flood events in the US, including nuisance flooding since 1950s (Strauss et al., 2016). CRS activities involve the three types of adaptation measures intended to combat sea level rise: protection, accommodation, and retreat. Research has demonstrated that CRS measures are effective in reducing flood risk and damage, including open space preservation, freeboarding, and flood protection (Brody \& Highfield, 2013; Highfield \& Brody, 2013). As a result, CRS scores provide a uniform and reliable measure of communities' effectiveness in reducing flood risk and damage to the built environment across US cities.

The responding cities that do not participate in the CRS were excluded from this study, leaving 94 cases for analysis. Among the cities in the sample, the lowest CRS score is 577 , while the highest is 2977 . Because the distribution of the outcome variable was skewed, I transformed the variable by using its natural logarithm. Table 5 shows the distribution of untransformed CRS scores across the 94 analyzed cities. Only a few cities have very low CRS scores (9), between 501 and 1000. Most of the CRS scores (37 cities) in the sample are clustered around the mean (1671), ranging from 1501 to 2000.

Table 5. The Distribution of CRS Scores Across the Cities in the Study

\begin{tabular}{ll}
\hline CRS Score Range & Number of Cities in the Study \\
\hline $501-1000$ & 9 \\
$1001-1500$ & 18 \\
$1501-2000$ & 37 \\
$2001-2500$ & 25 \\
$2501-3000$ & 5 \\
\hline
\end{tabular}




\subsubsection{Main Independent Variables - Horizontal Collaborative Activity and Activity by Partner Type}

Collaborative activity is the main independent variable in both models. The first model tested the relationship between the collaborative activity and sea level rise adaptation outputs, and the second model tested the relationship between the collaborative activity and sea level rise adaptation outcomes. The operationalization of Collaborative Activity is described in detail in Chapter 6 as the main dependent variable for the first research question. Both models were first run using an aggregate score of collaborative activity with all five types of horizontal partners (Collaborative Activity).

To test the relationship between collaborative activity and outputs and outcomes by partner type, I compiled five additional independent variables that involve the number of 11 possible collaborative activities by partner type: Cities (other municipalities), Institutions of Higher Learning, Businesses, Nonprofits, and Community Groups. Fortysix cities in the sample reported no collaborative involvement with other municipalities for sea level rise adaptation, while four cities reported involvement in all 11 activities in the survey. Regarding the Institutions of Higher Learning variable, 84 cities in the sample reported no involvement, and one reported involvement in all 11 activities. Similarly, 78 cities reported no involvement with nonprofit organizations to prepare for sea level rise, while one city reported being involved in nine activities. Collaboration with businesses is the least common: 113 cities reported no involvement in sea level rise issues, and seven cities are involved in three activities. Finally, 95 cities reported no involvement with community groups, and one city is involved in eight activities. 
Table 6. Descriptive Statistics for the Variables for the Second and Third Research Questions

\begin{tabular}{lllll}
\hline Variable & Mean & Std. Dev. & Min. & Max. \\
\hline Sea Level Rise Adaptation Outputs & 2.692 & 1.559 & 1 & 6 \\
Sea Level Rise Adaptation Outcomes $(\log )$ & 7.37 & 0.337 & 6.358 & 7.999 \\
Collaborative Activity $(\log )$ & 1.442 & 0.988 & 0 & 3.402 \\
Cities & 2.274 & 2.64 & 0 & 11 \\
Institutions of Higher Learning & 0.993 & 1.7 & 0 & 11 \\
Nonprofits & 1.309 & 1.937 & 0 & 9 \\
Businesses & 0.345 & 0.805 & 0 & 3 \\
Community Groups & 0.791 & 1.506 & 0 & 8 \\
Collaborative Process & 3.248 & 0.743 & 1 & 5 \\
Threat Level & 13.865 & 19.18 & 0 & 87.1 \\
Political Affiliation & 55.953 & 14.05 & 21.6 & 85.2 \\
ICLEI Membership & 0.164 & 0.372 & 0 & 1 \\
Budget per capita & 1998.91 & 1408.1 & 490.48 & 6548.93 \\
Population (log) & 10.69 & 1.151 & 9.22 & 14.265 \\
Manager Form & 0.75 & 0.434 & 0 & 1 \\
\hline
\end{tabular}

\subsubsection{Control Variables}

In the models, I included a set of control variables to account for alternative plausible explanations of sea level rise adaptation outputs and outcomes suggested by previous research: collaborative process, problem severity, political commitment, and organizational characteristics.

Most importantly, research has shown that collaborative processes shape various outputs and outcomes of collaboration (Emerson \& Nabatchi, 2015b; Thomson et al., 2008; Ulibarri, 2015). I included a measure of city experience with the collaborative process, consisting of three survey questions: (1) To what extent the benefits are distributed to partners fairly; (2) To what extent partners fulfill their commitments, and (3) To what extent conflict among partners is rare? The questions were measured on a scale from 1 (strongly disagree) to 5 (strongly agree), and scores were summed and averaged to form the composite Collaborative Process measure (Cronbach's 
Alpha $=0.79$ ). It was expected that higher values of Collaborative Process would be associated with higher outputs and outcomes of sea level rise. The lowest value of the Collaborative Process variable across the sample is 1 (reported by four cities), and the highest is 5 (reported by five cities).

Additionally, I included control variables for problem severity, political commitment, and organizational characteristics that have been used in previous studies. To control for the problem severity, I used a variable to account for the percent of population that would be living under the future high-tide line by 2020 (Threat Level). It was expected that cities with larger populations at risk would have higher outputs and outcomes of sea level rise preparedness. To account for political commitment to climate change as a public issue, I included two variables that were used in the model explaining collaborative activity: ICLEI Membership and Political Affiliation. Finally, to account for the government's capacity to attain higher outputs and outcomes, I included a set of variables that represent city resourcefulness (Budget per Capita), task difficulty (Population), and governmental professionalism (Manager Form).

Finally, scholars have argued that outputs of collaboration lead to outcomes (Emerson \& Nabatchi, 2015a). As a result, in the models that explain Outcomes, I included the stage of sea level rise planning in the city (Outputs). However, since the Outputs variable was not statistically significant, and the results remained qualitatively identical, I excluded the variable in the final estimations.

Table 7 provides operationalization of variables used to model the relationship between collaborative activity and sea level rise adaptation outputs and outcomes. 
Table 7. Variable Operationalization and Data Sources for the Second and Third Research Questions

\begin{tabular}{|c|c|c|}
\hline Type of Variable & Variable Name & Operationalization and Data Sources \\
\hline \multirow[t]{2}{*}{$\begin{array}{l}\text { Dependent } \\
\text { variables }\end{array}$} & $\begin{array}{l}\text { Sea Level Rise } \\
\text { Adaptation Outputs }\end{array}$ & $\begin{array}{l}\text { An index, measuring the stage of a city's } \\
\text { planning for sea level rise adaptation, } \\
\text { ranging from } 1 \text { (not on the agenda) to } 6 \\
\text { (an action plan is being implemented). } \\
\text { Source: Survey. }\end{array}$ \\
\hline & $\begin{array}{l}\text { Sea Level Rise } \\
\text { Adaptation Outcomes }\end{array}$ & $\begin{array}{l}\text { Natural logarithm of FEMA's } \\
\text { Community Rating Systems score of a } \\
\text { city. Source: FEMA. }\end{array}$ \\
\hline \multirow[t]{6}{*}{$\begin{array}{l}\text { Main Explanatory } \\
\text { Variables }\end{array}$} & Collaborative Activity & $\begin{array}{l}\text { Additive measure of collaborative } \\
\text { activities with five partners for sea level } \\
\text { rise preparedness in the past three years, } \\
\text { transformed to a natural logarithm. } \\
\text { Source: Survey. }\end{array}$ \\
\hline & Cities & $\begin{array}{l}\text { Additive measure of collaborative } \\
\text { activities with other cities for sea level } \\
\text { rise preparedness in the past three years, } \\
\text { ranging from } 0 \text { (no involvement) to } 11 . \\
\text { Source: Survey. }\end{array}$ \\
\hline & $\begin{array}{l}\text { Institutions of Higher } \\
\text { Learning }\end{array}$ & $\begin{array}{l}\text { Additive measure of collaborative } \\
\text { activities with institutions of higher } \\
\text { learning for sea level rise preparedness in } \\
\text { the past three years, ranging from } 0 \text { (no } \\
\text { involvement) to 11. Source: Survey. }\end{array}$ \\
\hline & Nonprofits & $\begin{array}{l}\text { Additive measure of collaborative } \\
\text { activities with nonprofit organizations for } \\
\text { sea level rise preparedness in the past } \\
\text { three years, ranging from } 0 \text { (no } \\
\text { involvement) to } 11 \text {. Source: Survey. }\end{array}$ \\
\hline & Businesses & $\begin{array}{l}\text { Additive measure of collaborative } \\
\text { activities with businesses for sea level rise } \\
\text { preparedness in the past three years, } \\
\text { ranging from } 0 \text { (no involvement) to } 11 . \\
\text { Source: Survey. }\end{array}$ \\
\hline & Community Groups & $\begin{array}{l}\text { Additive measure of collaborative } \\
\text { activities with community groups for sea } \\
\text { level rise preparedness in the past three } \\
\text { years, ranging from } 0 \text { (no involvement) to } \\
\text { 11. Source: Survey. }\end{array}$ \\
\hline
\end{tabular}


Control variables Collaborative Process An average score for three 5-point Likerttype scale questions, regarding fair distribution of collaborative benefits, fulfillment of commitments, and prevalence of conflict. Source: Survey.

Threat Level

The percent of a city's population that will be living under the projected high tide line by 2020. Source: Climate Central.

ICLEI Membership $\quad 1=$ the city is a member of ICLEI, $0=$ otherwise. Source: ICLEI website.

Political Affiliation Percent voters in the county that voted for President Obama in the 2012 Presidential Election. Source: Politico.

Budget per Capita City expenditures per capita in 2016. Source: City government budget documents.

Population A natural logarithm of city population in 2016. Source: US Census Bureau.

Manager Form $\quad 1=$ the city has the council-manager form of government, $0=$ otherwise. Source:

City government websites.

\subsubsection{Estimation Routine and Results (Research Question 2)}

The dependent variable for the second research question is sea level rise adaptation outputs, measured as an ordinal variable (ranging from 1 to 6 ). Before running the ordinal logistic regression, I performed tests to check whether any assumptions of the ordinal logistic regression had been violated. To test for multicollinearity, I inspected VIF values of the independent variables. The highest VIF value is 1.68 (Community Groups), indicating that none of the independent variables highly correlate with each other. Next, the assumption of proportional odds for the ordered logistic regression was tested using 
the Brant test. The test statistic for the models was insignificant, indicating that the proportional odds assumption was met.

Table 8 presents ordinal logistic regression results with coefficients, odds ratios, and robust standard errors, clustered by state. Model 1 tested the relationship between sea level rise adaptation outputs and collaborative activity operationalized as an additive index with all partners of horizontal collaboration. The results indicate that the relationship between Collaborative Activity and sea level rise adaptation outputs is statistically significant at the $1 \%$ level. For a one percent increase in Collaborative Activity, the odds of having higher outputs than lower outputs are 1.8435 times greater, holding other variables constant. This finding reaffirms collaborative governance as a tool that public organizations can use to improve their decision-making and policy development. Not surprisingly, the same holds for cities with larger populations at risk of sea level rise, as indicated by a statistically significant relationship between the dependent variable and Threat Level. Both measures that account for governmental capacity_Budget per Capita and Population-are also positively related to outputs, indicating that cities with higher expenditures per capita and cities serving larger populations are further advanced in sea level rise adaptation planning.

Model 2 tested the relationship between sea level rise adaptation outputs and collaborative activity, broken down by partner type. Interestingly, only two of the main independent variables are statistically significant: Institutions of Higher Learning at the $10 \%$ level and Businesses at the $1 \%$ level, indicating that the relationship varies according to the partner type. The result is consistent with expectations, given that institutions of higher learning provide local governments with scientific data and 
expertise on climate science, and a number of private foundations, such as the Kresge Foundation and the Rockefeller Foundation, supply local governments with financial resources and decision-making tools for climate change adaptation. These resources can help cities improve their planning for sea level rise. However, the lack of statistical significance for Cities was surprising, given the large extent of horizontal collaboration cities reported in the survey. It is possible that the benefits of city-to-city collaboration manifest in higher progress in climate change adaptation (e.g., the implementation). In terms of nonprofits and community groups, cities may involve these actors to increase the legitimacy of their decisions (Scott \& Thomas, 2017) and give a voice to the community. In line with previous research, the results suggest that the Collaborative Process variable is positively related to public policy outputs in Model 2: cities that have more positive experiences with distribution of benefits and fulfillment of commitments, and less conflict with their collaborative partners, are more likely to be further advanced in planning for sea level rise adaptation.

Table 8. Ordinal Logistic Regression Results with Coefficients and Robust Standard Errors, Clustered by State (Dependent Variable - Outputs)

\begin{tabular}{lllll}
\hline Independent Variables & $\begin{array}{c}\text { Model 1 } \\
\text { B }\end{array}$ & $\begin{array}{c}\text { Model 1 } \\
\text { Odds } \\
\text { Ratios }\end{array}$ & $\begin{array}{c}\text { Model 2 } \\
\text { B }\end{array}$ & $\begin{array}{c}\text { Model 2 } \\
\text { Odds } \\
\text { Ratios }\end{array}$ \\
\hline Collaborative Activity & $0.6116^{* * * *}$ & $1.8435^{* * *}$ & & \\
Cities & $(0.1231)$ & $(0.2268)$ & & \\
& & & -0.0687 & 0.934 \\
Institutions of Higher Learning & & & $(0.0499)$ & $(0.0465)$ \\
& & & $0.1398^{*}$ & $1.151^{*}$ \\
Nonprofits & & $(0.0826)$ & $(0.095)$ \\
Businesses & & 0.1208 & 1.128 \\
& & & $(0.163)$ & $(0.184)$ \\
Community Groups & & & $0.7458^{* * *}$ & $2.108^{* * *}$ \\
\end{tabular}




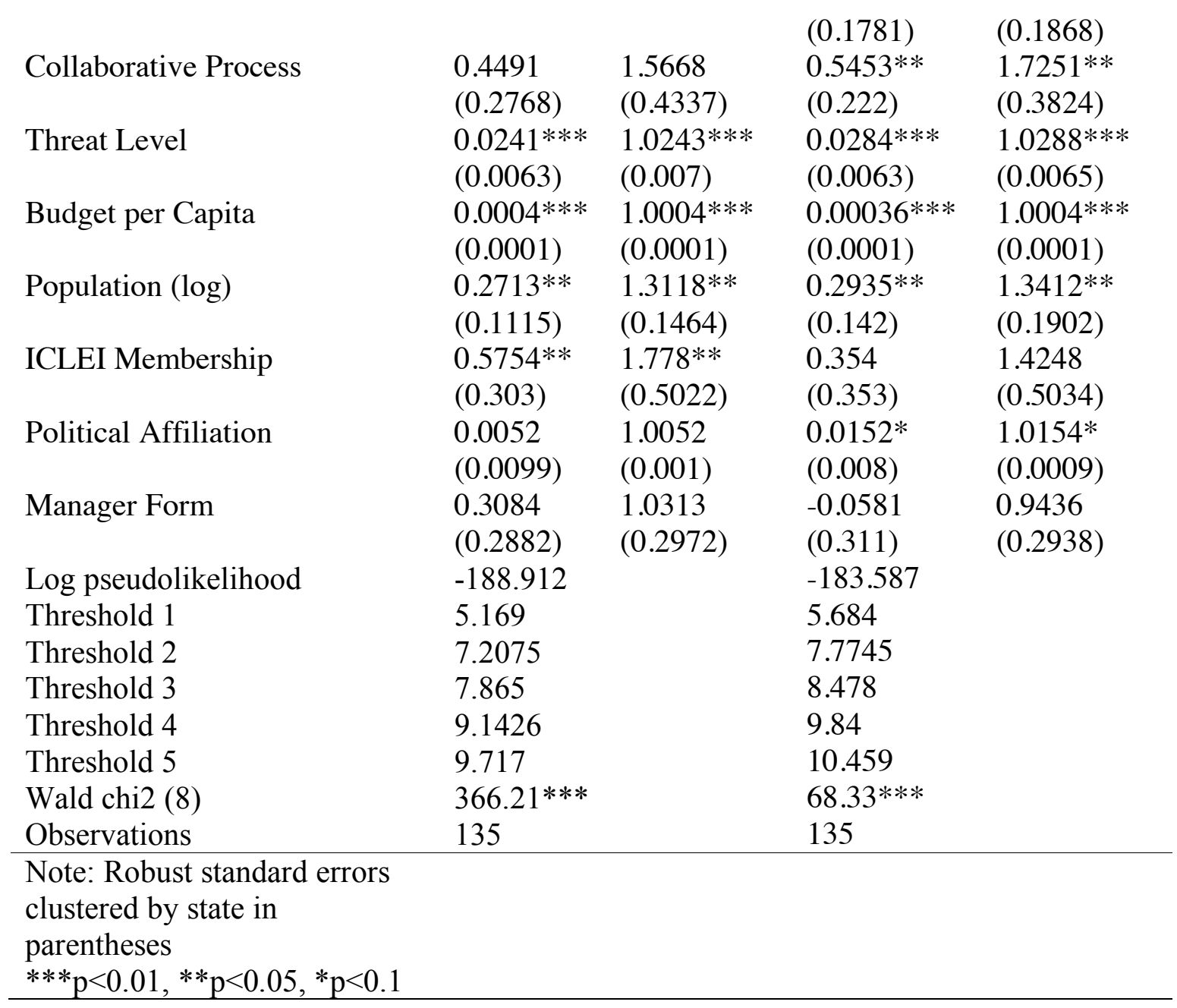

\subsubsection{Estimation Routine and Results (Research Question 3)}

Finally, the remaining two models tested the relationship between Collaborative Activity and sea level rise adaptation outcomes. I only included cities that participate in FEMA's CRS program, so the number of observations dropped from 135 to 94 . I ran diagnostic tests to check if the model violates any OLS regression assumptions. First, I checked for multicollinearity between independent variables in the models to establish if any independent variables are correlated with each other and may violate the OLS regression assumption of no perfect collinearity. To check for this, I inspected VIF values of the independent variables. The highest VIF value is 2.64 (Nonprofits), which is 
significantly lower than the value of 10 that is typically used-as a rule of thumb-to further investigate the relationships between independent variables. As a result, the OLS regression assumption of an absence of multicollinearity was violated.

To test for heteroscedasticity, or constant variance of error terms, I ran the Breusch-Pagan test in STATA. The null hypothesis of the test is that the error terms are homoscedastic. The p-value of the tests is 0.545 (Model 1) and 0.119 (Model 2), indicating that the null hypothesis that the residuals are homoscedastic could not be rejected. Table 9 presents OLS regression results with coefficients and robust standard errors, clustered by state for both models.

To check whether the exclusion of 41 cities that do not participate in the CRS introduces bias in the remaining sample, I compared the averages of these 41 cities with the 341 in the sample in terms of vulnerability to sea level rise, population, and household income. The excluded cities were representative of the sample in terms of population size and household income, while, on average, they were slightly less vulnerable to sea level rise ( $26.4 \%$ of population will be significantly affected by 2050 ) than the whole sample with $31 \%$.

Additionally, I ran separate analyses to check for two potential endogeneity concerns. Ideally endogeneity can be addressed by using a lagged dependent variable as one of the regressors, but due to unavailable data, I utilized a different approach. First, to examine whether better performing cities are more likely to attract more collaborative partners, I ran analyses with 30 top performing cities. The results of the top 30 performers were qualitatively the same as those derived from the whole sample. Second, to check whether more threatened cities are more willing to engage in collaboration to 
improve outcomes, I compared the results of the top 30 cities most threatened by sea level rise to the whole sample, which remained qualitatively the same.

Table 9. OLS Regression Results with Coefficients and Robust Standard Errors, Clustered by State (Dependent Variable - Outcomes)

\begin{tabular}{lll}
\hline Independent Variables & Model 1 & Model 2 \\
\hline Collaborative Activity & -0.0272 & \\
Cities & $(0.0401)$ & \\
& & $0.0166^{* *}$ \\
Institutions of Higher Learning & & $(0.0086)$ \\
& & -0.0339 \\
Nonprofits & & $-0.0197)$ \\
& & $(0.0218)$ \\
Businesses & & $0.0382^{* *}$ \\
& & $(0.0185)$ \\
Community Groups & & 0.0002 \\
& & $(0.0189)$ \\
Collaborative Process & 0.0478 & 0.0491 \\
& $(0.0393)$ & $(0.0399)$ \\
Threat Level & 0.0015 & 0.0019 \\
& $(0.0015)$ & $(0.00135)$ \\
Budget per Capita & -0.0001 & -0.0001 \\
& $(0.0001)$ & $(0.0001)$ \\
Population (log) & $0.0937 * *$ & $0.0895^{* *}$ \\
& $(0.038)$ & $(0.0299)$ \\
ICLEI Membership & $0.2439 * *$ & $0.2123^{* *}$ \\
& $(0.0846)$ & $(0.0833)$ \\
Political Affiliation & $-0.012 * * *$ & $-0.0133^{* * *}$ \\
& $(0.0023)$ & $(0.0024)$ \\
Manager Form & $0.1678^{* *}$ & $0.1845^{* *}$ \\
& $(0.0733)$ & $(0.0744)$ \\
Constant & $6.7408^{* * *}$ & $6.7664 * * *$ \\
$\mathrm{R}^{2}$ & 0.257 & 0.289 \\
Observations & 94 & 94 \\
\hline Note: Robust standard errors & & \\
clustered by state in & & \\
parentheses & & \\
$* * *$ p $<0.01, * * p<0.05, * p<0.1$ & & \\
\hline
\end{tabular}


Overall, the models explain $26 \%$ to $29 \%$ of variation of the Outcomes variable. Model 1 tested the relationship between Collaborative Activity for all five types of partner of horizontal collaboration and Outcomes. Interestingly, the Collaborative Activity variable does not follow the same pattern demonstrated in the case of sea level rise adaptation outputs-it is not statistically significant. It is possible that the relationship between collaboration and outputs is more straightforward, and less so with outcomes, which take more time to achieve, given that implementation of sea level rise measures typically requires extensive resources, including funding and staff time. The same holds for the Collaborative Process variable: unlike the outputs, experience with the process of collaboration is not a statistically significant factor in attaining better outcomes. One plausible explanation for this finding is that the relationship between the process and outcomes is more complex than with outputs, and not enough time may have passed for some municipalities to translate their policies into results on the ground.

Cities with larger populations have attained better outcomes for sea level rise, as indicated by a positive and statistically significant sign of Population. Variables that measure political commitment to climate change as a public issue follow different patterns than those in the models of sea level rise adaptation outputs: while cities that are ICLEI members have attained higher outcomes, the relationship between Political Affiliation and outcomes is negative; cities that are located in counties where a higher percentage of voters voted for President Obama in the 2012 Presidential Election have lower outcomes of sea level rise preparedness. This finding is not entirely surprising, given that city officials may not recognize the causal relationship between an increase in flooding or permanent inundation of city locations and climate change. Initiatives for sea 
level rise preparedness may be undertaken and justified as a means of combating flooding and protecting residents from flood damage, relating it to natural variation in climate patterns instead of human-caused adverse effects of climate change.

In Model 2, collaborative activity of cities is broken down by partner type of horizontal collaboration. Comparing it to Model 1, the results reveal that collaborative activity with two partners - other cities and businesses - is statistically significant at the $5 \%$ level, and positively related to Outcomes. The results also indicate that the additive measure Collaborative Activity in Model 1 conceals individual partner effects. Given that cities face similar sea level rise risks, it is not surprising that the variable Cities is associated with better outcomes; other municipalities are the most frequent partner of collaboration for sea level rise adaptation, including a large degree of information sharing. Because technical solutions to sea level preparedness are continuously being developed and tested, collaborating with others can help garner better information and decrease costs of trial and error solutions. Moving to businesses, many local private stakeholders have a vested interest in city preparedness for sea level rise, especially real estate development and insurance companies. Apart from local level stakeholders, a number of private foundations (e.g., Kresge Foundation and Rockefeller Foundation) fund projects nationally and help cities finance climate change adaptation planning and measures. 


\section{CHAPTER 7: COMPLEMENTARY QUALITATIVE RESEARCH FINDINGS}

This chapter presents findings from the second phase of the study: in-depth interviews with policymakers and public administrations in Florida's local governments. For the analysis, each respondent was assigned a number (ranging from 1 to 13) in the order they were interviewed, and the respondent number is indicated in the direct quotes from the interviews in this chapter. Table 10 shows the characteristics of the interview respondents, along with their gender, positions in the city or county government, city or county population size, and the percent of population that will be exposed to sea level rise by 2050 . To help protect respondents' identities, I provide ranges of demographic city data and respondents' position type (i.e., elected official and public administrator) rather than specific city data and respondents' position titles.

Table 10. The Characteristics of the Interview Respondents

\begin{tabular}{lllll}
\hline $\begin{array}{l}\text { Respondent } \\
\text { Number }\end{array}$ & Gender & Position & $\begin{array}{l}\text { City/County } \\
\text { Population } \\
\text { Size }\end{array}$ & $\begin{array}{l}\text { Population Threat to } \\
\text { Sea Level Rise by } \\
\text { 2050 }\end{array}$ \\
\hline Respondent 1 & Male & Elected official & $<10,000$ & $81-100 \%$ \\
\hline Respondent 2 & Male & Elected official & $10,000-25,000$ & $61-80 \%$ \\
\hline Respondent 3 & Male & Elected official & $25,001-50,000$ & $61-80 \%$ \\
\hline Respondent 4 & Female & $\begin{array}{l}\text { Public } \\
\text { administrator }\end{array}$ & $10,000-25,000$ & $61-80 \%$ \\
\hline Respondent 5 & Female & $\begin{array}{l}\text { Public } \\
\text { administrator }\end{array}$ & $>100,000$ & $81-100 \%$ \\
\hline Respondent 6 & Female & $\begin{array}{l}\text { Public } \\
\text { administrator }\end{array}$ & $75,001-100,000$ & $81-100 \%$ \\
\hline Respondent 7 & Male & $\begin{array}{l}\text { Public } \\
\text { administrator }\end{array}$ & $>100,000$ & $61-80 \%$ \\
\hline Respondent 8 & Male & Elected official & $25,001-50,000$ & $81-100 \%$ \\
\hline Respondent 9 & Male & $\begin{array}{l}\text { Public } \\
\text { administrator } \\
\text { (county) }\end{array}$ & $>100,000$ & $61-80 \%$ \\
\hline Respondent 10 & Male & $\begin{array}{l}\text { Public } \\
\text { administrator } \\
\text { county) }\end{array}$ & $>100,000$ & $61-80 \%$ \\
\hline
\end{tabular}




\begin{tabular}{lllcc}
\hline Respondent 11 & Male & $\begin{array}{l}\text { Public } \\
\text { administrator }\end{array}$ & $>100,000$ & $81-100 \%$ \\
\hline Respondent 12 & Female & $\begin{array}{l}\text { Public } \\
\text { administrator }\end{array}$ & $25,001-50,000$ & $81-100 \%$ \\
\hline Respondent 13 & Male & $\begin{array}{l}\text { Public } \\
\text { administrator }\end{array}$ & $25,001-50,000$ & $81-100 \%$ \\
\hline
\end{tabular}

The goal of the interviews was two-fold: first, to inform the survey, which was designed and administered to answer the first three research questions. Second, to complement findings from the first phase of data collection, which used quantitative methods. More specifically, the fourth research question guided the investigation of how collaboration helps cities improve their preparedness for sea level rise. The main intent of the interviews was to uncover the ways in which horizontal collaboration improves sea level rise preparedness in US cities using in-depth accounts of the respondents.

During the interview data analysis, described in detail in Chapter 5, multiple themes were identified, including city vulnerability to sea level rise, adaptation initiatives in the city, motivation to adapt, intergovernmental relations, and horizontal collaboration, including benefits and challenges of collaboration as a tool to better prepare for sea level rise. Data analysis helped identify common themes associated with the benefits of horizontal collaboration as a means to improve service delivery in the context of sea level rise. Two major themes were revealed in the interviews as benefits of collaboration for better public service delivery: first, learning, which includes increase in knowledge on the risks and solutions of sea level rise, and, second, cost savings, which occur by avoiding duplication and trial and error while designing and implementing solutions.

\subsection{Learning}

First, in line with findings from other research (Leach et al., 2013), respondents 
identified several ways that horizontal collaboration helps them learn from others in the context of sea level rise preparedness. Through formal and informal channels of information exchange, both elected officials and public administrators reported that horizontal collaboration provides tools to learn from public and non-governmental actors about solutions to sea level rise and their implementation. The interviews revealed that learning through collaboration is a major benefit, given the lack of established best practices for how to manage preparedness to climate change in US cities (Measham et al., 2011; Woodruff \& Stults, 2016).

The respondents differed in their reports about learning processes. Elected officials emphasized learning about general issues surrounding sea level rise, often with partners that were not limited to their region, including actors from other countries that face sea level rise risks. On the other hand, public administrators stressed more specific cases, including navigating the political climate and technical aspects of adaptation in their city. Moreover, the partners that public administrators mentioned were mostly local, including other municipalities, universities, and nonprofits. To describe learning processes that occur through collaboration, one city mayor in Florida shared his views on borrowing ideas from other organizations:

Through that and personal and professional networking, I am able to find out an awful lot about what other communities are doing, and beyond that, I am shameless. A good idea is a good idea. I do not care if it comes from somebody that I am not aligned with philosophically or politically, it does not matter to me. If it is good for the community, it is good for the community. That is like 
personalities, put that to the side. And it is the same thing, if you see another community doing something that is intelligent, let us do it. (Respondent 1)

The interviews also revealed that certain cities in South Florida are considered champions of sea level rise preparedness - actively disseminating their knowledge and experience to other cities, providing incentives to act. One city mayor in Florida described providing learning tools to stakeholders that were completed at significant financial cost to the city. More specifically, the city conducted a comprehensive study on sea level rise adaptation that can be applied in other contexts and shared it with collaborative partners:

You learn from them. Just like the people that we work with are going to get the study, which cost us hundreds of thousands of dollars. They are going to get a study they do not have to replicate, they can draw ideas from it. I showed this map at the conferences, student groups, so that they say my university should do that. (Respondent 2)

On the other hand, public administrators emphasized learning in the context of a political environment that may oppose climate change action. In terms of partners that facilitate the learning process, the respondents largely focused on city-to-city collaboration. Similarities, in terms of challenges and risks to sea level rise, particularly among neighboring cities, have motivated them to frequently partner in horizontal collaboration. One public administrator described the challenges of passing an ordinance that required property owners to incur financial costs for adaptation to sea level rise:

We are all trying to learn from each other to see what works, but the politics are local, and so what works for one municipality might not work in another, but, on 
the other hand, if something does work in a municipality, you can at least talk to your officials and say this is what they did, what portion of this will work for us? We can use best practices that go between the different municipalities. You know, how did you test your politics? How were you able to pass what might have been a very controversial ordinance? What did you do? Sharing that kind of information. (Respondent 5)

In addition to learning how to navigate the political climate surrounding sea level rise adaptation from other stakeholders, public administrators also emphasized learning to decrease uncertainty. Uncertainty is a characteristic of both evaluation of risk regarding the exact time frames and magnitude of sea level rise (McGuire, 2013). Technical sea level rise solutions are very site-specific and are constantly evolving. As a result, public administrators reported exchanging information and ideas on the technical aspects of preparedness:

Information sharing, but information sharing in the context of you try this technology, did it work? Did it not work? Where did it work? It only works if you were at one-foot elevation, did not work if you were at five-foot elevation? So that information and then the policy aspect of it is important too [...]. Oh, you have never seen what a tidal valve looks like? Come to our city and we will show you where we installed one, how it is and how it works. (Respondent 5)

\subsection{Cost Savings}

The second major theme identified in the interviews is the benefit of collaboration as a cost saving tool. The findings reveal two common ways in which cities can use their resources more efficiently in preparation for sea level rise through horizontal 
collaboration: avoiding duplication and minimizing trial and error costs. When talking about the benefits of horizontal collaboration, the respondents predominantly discussed collaboration with other cities and private entities as main partners that help decrease costs of adaptation. These qualitative research findings also provide support for quantitative research findings for the third research question, which shows that horizontal collaboration with other municipalities and businesses is associated with greater outcomes of sea level rise adaptation.

In terms of avoiding duplication, elected officials and public administrators indicated that through horizontal collaboration, there is a potential to increase the efficiency of service delivery by creating economies of scale and regional approaches to public service delivery. An elected city official provided a practical example to illustrate the benefit of cost savings:

I think regionalization is a key factor. You are not wasting money, because you are not building redundancies that not necessarily do not have to be built in there. Let me go back to the water plant example. I believe there are 15 water plants in the county. My water plant is as I said, I am producing 9 million gallons of water a day, I have capacity to use 6 million a day. And then I can probably expand it to 15 million. There is a lot of capacity that is sitting on a shelf. I built it, I am not using it, it is a waste of money. If every one of those 15 water plants have a third excess capacity, well I could have built a third less water plants, had we had regionalization when people were doing this. It is kind of crazy to say everybody has got at least a $10 \%$ overcapacity, now they have got 20 or $30 \%$, why do I build 15 plants, maybe I only needed to build $9,10,11$ of them? So that is a lot money 
going down the tubes that can potentially be used to do other things. (Respondent 8)

In the above quote, Respondent 8 , an elected official, described a scenario in which lack of regional public collaboration resulted in inefficient public service delivery. Additionally, other respondents explained how collaboration helps avoid duplication, because cities can borrow from each other without investing staff time and financial resources to repeat the same steps that other cities have already taken:

I look for instance for difficult bits of code that somebody has written, and we can borrow, for instance. I am looking for experiments they have done that have worked, that we can do this too. We try to build off each other's successes and that is something that we do pretty well locally. If somebody has done something and it worked well, and it is popular then it gets adopted by a nearby city we say hey, we like that. (Respondent 5)

Similarly, other respondents stressed that when local stakeholders are advanced in sea level rise adaptation, innovation can spread to neighboring cities. In one example, a city in South Florida included a climate change element in its comprehensive development plan because a neighboring municipality was an early adopter of sea level rise adaptation policies and considered a leader in the county.

Apart from avoiding duplication, these findings also show that horizontal collaboration can help decrease the risks of trial and error when seeking appropriate solutions to sea level rise, due to a high degree of uncertainty regarding the effectiveness of specific solutions in the local government context. Other local stakeholders, not limited to municipalities, that are facing sea level rise risks have also been contributing to 
improved preparedness. For instance, one local public administrator explained how a local homeowner's association helped decrease the financial risk of trying a solution locally:

A group of homeowners approached the city and said that they knew about this technology called tidal valves that will prevent the flood waters from coming up to storm drain system, will the city put them in? And we said that we do not have the money right now to do it. And as a pilot project, just to see if it worked, the homeowner's association actually put up the money and the city installed the valves. They had a contract between the city and the homeowner's association that if the valves worked, the city will pay for them. They reimbursed the homeowner's association. (Respondent 5)

Further, in the above case, once the city tried the tidal valve solution and it proved to be effective, more valves were installed in other areas of the city. In effect, horizontal collaboration with private actors helped the city decrease the financial risks of trying a new method of adaptation that was later adopted by the city. Similarly, cities can decrease their trial and error risks with the help of city-to-city horizontal collaboration:

Other people are able to learn from our mistakes as well as from our successes. They do not have to go through the pain of making the mistakes, they can jump in and say okay, this works. We know this works in this environment so let us do that. The city tried five different ways, one way worked, let us use the one way that worked for them and then we do not have to make an additional investment. (Respondent 5)

As a result, cities can reap the benefits from the successes and failures of others, 
which helps decrease overall costs of sea level rise adaptation action. According to a few respondents, this creates a larger burden for early adopters, because they typically bear higher costs of trying innovative approaches. However, because negative externalities are common for sea level rise adaptation, horizontal collaboration is viewed as a tool that helps serve the interests of local communities, both for early adopters and those that are only beginning their adaptation efforts. 


\section{CHAPTER 8: CONCLUSION}

This dissertation answered four research questions: (1) What are the factors that facilitate city-level collaboration for sea level rise adaptation?; (2) Is city-level collaborative activity associated with higher outputs of sea level rise adaptation? Does the effect vary depending on the type of collaborative partner?; (3) Is the city-level collaborative activity associated with higher outcomes of sea level rise adaptation? Does the effect vary depending on the type of collaborative partner?; (4) How does collaboration help cities improve their preparedness for sea level rise? This chapter presents conclusions that can be drawn from the study, main contributions to the literature, strengths and limitations of the study, and finally, policy implications of the main findings.

\subsection{Findings Overview}

This study sought to shed more light on the factors that facilitate horizontal collaboration and its relationship with outputs and outcomes in public service delivery. Using the case of a complex public problem (i.e., sea level rise adaptation in municipal governments in the US), I analyzed voluntary horizontal collaboration. The analysis reveals a few principal findings. For the first research question, which investigated the relationship between factors that facilitate collaboration and horizontal collaborative activity, two drivers are found to be important: uncertainty and leadership. Interestingly, higher uncertainty is negatively related to collaborative activity. Because cities reported collaborative activity over the past three years, it is possible that collaboration may have helped to improve information regarding sea level rise risks and solutions for US cities. 
Moreover, city leadership plays an important role in brokering partnerships with local stakeholders, given that cities with more supportive leadership are more active in collaboration. The second major finding is that, in line, with extant research, horizontal collaboration can occur when there is inadequate support from higher levels of government, because cities that are located in states with a climate change adaptation plan are less active in collaborating.

For the second and third research questions, I tested the proposition that municipalities that collaborate more actively with other city governments, nonprofit organizations, institutions of higher learning, businesses, and community groups will achieve higher outputs and outcomes of sea level rise adaptation. I find support for the hypotheses that collaboration helps organizations generate improved outputs and outcomes of sea level rise preparedness at the local level. In relation to outputs, cities that are more actively collaborating with other municipalities and non-governmental stakeholders are more likely to be further advanced in terms of progress made toward design and implementation of sea level rise planning efforts than cities that are less active, or do not collaborate at all. The same holds for outcomes, but the type of a collaborative partner matters: only horizontal collaboration with other cities and businesses is found to be associated with better preparedness for sea level rise. The findings offer additional evidence for collaboration as a tool for public managers to pool resources and work together to attain mutually beneficial goals. In the absence of financial support and technical advice from higher levels of government, collaborative action provides an alternative route for city governments to serve their communities. Cities can take advantage of local knowledge by working not only with other 
municipalities, but non-state stakeholders as well. Finally, the fourth research question was answered through qualitative methods, investigating how horizontal collaboration leads to better sea level rise preparedness. The findings reveal that two main processeslearning and cost savings - contribute to better preparedness in Florida's cities. In line with the quantitative findings, the interviews also show that many of these processes involve other municipalities and businesses.

\subsection{Contributions to the Literature}

The dissertation contributes to at least two bodies of literature. First, it adds to research on climate change adaptation in the field of planning. Second, it contributes to the public management literature, focusing on the antecedents and consequences of horizontal collaborative activity. Much of the previous research on climate change policy investigates initiatives of climate change mitigation. While climate change mitigation measures are an important policy tool to reverse the effects of climate change, many localities in the US are already experiencing increasing flooding and permanent inundation of areas due to sea level rise. In the US, climate change adaptation is typically considered a local issue, and most action to adapt to changes in climate occurs at the local government level. Agencies at higher levels of government, including federal, and in some cases, state governments, provide administrative advice and financial assistance for adaptation, but often municipalities must utilize local resources and implement climate change adaptation measures using local taxpayer money. There are few large- $N$ studies that investigate climate change adaptation in this context, typically using content analysis to measure climate change adaptation plan quality. 
While the body of knowledge on collaborative governance is growing, much of the literature focuses on vertical collaboration, which pertains to collaborative activities between higher and lower levels of the government. Existing research on horizontal collaboration typically explores city-to-city collaboration, including partnerships for joint service delivery. Few studies on outcomes of horizontal collaboration exist, and even fewer studies have examined the factors that contribute to improved organizational performance.

This dissertation links the extant knowledge on climate change adaptation and collaborative governance to explore what factors drive horizontal collaboration for sea level rise in US cities and examine the relationship between horizontal collaborative activity and objective outputs and outcomes of climate change adaptation service delivery. Primarily, it contributes to an improved understanding of public management tools that can be used to increase community resilience to sea level rise at the local level of government.

\subsection{Strengths, Limitations and Opportunities for Future Research}

One strength of the study is the use of a mixed-method approach using both quantitative and qualitative data. The survey questionnaire was informed by qualitative semi-structured interviews that helped reduce bias and more accurately capture the study context. The primary data were complemented by secondary data sources to answer the research questions. On the other hand, the study has several limitations that point toward opportunities for future research.

The survey data collected for the purposes of this study are cross-sectional in nature, given that they were collected at one point in time. As a result, the data do not 
provide insights into how the relationship between independent and dependent variables may change over time. While the conclusions about the relationship between the variables of interest are consistent with extant research, establishing causal relationships between collaboration and public service outputs and outcomes in the absence of longitudinal data is challenging (Koontz \& Thomas, 2006). Scholars have indicated that achieving outcomes through collaborations is a complex and lengthy process, and longer time spans may be needed to observe the effects of these activities. Yet, such data are often scarce or unavailable. Future research using panel data could provide a more detailed picture of causal effects.

Another potential limitation is the measurement of the variables Collaborative Activity, Outputs, and Outcomes. While collaboration has been measured as an additive index of various activities and collaborative partners in previous studies (e.g., Agranoff \& McGuire, 2003; Foster \& Meinhard, 2002; Gazley, 2010; McGuire \& Silvia, 2010; Meier \& O'Toole, 2003), it does not account for the extent or frequency of collaborative activities. The same holds for the measures for sea level rise adaptation outputs and outcomes. For the output measure, the city planning departments were asked to identify the stage of planning for sea level rise and not the perceptual effectiveness of these efforts. While the question inquired about objective and verifiable data, the results may be, to some degree, affected by subjectivity. Issues of potential overestimation of organizational performance and common source bias are more apparent in cases where managers were asked to evaluate performance of their organizations (Meier, Winter, O'Toole, Favero, \& Andersen, 2015). While this is not the case in the present study, managers are invested in their organizations, and may have overestimated the stage of sea 
level rise planning in their cities. The measure also does not account for the scope and quality of planning efforts. All sample cities that are implementing action steps received the same score for outputs, but there may be important differences between the comprehensiveness of their efforts. The sea level rise outcome measure, used in the present study, does not account for all components of sea level rise adaptation, and focuses on resilience to flooding of the built environment. Future studies should consider other outcomes, which may pertain to conservation of animal species threatened by sea level rise and reversing drinking water contamination from salt water intrusion.

While the literature suggests that collaboration may positively affect outputs and outcomes of sea level rise preparedness, the potential for endogeneity cannot be completely ruled out. Cities that are more advanced in their planning and implementation of sea level rise adaptation may be more desirable to potential collaborators - who would be more willing to partner with the best-performing cities and reap the benefits. Yet, the potential for endogeneity in the present study is weak on theoretical grounds, given organizations are motivated to collaborate to secure access to various resources that they lack to adapt to their environments and improve their performance (Ansell \& Gash, 2008; Feiock, 2013; Krueathep et al., 2010; Pfeffer \& Salancik, 2003). Additionally, by definition, collaboration occurs when organizations are unable to effectively achieve results on their own (Agranoff \& McGuire, 2003; Kettl, 2006b; McGuire, 2006; O’Leary et al., 2006). In effect, even cities that are performing relatively well are expected to engage in collaboration for its benefits, because organizations rarely collaborate for purely altruistic reasons (Emerson \& Nabatchi, 2015b). In future studies, triangulating 
cross-sectional data with multiple sources of qualitative data (e.g., focus groups with key collaboration partners and case studies) would help disentangle these concerns.

\subsection{Implications for Policy and Practice}

The findings of this dissertation offer some important implications for policy and practice in public administration. The first research question addresses city propensity for horizontal collaboration with five partner-types in sea level rise adaptation. The results indicate that leadership at the local level is an important factor in facilitating collaboration for local problem-solving. In effect, local leaders can broker relationships with other public and non-governmental stakeholders to address complex public problems. While horizontal collaboration may take informal forms, local leaders can forge partnerships with other entities to introduce a level of commitment and accountability into collaborative efforts. Additionally, formal agreements may increase the sustainability of collaborative activities once city leadership changes. Because city employees may be involved in collaboration and, as a result, be diverted from their dayto-day activities, local leaders should also periodically evaluate the value of these collaborative activities to the city's mission and goals.

Similarly, commitment to the public problem affects collaborative problemsolving: both from city officials, and city residents. Residents that view climate change adaptation as an issue that must be addressed in their city can advocate for change and elect local leaders that share their views. On the other hand, city governments that seek resident approval of climate change adaptation measures can take advantage of various tools to educate the public about the adverse effects of climate change in their city. For 
instance, some cities have already started installing sea level rise awareness poles on beaches to help residents visualize the current and future risks of sea level rise.

Further, the second and third research questions address the relationship between horizontal collaborative activity and outputs and outcomes of sea level rise adaptation. The findings indicate that collaboration is associated with more advanced planning for sea level rise adaptation, and the partnerships that contribute to outputs are institutions of higher learning and businesses. In terms of outcomes, collaborative activity with other cities and businesses is associated with higher resiliency to sea level rise. The results suggest that city leaders should consider collaboration as a tool to serve their communities, especially in situations when support from higher levels of government is insufficient. Cities can utilize local talent and gain access to various resources through collaboration, such as technical expertise and scientific research. Findings from the interviews also reveal that collaboration helps cities achieve better preparedness through various learning processes and cost saving practices, which can help local leaders decrease the financial risks of adaptation.

While collaborative activity with nonprofit organizations and community groups is not found to be statistically significant, this does not suggest that cities should exclude other local actors from collaboration processes. In the context of sea level rise, nonprofit organizations provide education and training for city employees and residents on climate science and the effects of climate change. Involvement of community groups may increase the legitimacy of the collaborative process and provide the perspective of local residents on possible solutions to the problem. 


\section{REFERENCES}

Adger, W. N., Huq, S., Brown, K., Conway, D., \& Hulme, M. (2003). Adaptation to climate change in the developing world. Progress in Development Studies, 3(3), 179-195.

Agranoff, R. (2006). Inside collaborative networks: Ten lessons for public managers. Public Administration Review, 66(s1), 56-65.

Agranoff, R., \& McGuire, M. (2003). Collaborative public management: New strategies for local governments. Washington, D.C.: Georgetown Univ. Press.

Agrawala, S., Crick, F., Jette-Nantel, S., \& Tepes, A. (2008). Empirical estimates of adaptation costs and benefits: A critical assessment. In S. Agrawala, \& S. Fankhauser (Eds.), Economic Aspects of Adaptation to Climate Change Costs, Benefits, and Policy Instruments, (pp. 29-84). Paris: OECD Publishing.

American Society of Civil Engineers (2013). 2013 report card for America's infrastructure. Retrieved from http://2013.infrastructurereportcard.org/a/\#p/levees/conditions-and-capacity

Amirkhanyan, A. A. (2008). Collaborative performance measurement: Examining and explaining the prevalence of collaboration in state and local government. Journal of Public Administration Research and Theory, 19(3), 523-554.

Andrews, R., \& Entwistle, T. (2010). Do cross-sectoral partnerships deliver? An empirical exploration of public service effectiveness, efficiency, and equity. Journal of Public Administration Research and Theory, 20(3), 679-701.

Ansell, C., \& Gash, A. (2008). Collaborative governance in theory and practice. Journal of Public Administration Research and Theory, 18(4), 543-571.

Ansell, C., \& Torfing, J. (2015). How does collaborative governance scale? Policy \& Politics, 43(3), 315-329.

Babcock, M. (2013). State hazard mitigation plans and climate change: Rating the states. Retrieved from http://wordpress.ei.columbia.edu/climate-changelaw/files/2016/06/Babcock-2013-11-State-Hazard-Mitigation-and-ClimateChange.pdf

Bardach, E. (1998). Getting agencies to work together: The practice and theory of managerial craftsmanship. Washington, D.C.: Brookings Institution Press.

Barnett, J. (2001). Adapting to climate change in Pacific Island countries: The problem of uncertainty. World Development, 29(6), 977-993. 
Bassett, E., \& Shandas, V. (2010). Innovation and climate action planning. Journal of the American Planning Association, 76(4), 435-450.

Bedsworth, L. W., \& Hanak, E. (2010). Adaptation to climate change: A review of challenges and tradeoffs in six areas. Journal of the American Planning Association, 76(4), 477-495.

Bentrup, G. (2001). Evaluation of a collaborative model: A case study analysis of watershed planning in the Intermountain West. Environmental Management, 27(5), 739-748.

Berg, B. L. (2009). Qualitative research methods for the social sciences, $8^{\text {th }}$ ed. Needham Heights, MA: Pearson.

Berke, P., Cooper, J., Aminto, M., Grabich, S., \& Horney, J. (2014). Adaptive planning for disaster recovery and resiliency: An evaluation of 87 local recovery plans in eight states. Journal of the American Planning Association, 80(4), 310-323.

Berke, P., \& French, S. P. (1994). The influence of state planning mandates on local plan quality. Journal of Planning and Education Research, 13(4): 237-250.

Berke, P., \& Godschalk, D. (2009). Searching for the good plan: A meta-analysis of plan quality studies. Journal of Planning Literature, 23(3), 227-240.

Berke, P., \& Lyles, W. (2013). Public risks and the challenges to climate-change adaptation: A proposed framework for planning in the age of uncertainty. Cityscape: A Journal of Policy Development and Research, 15(1), 181-208.

Berke, P., Newman, G., Jaekyung, L., Combs, T., Kolosna, C., \& Salvesen, D. (2015). Evaluation of networks of plans and vulnerability to hazards and climate change. Journal of the American Planning Association, 81(4), 287-302.

Berrang-Ford, L., Ford, J. D., \& Paterson, J. (2011). Are we adapting to climate change? Global Environmental Change, 21(1), 25-33.

Bierbaum, R., Smith, J. B., Lee, A., Blair, M., Carter, L., Chapin III, F. S., ... Verduzco, L. (2013). A comprehensive review of climate adaptation in the United States: more than before, but less than needed. Mitigation and Adaptation Strategies for Global Change, 18(3), 361-406.

Biernacki, P., \& Waldorf, D. (1981). Snowball sampling: Techniques of chain referral sampling. Sociological Methods \& Research, 10(2), 141-163. 
Birkmann, J., \& von Teichmann, K. (2010). Integrating disaster risk reduction and climate change adaptation: Key challenges - scales, knowledge, and norms. Sustainability Science, 5(2), 171-184.

Brody, S. D. (2003a). Are we learning to make better plans? A longitudinal analysis of plan quality associated with natural hazards. Journal of Planning Education and Research, 23(2), 191-201.

Brody, S. D. (2003b). Measuring the effects of stakeholder participation on the quality of local plans based on the principles of collaborative ecosystem management. Journal of Planning Education and Research, 22(4), 407-419.

Brody, S. D., \& Highfield, W. (2013). Open space protection and flood mitigation: A national study. Land Use Policy, 32, 89-95.

Brody, S. D., Highfield, W., \& Carrasco, V. (2004). Measuring the collective planning capabilities of local jurisdictions to manage ecological systems in southern Florida. Landscape and Urban Planning, 69(1), 33-50.

Brooks, N., Adger, N. W., \& Kelly, P. M. (2005). The determinants of vulnerability and adaptive capacity at the national level and the implications for adaptation. Global Environmental Change, 15, 151-163.

Broto, V. C., \& Bulkeley, H. (2013). A survey of urban climate change experiments in 100 cities. Global Environmental Change, 23(1), 92-102.

Bryson, J. M., Crosby, B. C., \& Stone, M. M. (2006). The design and implementation of cross-sector collaborations: Propositions from the literature. Public

Administration Review, 66(s1), 44-55.

Burch, S. (2010). Transforming barriers into enablers of action on climate change: Insights from three municipal case studies in British Columbia, Canada. Global Environmental Change, 20(2), 287-297.

California Natural Resources Agency (2009). 2009 Climate change adaptation strategy: A report to the Governor of the State of California in response to Executive Order S-13-2008. Retrieved from http://resources.ca.gov/docs/climate/Statewide_Adaptation_Strategy.pdf

Caruson, K., \& MacManus, S. A. (2011). Interlocal emergency management collaboration: Vertical and horizontal roadblocks. Publius: The Journal of Federalism, 42(1), 162-187.

Charmaz, K. (2006). Constructing grounded theory: A practical guide through qualitative analysis. Thousand Oaks, CA: Sage Publications. 
Chen, B. (2010). Antecedents or processes? Determinants of perceived effectiveness of interorganizational collaborations for public service delivery. International Public Management Journal, 13(4), 381-407

Climate Central (n.d.). Surging seas risk finder. Retrieved from https://riskfinder.climatecentral.org/state/florida.us?comparisonType=county\&for ecast Type $=$ NOAA2017_int $\_50 \& l e v e l=6 \&$ unit $=\mathrm{ft}$

Climate Central (2017). Cities below future seas. Retrieved from http://www.climatecentral.org/wgts/FutureSeas/map.html

Congressional Research Service (2015). Climate change adaptation by federal agencies: An analysis of plans and issues for Congress. Retrieved from https://fas.org/sgp/crs/misc/R43915.pdf

Crosby, B. C., \& Bryson, J. M. (2005). A leadership framework for cross-sector collaboration. Public Management Review, 7(2), 177-201.

Denton, F. (2002). Climate change vulnerability, impacts, and adaptation: Why does gender matter? Gender and Development, 10(2), 10-20.

Disaster Mitigation Act, Public Law No: 106-390 (2000).

Doran, P. T., \& Zimmerman, M. K. (2009). Explaining the scientific consensus on climate change. Eos: Transactions of the American Geophysical Union, 90(3), 2223.

Drummond, W. J. (2010). State versus greenhouse: Have state-level climate action planners and policy entrepreneurs reduced greenhouse gas emissions? Journal of the American Planning Association, 76(4), 413-433.

Ebrahim, A. (2004). Institutional preconditions to collaboration: Indian forest and irrigation policy in historical perspective. Administration and Society, 36(2), 208242.

Eisenack, K., Moser, S. C., Hoffmann, E., Klein, R. J. T., Oberlack, C., Pechan, A., ... Termeer, C. J. A. M. (2014). Explaining and overcoming barriers to climate change adaptation. Nature Climate Change, 4(10), 867-872.

Emerson, K., \& Nabatchi, T. (2015a). Collaborative governance regimes. Washington, D.C.: Georgetown Univ. Press.

Emerson, K., \& Nabatchi, T. (2015b). Evaluating the productivity of collaborative governance regimes: A performance matrix. Public Performance and Management Review, 38(4), 717-747. 
Emerson, K., Nabatchi, T., \& Balogh, S. (2012). An integrative framework for collaborative governance. Journal of Public Administration Research and Theory, 22(1), 1-29.

Environmental Protection Agency (2014). Causes of climate change. Retrieved from http://www.epa.gov/climatechange/science/causes.html

Eriksen, S. H., \& O'Brien, K. (2011). Vulnerability, poverty and the need for sustainable adaptation measures. Climate Policy, 7(4), 337-352.

Exec. Order No. 13514, 3 C.F.R. 248-260 (2009).

Exec. Order No. 13653, 3 C.F.R. 1-7 (2013).

Exec. Order No. 13783, 3 C.F.R. 1-5 (2017).

Federal Emergency Management Agency (2015). State mitigation plan review guide.

Retrieved from https://www.fema.gov/media-library-

data/1425915308555aba3a873bc5f1140f7320d1ebebd18c6/State_Mitigation_Plan _Review_Guide_2015.pdf

Federal Emergency Management Agency (2017). Hazard mitigation plan status. Retrieved from https://www.fema.gov/hazard-mitigation-plan-status

Feiock, R. C. (2007). Rational choice and regional governance. Journal of Urban Affairs, 29(1), 47-63.

Feiock, R. C. (2008). Institutional collective action and local government collaboration. In L. Blomgren Bingham \& R. O'Leary (Eds.), Big ideas in collaborative public management (pp. 195-210). Armonk, NY: M.E. Sharpe.

Feiock, R. C. (2013). The institutional collective action framework. Policy Studies Journal, 41(3), 397-425.

Feiock, R. C., \& Scholz, J. T. (2010). Self-organizing governance of institutional collective action dilemmas. In R. C. Feiock \& J. T. Scholz (Eds.), Self-organizing federalism: collaborative mechanisms to mitigate institutional collective action dilemmas (pp. 3-32). New York, NY: Cambridge Univ. Press.

Foster, M. K., \& Meinhard, A. G. (2002). A regression model explaining predisposition to collaborate. Nonprofit and Voluntary Sector Quarterly, 31(4), 549-564.

Fu, X., Song, J., Sun, B., \& Peng, Z.-R. (2016). "Living on the edge": Estimating the economic cost of sea level rise on coastal real estate in the Tampa Bay region, Florida. Ocean \& Coastal Management, 133, 11-17. 
Gazley, B. (2010). Linking collaborative capacity to performance measurement in government-nonprofit partnerships. Nonprofit and Voluntary Sector Quarterly, 39(4), 653-673.

Georgetown Climate Center (n.d.). State and local adaptation plans. Retrieved from http://www.georgetownclimate.org/adaptation/plans.html

Gornitz, V. (2013). Rising seas: Past, present, future. New York, NY: Columbia Univ. Press.

Government Accountability Office (2009). Report to congressional requesters. Alaska native villages: Limited progress has been made on relocating villages threatened by flooding and erosion. Retrieved from

http://www.gao.gov/new.items/d09551.pdf

Gray, B. (2000). Assessing inter-organizational collaboration: Multiple conceptions and multiple methods. In D. Faulkner \& M. de Rond (Eds.), Cooperative strategy: Economic, business, and organization issues (pp. 243-260). New York, NY: Oxford Univ. Press.

Griggs, G. (2017). Coasts in crisis: A global challenge. Oakland, CA: Univ. of California Press.

Grothmann, T., \& Patt, A. (2005). Adaptive capacity and human cognition: The process of individual adaptation to climate change. Global Environmental Change, 15, 199-213.

Haddad, B. M. (2005). Ranking the adaptive capacity of nations to climate change when sociopolitical goals are explicit. Global Environmental Change, 15(2), 165-176.

Hamin, E. M., Gurran, N., \& Emlinger, A. M. (2014). Barriers to municipal climate adaptation: Examples from coastal Massachusetts' smaller cities and towns. Journal of the American Planning Association, 80(2), 110-122.

Hawkins, C. V. (2010). Competition and cooperation: Local government joint ventures for economic development. Journal of Urban Affairs, 32(2), 253-275.

Hawkins, C. V., Krause, R. M., Feiock, R. C., \& Curley, C. (2016). Making meaningful commitments: Accounting for variation in cities' investments of staff and fiscal resources to sustainability. Urban Studies, 53(9), 1902-1924.

Highfield, W. E., \& Brody, S. D. (2013). Evaluating the effectiveness of local mitigation activities in reducing flood losses. Natural Hazards Review, 14(4), 229-236.

Hino, M., Field, C. B., \& Mach, K. (2017). Managed retreat as a response to natural hazard risk. Nature Climate Change, 7, 364-370. 
Hsiang, S., Kopp, R., Jina, A., Rising, J., Delgado, M., Mohan, S., ... Houser, T. (2017). Estimating economic damage from climate change in the United States. Science, $356,1362-1369$.

Huang, K., \& Provan, K. G. (2007). Resource tangibility and patterns of interaction in a publicly funded health and human services network. Journal of Public Administration Research and Theory, 17(3), 435-454.

Hultquist, A., Wood, R. S., Romsdahl, R. J. (2017). The relationship between climate change policy and socioeconomic changes in the U.S. Great Plains. Urban Affairs Review, 53(1), 138-174.

Imperial, M. T. (2005). Using collaboration as a governance strategy: Lessons from six watershed management programs. Administration and Society, 37(3), 281-320.

Jang, H. S., Feiock, R. C., \& Saitgalina, M. (2016). Institutional collective action issues in nonprofit self-organized collaboration. Administration \& Society, 48(2), $163-$ 189.

Janssen, M. A., \& Ostrom, E. (2006). Resilience, vulnerability, and adaptation: A crosscutting theme of the International Human Dimensions Programme on Global Environmental Change. Global Environmental Change, 16(3), 237-239.

Kelman, S., Hong, S., \& Turbitt, I. (2012). Are there managerial practices associated with the outcomes of an interagency service delivery collaboration? Evidence from British crime and disorder reduction partnerships. Journal of Public Administration Research and Theory, 23(3), 609-630.

Kettl, D. F. (2002). The transformation of governance: Public administration for twentyfirst century America. Baltimore, MD: John Hopkins Univ. Press.

Kettl, D. F. (2006a). Is the worst yet to come? The Annals of the American Academy of Political and Social Science, 604(1), 273-287.

Kettl, D. F. (2006b). Managing boundaries in American administration: The collaborative imperative. Public Administration Review, 66(s1), 10-19.

Koontz, T. M., \& Thomas, C. W. (2006). What do we know and need to know about the environmental outcomes of collaborative management? Public Administration Review, 66(s1), 111-121.

Krause, R. M. (2010). Policy innovation, intergovernmental relations, and the adoption of climate protection initiatives by U.S. cities. Journal of Urban Affairs 33(1), 4560 . 
Krause, R. M., Feiock, R. C., \& Hawkins, C. V. (2014). The administrative organization of sustainability within local government. Journal of Public Administration Research and Theory, 26(1), 113-127.

Krause, R. M., Yi, H., \& Feiock, R. C. (2016). Applying policy termination theory to the abandonment of climate protection initiatives by US local governments. Policy Studies Journal, 44(2), 176-195.

Krueathep, W., Riccucci, N. M., \& Suwanmala, C. (2010). Why do agencies work together? The determinants of network formation at the subnational level of government in Thailand. Journal of Public Administration Research and Theory, 20(1), 157-185.

Kuhlicke, K., Kabisch, S., Krellenberg, K., \& Steinfuehrer, A. (2012). Urban vulnerability under conditions of global environmental change: Conceptual reflections and empirical examples from growing and shrinking cities. In S. Kabisch, A. Kunath, P. Schweizer-Ries, \& A. Steinfuehrer (Eds.), Vulnerability, risks, and complexity: Impacts of global change on human habitats (pp. 27-38). Bern: Hogrefe Publishing.

Kwon, S.-W., \& Feiock, R. C. (2010). Overcoming the barriers to cooperation: Intergovernmental service agreements. Public Administration Review, 70(6), 876884 .

Leach, W. D., \& Sabatier, P. A. (2005). Are trust and social capital the keys to success? Watershed partnerships in California and Washington. In P. A. Sabatier, W. Focht, M. Lubell, Z. Trachtenberg, A. Vedlitz, \& M. Matlock (Eds.), Swimming upstream: Collaborative approaches to watershed management (pp. 233-258). Cambridge, MA: MIT Press.

Leach, W. D., Weible, C. M., Vince, S. R., Siddiki, S. N., \& Calanni, J. C. (2013). Fostering learning through collaboration: Knowledge acquisition and belief change in marine aquaculture partnerships. Journal of Public Administration Research and Theory, 24(3), 591-622.

Leech, B. L. (2002). Asking questions: Techniques for semi-structured interviews. Political Science and Politics, 35(4), 665-668.

Leiserowitz, A., Maibach, E., Roser-Renouf, C., Feinberg, G., \& Howe, P. (2013). Climate change in the American mind: Americans' global warming beliefs and attitudes in April, 2013. New Haven, CT: Yale Project on Climate Change Communication.

Lubell, M. (2005). Do watershed partnerships enhance beliefs conducive to collective action? In P. A. Sabatier, W. Focht, M. Lubell, Z. Trachtenberg, A. Vedlitz, \& M. 
Matlock (Eds.), Swimming upstream: Collaborative approaches to watershed management (pp. 201-232). Cambridge, MA: MIT Press.

Lyles, W., Berke, P., \& Heiman-Overstreet, K. (2017). Where to begin municipal climate adaptation planning? Evaluating two local choices. Journal of Environmental Planning and Management, (October), 1-21. https://doi.org/10.1080/09640568.2017.1379958

Lyles, W., \& Stevens, M. (2014). Plan quality evaluation 1994-2012: Growth and contributions, limitations, and new directions. Journal of Planning Education and Research, 34(4), 433-450.

Marshall, M. N. (1996) Sampling for qualitative research. Family Practice, 13(6), 522526.

McGuire, C. (2013). Adapting to sea level rise in the coastal zone: Law and policy considerations. Boca Raton, FL: CRC Press.

McGuire, M. (2006). Collaborative public management: Assessing what we know and how we know it. Public Administration Review, 66(s1), 33-43.

McGuire, M., \& Silvia, C. (2010). The effect of problem severity, managerial and organizational capacity, and agency structure on intergovernmental collaboration: Evidence from local emergency management. Public Administration Review, 70(2), 279-288.

Measham, T. G., Preston, B. L., Smith, T. F., Brooke, C., Gorddard, R., Withycombe, G., \& Morrison, C. (2011). Adapting to climate change through local municipal planning: Barriers and challenges. Mitigation and Adaptation Strategies for Global Change, 16(8), 889-909.

Meier, K. J., \& O’Toole, L. J. (2003). Public management and educational performance: The impact of managerial networking. Public Administration Review, 63(6), 689699.

Meier, K. J., Winter, S. C., O’Toole, L. J., Favero, N., \& Andersen, S. C. (2015). The validity of subjective performance measures: School principals in Texas and Denmark. Public Administration, 93(4), 1084-1101.

Mitchell, G. E., O’Leary, R., \& Gerard, C. (2015). Collaboration and performance: Perspectives from public managers and NGO leaders. Public Performance and Management Review, 38(4), 684-716.

Montz, B. E., \& Tobin, A. A. (2008). Livin' large with levees: Lessons learned and lost. Natural Hazards Review, 9(3), 150-157. 
Moser, S. C. (2013). Navigating the political and emotional terrain of adaptation: Community engagement when climate change comes home. In S. C. Moser, \& M. T. Boykoff (Eds.), Successful adaptation to climate change: Linking science and policy in a rapidly changing world (pp. 289-305). New York, NY: Routledge.

Moser, S. C., \& Boykoff, M. T. (2013). Climate change and adaptation success: The scope of the challenge. In S. C. Moser, \& M. T. Boykoff (Eds.), Successful adaptation to climate change: Linking science and policy in a rapidly changing world (pp. 1-33). New York, NY: Routledge.

Moser, S. C., \& Ekstrom, J. A. (2010). A framework to diagnose barriers to climate change adaptation. Proceedings of the National Academy of Sciences of the United States of America, 107(51), 22026-22031.

Moynihan, D. P. (2008). Learning under uncertainty: Networks in crisis management. Public Administration Review, 68(2), 350-365.

Mozumder, P., Flugman, E., \& Randhir, T. (2011). Adaptation behavior in the face of global climate change: Survey responses from experts and decision makers serving the Florida Keys. Ocean \& Coastal Management, 54(1), 37-44.

National Academies of Sciences, Engineering, and Medicine. (2017). Accomplishments of the U.S. Global Change Research Program. Retrieved from https://nassites.org/americasclimatechoices/other-reports-on-climatechange/accomplishments-of-the-u-s-global-change-research-program-2017/

National Oceanic and Atmospheric Administration (n.d.). Is sea level rising? Retrieved from https://oceanservice.noaa.gov/facts/sealevel.html

Nicholls, R. J. (2002). Rising sea levels: Potential impacts and responses. In R. E. Hester, \& R. M. Harrison (Eds.), Global environmental change: Issues in environmental science and technology (pp. 83-109). Cambridge: The Royal Society of Chemistry.

Nicholls, R. J., \& Cazenave, A. (2010). Sea-level rise and its impact on coastal zones. Science, 328(5985), 1517-1520.

Office of the Press Secretary. (2015). Remarks by the President on the impacts of climate change [Press release]. Retrieved from https://www.whitehouse.gov/the-pressoffice/2015/04/22/remarks-president-impacts- climate-change

O'Leary, R., Gerard, C., \& Blomgren Bingham, L. (2006). Introduction to the symposium on collaborative public management. Public Administration Review, 66(s1), 6-9. 
Petes, L. E., Howard, J. F., Helmuth, B. S., \& Fly, E. K. (2014). Science integration into US climate and ocean policy. Nature Climate Change, 4, 671-677.

Pfeffer, J., \& Salancik, G. R. (2003). The external control of organizations: A resource dependence perspective. Stanford, CA: Stanford Univ. Press.

Preston, B. L., Westaway, R. M., \& Yuen, E. J. (2011). Climate adaptation planning in practice: An evaluation of adaptation plans in three developed countries. Mitigation and Adaptation Strategies for Global Change, 16(4), 407-438.

Provan, K. G., \& Milward, H. B. (1995). A preliminary theory of interorganizational network effectiveness: A comparative study of four community mental health systems. Administrative Science Quarterly, 40(1), 1-33.

Provan, K. G., \& Milward, H. B. (2001). Do networks really work? A framework for evaluating public-sector organizational networks. Public Administration Review, 61(4), 414-423.

Quay, R. (2010). Anticipatory governance: A tool for climate change adaptation. Journal of the American Planning Association, 76(4), 496-511.

Rao, K. (2017). Climate change and housing: Will a rising tide sink all homes? Retrieved from https://www.zillow.com/research/climate-change-underwater-homes-12890

Rittel, H. W. J., \& Webber, M. M. (1973). Dilemmas in a general theory of planning. Policy Sciences, 4(2), 155-169.

Saldana, J. (2009). The coding manual for qualitative researchers. Thousand Oaks, CA: SAGE Publications Ltd.

Schrock, G., Bassett, E. M., \& Green., J. (2015). Pursuing equity and justice in a changing climate: Assessing equity in local climate and sustainability plans in U.S. cities. Journal of Planning Education and Research, 35(3), 282-295.

Scott, T. A. (2015). Does collaboration make any difference? Linking collaborative governance to environmental outcomes. Journal of Policy Analysis and Management, 34(3), 537-566.

Scott, T. A. (2016). Is collaboration a good investment? Modeling the link between funds given to collaborative watershed councils and water quality. Journal of Public Administration Research and Theory, 26(4), 769-786.

Scott, T. A., \& Thomas, C. (2017). Unpacking the collaborative toolbox: Why and when do public managers choose collaborative governance strategies? Policy Studies Journal, 45(1), 191-214. 
Selden, S. C., Sowa, J. E., \& Sandfort, J. (2006). The impact of nonprofit collaboration in early child care and education on management and program outcomes. Public Administration Review, 66(3), 412-425.

Shi, L., Chu, E., \& Debats, J. (2015). Explaining progress in climate adaptation planning across 156 U.S. municipalities. Journal of the American Planning Association, 81(3), 191-202.

Silvia, C. (2017). Picking the team: A Preliminary experimental study of the activation of collaborative network members. Journal of Public Administration Research and Theory, 28(1), 120-137.

Smit, B., \& Pilifosova, O. (2001). Adaptation to climate change in the context of sustainable development and equity. In J. J. McCarthy, O.F. Canziani, N.A. Leary, D. J. Dokken, \& K. S. White (Eds.), Climate change 2001: Impacts, adaptation and vulnerability (pp. 877-912). Cambridge: Cambridge Univ. Press.

Southeast Florida Regional Climate Change Compact. (2016). Who we are. Retrieved from http://www.southeastfloridaclimatecompact.org/who-we-are/

Steinacker, A. (2010). The institutional collective action perspective on self-organizing mechanisms: Market failures and transaction cost problems. In R. C. Feiock, \& J. T. Scholz (Eds.), Self-organizing federalism: Collaborative mechanisms to mitigate institutional collective action (pp. 51-72). New York, NY: Cambridge Univ. Press.

Strauss, B. H., Kopp, R. E., Sweet, W. V., \& Bittermann, K. (2016). Unnatural coastal floods: Sea level rise and the human fingerprint on U.S. floods since 1950. Climate Central Research Report, 1-16. Retrieved from http://sealevel.climatecentral.org/uploads/research/Unnatural-Coastal-Floods2016.pdf

Strauss, B. H., Ziemlinski, R., Weiss, J. L., \& Overpeck, J. T. (2012). Tidally adjusted estimates of topographic vulnerability to sea level rise and flooding for the contiguous United States. Environmental Research Letters, 7, 1-12. doi:10.1088/1748-9326/7/1/014033

Stults, M. (2017). Integrating climate change into hazard mitigation planning: Opportunities and examples in practice. Climate Risk Management, 17, 21-34.

Tang, Z., \& Brody, S. D. (2009). Linking planning theories with factors influencing local environment-plan quality. Environment and Planning B: Planning and Design, 36(3), 522-537. 
Tang, Z., Brody, S. D., Quinn, C., Chang, L., \& Wei, T. (2010). Moving from agenda to action: Evaluating local climate change action plans. Journal of Environmental Planning and Management, 53(1), 41-62.

Thomson, A. M., \& Perry, J. L. (2006). Collaboration processes: Inside the black box. Public Administration Review, 66(s1), 20-32.

Thomson, A. M., Perry, J. L., \& Miller, T. K. (2008). Linking collaboration process and outcomes: Foundations for advancing empirical theory. In L. Blomgren Bingram \& R. O'Leary (Eds.), Big ideas in collaborative public management (pp. 97-120). Armonk, NY: M.E. Sharpe.

Thurmaier, K. (2006). High-intensity interlocal collaboration in three Iowa cities. Public Administration Review, 66(s1), 144-146.

Tobin, G. A. (1995). The levee love affair: A stormy relationship? Journal of the American Water Resources Association, 31(3), 359-367.

Tribbia, J., \& Moser, S. C. (2008). More than information: What coastal managers need to plan for climate change. Environmental Science \& Policy, 11(4), 315-328.

Ulibarri, N. (2015). Collaboration in federal hydropower licensing: Impacts on process, outputs, and outcomes. Public Performance and Management Review, 38(4), 578606.

US Global Change Research Program (2009). Global climate change. Retrieved from https://downloads.globalchange.gov/usimpacts/pdfs/Global.pdf

US Global Change Research Program (2014). Climate change impacts in the United States: U.S. national climate assessment. Retrieved from https://nca2014.globalchange.gov

Van Bueren, E. M., Klijn, E.-H., \& Koppenjan, J. F. M. (2003). Dealing with wicked problems in networks: Analyzing environmental debate from a network perspective. Journal of Public Administration Research and Theory, 13(2), 193212.

Varda, D. M., \& Retrum, J. H. (2015). Collaborative performance as a function of network members' perceptions of success. Public Performance and Management Review, 38(4), 632-653.

Wheeler, S. M. (2008). State and municipal climate change plans: The first generation. Journal of the American Planning Association, 74(4), 481-496. 
White House (2015). Celebrating the $25^{\text {th }}$ Anniversary of the U.S. Global Change Research Program. Retrieved from https://obamawhitehouse.archives.gov/blog/2015/11/16/celebrating-25thanniversary-us-global-change-research-program

Whittemore, R., Chase, S. K., \& Mandle, C. L. (2001). Validity in qualitative research. Qualitative Health Research, 11(4), 522-537.

Wigley, T. M. L. (2005). The climate change commitment. Science, 307(5716), 17661769.

Woodruff, S. C., \& Stults, M. (2016). Numerous strategies but limited implementation guidance in US local adaptation plans. Nature Climate Change, 6, 796-802.

Zahran, S., Brody, S. D., Vedlitz, A., Grover, H., \& Miller, C. (2008). Vulnerability and capacity: Explaining local commitment to climate-change policy. Environment and Planning C: Government and Policy, 26(3), 544-562. 


\section{APPENDICES}

\section{Survey Questionnaire}

Hello, my name is Vaiva Kalesnikaite. I am seeking your help with my dissertation research about climate-related adaptation at the local government level. The purpose of this study is to explore the critical issues regarding sea level rise preparedness of American cities. The survey should not take more than 10 minutes. It is anticipated that this study will lead to recommendations on how to improve sea level rise preparedness through a better understanding of best practices. There are no foreseeable risks associated with participating in the study. There is no cost or payment to you. Your answers are confidential.

Any identifying information (position at the city government, city name) will be kept private and will be protected to the fullest extent provided by law. If you have questions you may contact Prof. Milena Neshkova by phone at 305-348-0486 or by email at mneshkov@fiu.edu. If you would like to talk with someone about being a respondent in this research study, you may contact the FIU Office of Research Integrity by phone ar 305-348-2494 or by email at ori@fiu.edu. Your participation in this research is voluntary. If you consent to participate in the study, please select "I agree" to begin the survey. If not, please select "I do not agree" to exit the survey.

Q1. Please provide the name of the city and state you currently work in:

Q2. What are the climate-related challenges your city is facing? (Please select all that apply):

O Sea level rise (1) 
Coastal flooding (2)

Inland flooding (3)

Increased hurricane frequency (4)

$\bigcirc$ Increased droughts (5)

Increased heat waves (6)

Increased precipitation (7)

$\bigcirc$ Increased wildfires (8)

Extinction of animal species (9)

Food and water shortages (10)

O Spread of disease (11)

Economic downturn (12)

Other (Please specify):

Q3. Has your city adopted a plan for climate-related mitigation?

Note: Climate-related mitigation refers to the efforts to reduce the release of the greenhouse gas emissions.
○ Yes (1)
○ No (2)
O I do not know (3) 
Q4. Has your city adopted a plan for climate-related adaptation?

Note: Climate-related adaptation refers to the efforts to prepare for the impacts of changes in climate.

$$
\begin{array}{ll}
\bigcirc & \text { Yes (1) } \\
& \text { No (2) } \\
& \text { I do not know (3) }
\end{array}
$$

Q5. Does the city climate-related adaptation plan address sea level rise?

$$
\begin{array}{ll}
\bigcirc & \text { Yes (1) } \\
\bigcirc & \text { No (2) } \\
& \text { I do not know (3) }
\end{array}
$$

Q6. Which of the following most accurately describes your city's effort to address sea level rise adaptation?

Not on the city agenda (1)

Vulnerability assessment is under way (2)

Vulnerability has been assessed and documented (3)

$\bigcirc \quad$ Action steps are being designed (4)

$\bigcirc \quad$ Action steps have been articulated and adopted (5)

$\bigcirc \quad$ Action steps are being implemented (6) 
Q7. Please evaluate the following statements regarding administrative decision-making for sea level rise preparedness in your city:

Note: $1=$ strongly disagree to $5=$ strongly agree

\begin{tabular}{|c|c|c|c|c|c|}
\hline & $\begin{array}{c}\text { Strongly } \\
\text { disagree } \\
\text { (1) }\end{array}$ & $\begin{array}{c}\text { Somewhat } \\
\text { disagree } \\
\text { (2) }\end{array}$ & $\begin{array}{c}\text { Neither } \\
\text { agree nor } \\
\text { disagree (3) }\end{array}$ & $\begin{array}{l}\text { Somewhat } \\
\text { agree (4) }\end{array}$ & $\begin{array}{l}\text { Strongly } \\
\text { agree (5) }\end{array}$ \\
\hline $\begin{array}{l}\text { Risks associated with sea } \\
\text { level rise are well } \\
\text { understood. (1) }\end{array}$ & 0 & 0 & 0 & 0 & 0 \\
\hline $\begin{array}{l}\text { Solutions to address sea } \\
\text { level rise are identified. } \\
\text { (2) }\end{array}$ & 0 & 0 & 0 & 0 & 0 \\
\hline $\begin{array}{l}\text { Solutions to sea level rise } \\
\text { are tailored to the city's } \\
\text { needs. (3) }\end{array}$ & 0 & 0 & 0 & 0 & 0 \\
\hline $\begin{array}{l}\text { The city has financial } \\
\text { resources to prepare for } \\
\text { sea level rise. (4) }\end{array}$ & 0 & 0 & 0 & 0 & 0 \\
\hline $\begin{array}{l}\text { The city has qualified } \\
\text { staff to prepare for sea } \\
\text { level rise. (5) }\end{array}$ & 0 & 0 & 0 & 0 & 0 \\
\hline Not all city efforts to & O & O & O & O & O \\
\hline
\end{tabular}




\begin{tabular}{|c|l|l|l|l|l|}
\hline $\begin{array}{c}\text { prepare have been } \\
\text { successful in the past. (7) }\end{array}$ & & & & & \\
\hline
\end{tabular}

Q8. How would you rank your city's preparedness for the following:

Note: $1=$ not prepared to $5=$ well prepared

\begin{tabular}{|c|c|c|c|c|c|}
\hline & $\begin{array}{c}\text { Not } \\
\text { prepared } \\
(1)\end{array}$ & $\begin{array}{c}\text { Slightly } \\
\text { prepared } \\
(2)\end{array}$ & $\begin{array}{c}\text { Somewhat } \\
\text { prepared } \\
(3)\end{array}$ & $\begin{array}{c}\text { Moderately } \\
\text { prepared (4) }\end{array}$ & Well \\
prepared \\
$(5)$
\end{tabular}

Q9. Please evaluate the support your city has received from higher levels of government in preparation for sea level rise:

Note: $1=$ strongly disagree to $5=$ strongly agree

\begin{tabular}{|c|c|c|c|c|c|}
\hline & $\begin{array}{l}\text { Strongly } \\
\text { disagree } \\
\text { (1) }\end{array}$ & $\begin{array}{c}\text { Somewhat } \\
\text { disagree } \\
\text { (2) }\end{array}$ & $\begin{array}{c}\text { Neither } \\
\text { agree nor } \\
\text { disagree (3) }\end{array}$ & $\begin{array}{l}\text { Somewhat } \\
\text { agree (4) }\end{array}$ & $\begin{array}{c}\text { Strongly } \\
\text { agree } \\
(5)\end{array}$ \\
\hline $\begin{array}{l}\text { The federal government } \\
\text { has provided technical } \\
\text { resources (1) }\end{array}$ & O & O & O & 0 & O \\
\hline
\end{tabular}




\begin{tabular}{|c|c|c|c|c|c|}
\hline $\begin{array}{c}\text { The federal government } \\
\text { has provided financial } \\
\text { support (2) }\end{array}$ & 0 & 0 & 0 & 0 & 0 \\
\hline $\begin{array}{c}\text { The state has provided } \\
\text { technical resources (3) }\end{array}$ & 0 & 0 & 0 & 0 & 0 \\
\hline $\begin{array}{c}\text { The state has provided } \\
\text { financial support (4) }\end{array}$ & 0 & 0 & 0 & 0 & 0 \\
\hline $\begin{array}{c}\text { Regional governmental } \\
\text { agencies have provided } \\
\text { technical resources (5) }\end{array}$ & 0 & 0 & 0 & 0 & 0 \\
\hline $\begin{array}{c}\text { Regional governmental } \\
\text { agencies have provided } \\
\text { financial support (6) }\end{array}$ & 0 & 0 & 0 & 0 & 0 \\
\hline $\begin{array}{c}\text { The county has } \\
\text { provided technical } \\
\text { resources (7) }\end{array}$ & 0 & 0 & 0 & 0 & 0 \\
\hline $\begin{array}{c}\text { The county has } \\
\text { provided financial }\end{array}$ & 0 & 0 & & & 0 \\
\hline support (8) & & & & & 0 \\
\hline
\end{tabular}

Q10. Please indicate the activities your city has partnered on with others for sea level rise preparedness in the last 3 years (select all that apply):

\begin{tabular}{|l|l|l|l|l|l|}
\hline & Other & Institutions & Non-profit & Private & Community \\
\hline
\end{tabular}




\begin{tabular}{|c|c|c|c|c|c|}
\hline & municipalities & of higher & organizations & businesses & groups (5) \\
(1) & learning (2) & $(3)$ & $(4)$ & \\
\hline $\begin{array}{c}\text { Sharing } \\
\text { information on } \\
\text { best practices } \\
\text { (1) }\end{array}$ & 0 & 0 & 0 & 0 & 0 \\
\hline $\begin{array}{c}\text { Sharing } \\
\text { workspace (2) }\end{array}$ & 0 & 0 & 0 & 0 & 0 \\
\hline $\begin{array}{c}\text { Sharing } \\
\text { volunteers (3) }\end{array}$ & 0 & 0 & 0 & 0 & 0 \\
\hline $\begin{array}{c}\text { Joint program } \\
\text { development } \\
\text { (4) }\end{array}$ & 0 & 0 & 0 & 0 & 0 \\
\hline $\begin{array}{c}\text { Advocacy to } \\
\text { volunteers (7) } \\
\text { higher levels of } \\
\text { government (5) }\end{array}$ & 0 & 0 & 0 & 0 & 0 \\
\hline $\begin{array}{c}\text { Joint } \\
\text { recruitment of } \\
\text { staff (6) }\end{array}$ & 0 & 0 & & & 0 \\
\hline Joint & & 0 & & & \\
\hline
\end{tabular}




\begin{tabular}{|c|c|c|c|c|c|}
\hline $\begin{array}{c}\text { Joint service } \\
\text { delivery (8) }\end{array}$ & 0 & 0 & 0 & 0 & 0 \\
\hline $\begin{array}{c}\text { Joint } \\
\text { fundraising (9) }\end{array}$ & 0 & 0 & 0 & 0 & 0 \\
\hline Joint \\
purchasing \\
(10)
\end{tabular}

Q11. Who is the city's most frequent partner on sea level rise issues?

Other municipalities (1)

Institutions of higher learning (2)

Non-profit organizations (3)

O Private businesses (4)

Community groups (5)

Other (Please specify):

Q12. Which best describes the partners with whom your city voluntarily collaborates on sea level rise preparedness:

Note: $1=$ strongly disagree to $5=$ strongly agree 


\begin{tabular}{|c|c|c|c|c|c|}
\hline & $\begin{array}{c}\text { Strongly } \\
\text { disagree } \\
(1)\end{array}$ & $\begin{array}{c}\text { Somewhat } \\
\text { disagree } \\
(2)\end{array}$ & $\begin{array}{c}\text { Neither } \\
\text { agree nor }\end{array}$ & $\begin{array}{c}\text { Somewhat } \\
\text { disagree (3) }\end{array}$ & $\begin{array}{c}\text { Strongly } \\
\text { agree } \\
\text { (5) }\end{array}$ \\
\hline $\begin{array}{c}\text { The city collaborates } \\
\text { mainly with partners } \\
\text { of similar size. (1) }\end{array}$ & 0 & 0 & 0 & 0 & 0 \\
\hline $\begin{array}{c}\text { The city collaborates } \\
\text { mainly with partners } \\
\text { possessing similar } \\
\text { resources. (2) }\end{array}$ & 0 & 0 & 0 & 0 & 0 \\
\hline $\begin{array}{c}\text { The city collaborates } \\
\text { mainly with partners } \\
\text { that it has worked with } \\
\text { on other issues. (3) }\end{array}$ & 0 & 0 & 0 & 0 & 0 \\
\hline
\end{tabular}

Q13. What best describes the city experience of the process of voluntary collaboration for sea level rise preparedness:

Note: $1=$ strongly disagree to $5=$ strongly agree

\begin{tabular}{|c|c|c|c|c|c|}
\hline & $\begin{array}{c}\text { Strongly } \\
\text { disagree }\end{array}$ & $\begin{array}{c}\text { Somewhat } \\
\text { disagree }\end{array}$ & $\begin{array}{c}\text { Neither } \\
\text { agree nor } \\
(1)\end{array}$ & Somewhat & Strongly \\
disagree (3) & agree (4) & agree (5) \\
\hline The benefits are & 0 & 0 & 0 & 0 & 0 \\
\hline
\end{tabular}




\begin{tabular}{|c|c|c|c|c|c|}
\hline $\begin{array}{c}\text { distributed to partners } \\
\text { fairly. (1) }\end{array}$ & 0 & 0 & 0 & 0 & 0 \\
\hline $\begin{array}{c}\text { Partners fulfill their } \\
\text { commitments. (2) }\end{array}$ & 0 & 0 & 0 & 0 & 0 \\
\hline $\begin{array}{c}\text { Conflict among partners } \\
\text { is rare. (3) }\end{array}$ & & & & & \\
\hline
\end{tabular}

Q14. What best reflects the city expectations from voluntary collaboration with partners on sea level rise preparedness:

Note: $1=$ strongly agree to $5=$ strongly disagree

\begin{tabular}{|c|c|c|c|c|c|}
\hline & $\begin{array}{c}\text { Strongly } \\
\text { disagree } \\
(1)\end{array}$ & $\begin{array}{c}\text { Somewhat } \\
\text { disagree } \\
(2)\end{array}$ & $\begin{array}{c}\text { Neither agree } \\
\text { nor disagree } \\
(3)\end{array}$ & $\begin{array}{c}\text { Somewhat } \\
\text { agree (4) }\end{array}$ & $\begin{array}{c}\text { Strongly } \\
\text { agree } \\
(5)\end{array}$ \\
\hline $\begin{array}{c}\text { The city will influence } \\
\text { policies of higher- } \\
\text { level governments. (1) }\end{array}$ & 0 & 0 & 0 & 0 & 0 \\
\hline $\begin{array}{c}\text { The city will attain } \\
\text { more funding. (2) }\end{array}$ & 0 & 0 & 0 & 0 & 0 \\
\hline $\begin{array}{c}\text { The city will raise the } \\
\text { awareness about the } \\
\text { problem. (3) }\end{array}$ & 0 & 0 & 0 & 0 & 0 \\
\hline The city will be more & 0 & 0 & 0 & 0 & 0 \\
\hline
\end{tabular}




\begin{tabular}{|c|l|l|l|l|l|}
\hline prepared for sea level & & & & & \\
rise. (4) & & & & & \\
\hline
\end{tabular}

Q15. What best describes your city leadership approach for collaborating with partners on sea level rise issues:

Note: $1=$ strongly disagree to $5=$ strongly agree

\begin{tabular}{|c|c|c|c|c|c|}
\hline & $\begin{array}{l}\text { Strongly } \\
\text { disagree (1) }\end{array}$ & $\begin{array}{l}\text { Somewhat } \\
\text { disagree } \\
\text { (2) }\end{array}$ & $\begin{array}{l}\text { Neither } \\
\text { agree nor } \\
\text { disagree (3) }\end{array}$ & $\begin{array}{l}\text { Somewhat } \\
\text { agree (4) }\end{array}$ & $\begin{array}{l}\text { Strongly } \\
\text { agree (5) }\end{array}$ \\
\hline $\begin{array}{l}\text { City leaders actively } \\
\text { seek out partners. (1) }\end{array}$ & 0 & 0 & 0 & 0 & 0 \\
\hline $\begin{array}{l}\text { City leaders actively } \\
\text { pursue collaboration. } \\
\text { (2) }\end{array}$ & 0 & 0 & 0 & 0 & 0 \\
\hline $\begin{array}{l}\text { City leaders highly } \\
\text { value collaboration. } \\
\text { (3) }\end{array}$ & 0 & 0 & 0 & 0 & 0 \\
\hline $\begin{array}{c}\text { City leaders } \\
\text { encourage } \\
\text { collaboration within } \\
\text { the city. (4) }\end{array}$ & 0 & 0 & 0 & 0 & 0 \\
\hline
\end{tabular}


Q16. What is your position within the city government (optional)?

○ City Mayor (1)

$\bigcirc$ City Manager (2)

Chief of Resilience (3)

Director of Public Works (4)

$\bigcirc$ Director of Planning and Zoning (5)

Floodplain manager (6)

Other (Please specify):

Q17. How long have you had this position?

$\bigcirc$ Less than 1 year (1)

○ $1-2$ years (2)

O 3-4 years (3)

More than 4 years $(4)$

Q18. What is your gender?

O Male (1)

Female (2)

Q19. What is your age?

O 18-25(1)

○ 26-30(2)

O $31-40(3)$ 
○ $41-50(4)$

O $51-60(5)$

over $60(6)$

Q20. Highest level of educational attainment:

Some high school (1)

High school graduate (2)

Some college (3)

$\bigcirc$ Associate degree (4)

O Bachelor's degree (5)

O Completed some postgraduate (6)

O Master's degree (7)

Doctoral, law, or medical degree (8)

O Other advanced degree beyond a Master's degree (9)

Q21. Please indicate the field of your highest degree:

O Public Administration (1)

Other (Please specify):

Q22. Please feel free to add any comments to the researchers (optional): 
Interview Questions

1. Background

1.1. What challenges does the city/county face in terms of climate change?

1.2. How is the climate change mitigation being addressed in the city/county?

1.3. How is the climate change adaptation being addressed in the city/county?

1.4. When has the climate change started appearing on the agenda?

1.5. What triggered city's/county's response to climate change?

1.6. What type of climate change adaptation initiatives has the city/county has undertaken? Are there any further plans for action?

1.7. How have these climate change adaptation initiatives been funded?

2. Collaboration

2.1. Is the city/county involved in national agreements and organizations that are addressing climate change adaptation?

2.2. Is the city/county currently collaborating with other cities and non-state stakeholders to address climate change adaptation?

If the answer to the Question 2.2. is positive:

1. Which other counties, cities and non-state stakeholders does the city/county work with to address climate change adaptation?

2. What were the main factors that pushed the city/county to consider collaboration to adapt to climate change?

3. What type of collaborative activities is the city/county involved in?

4. What goals are these collaborations trying to accomplish? 
5. Have any of these goals been attained so far?

6. How do you perceive the benefits that collaborations bring? What are they?

7. How do you perceive the drawbacks of collaborating? What are they?

8. Have your efforts to collaborate in the past, on other issues than climate change been successful?

9. How are power issues solved within collaborations? How do leaders emerge? If the answer to the Question 2.2. is negative:

1. Has the city/county considered collaborating with other cities or non-state. stakeholders in terms of climate change?

2. If it has considered collaboration, what factors prevented the city/county from undertaking it?

3. If it has not considered collaborating, why is that?

2.3. Do you know about what other cities/counties are doing in terms of climate change? Do you compare yourself to other cities/counties?

\section{Challenges \& Opportunities}

3.1. Does the city/county face any challenges that hinder successful adaptation to climate change?

3.2. How can these challenges be overcome?

3.3. What factors, based on your experience, could contribute to more successful climate change adaptation?

3.4. Is there anything you would like to add? 
VITA

\section{VAIVA KALESNIKAITE}

2011 B.A. in Political Science, Institute of International Relations and Political Science, Vilnius University, Lithuania

2014 M.A. in Empirical Social and Political Analysis, Institute of Social Sciences, University of Stuttgart, Germany, 2014

2017 Dissertation Evidence Acquisition Fellowship, Florida International University

2017 Dissertation Year Fellowship, Florida International University

2018 Founders' Fellows Fellowship, the American Society for Public Administration

2018

Ph.D. in Public Affairs, Department of Public Administration, Florida International University, Miami, FL

\section{PRESENTATIONS}

Kalesnikaite, V. (March, 2018). Explaining Horizontal Collaborative Activity for Sea Level Rise Preparedness in US Cities. Paper presented at the meeting of the American Society for Public Administration, Denver, Colorado.

Kalesnikaite, V. (November, 2017). Keeping Cities Afloat: Collaborative Governance and Preparedness for Sea Level Rise at the Local Level. Paper presented at the Association for Public Policy Analysis and Management Fall Research Conference, Chicago, Illinois.

Kalesnikaite, V. (October, 2017). Facing the Rising Tide: Does Collaboration Improve City-level Response to Sea Level Rise? Paper presented at the Southeastern Conference for Public Administration, Hollywood, Florida.

Kalesnikaite, V. (July, 2017). Keeping Cities Afloat: Collaborative Governance and Preparedness for Sea Level Rise at the Local Level. Paper presented at the $6^{\text {th }}$ International Young Scholars Workshop, Chennai, India.

Kalesnikaite, V. (June, 2017). Keeping Cities Afloat: Collaborative Governance and Preparedness for Sea Level Rise at the Local Level. Paper presented at the Public Management and Research Conference, Washington, DC. 
Kalesnikaite, V. (April, 2017). The Drivers Behind Florida's Local Level Collaborative Efforts for Climate Change Adaptation. Paper presented at the $13^{\text {th }}$ Transatlantic Dialogue, European Group of Public Administration and American Society for Public Administration, Miami, Florida.

Kalesnikaite, V. (March, 2017). The Drivers Behind Florida's Local Level Collaborative Efforts for Climate Change Adaptation. Paper presented at the $3^{\text {rd }}$ Annual Florida Public Administration Colloquium, Boca Raton, Florida.

Kalesnikaite, V. (March, 2017). The Multiple Roles of Public Administrators in Florida's Efforts to Adapt to Climate Change. Paper presented at the meeting of the American Society for Public Administration, Atlanta, Georgia.

Kalesnikaite, V. (April, 2016). Climate Change Adaptation at the Local Level: The Case of Florida. Paper presented at the meeting of the Midwest Political Science Association, Chicago, Illinois.

Kalesnikaite, V. (March, 2016). Climate Change Adaptation in South Florida: The Curious Case of Cities. Paper presented at the meeting of the American Society for Public Administration, Seattle, Washington.

Neshkova, M. I., and Kalesnikaite, V. (April, 2015). Citizen Participation and Public Corruption in Local Government. Paper presented at the meeting of the Midwest Political Science Association, Chicago, Illinois.

Kalesnikaite, V., and Neshkova, M. I. (March, 2015). Informational Pressures and Environmental Enforcement in the U.S. States. Paper presented at the meeting of the American Society for Public Administration, Chicago, Illinois. 